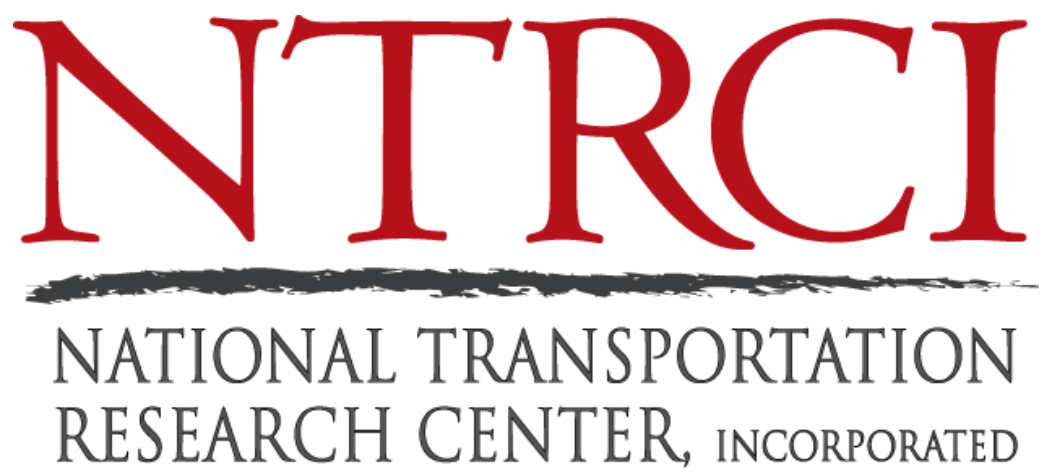

\title{
NTRCI Legacy Engine Research and Development Project Final Technical Report
}

The contents of this report reflect the views of the authors, who are responsible for the facts and the accuracy of the information presented herein. This document is disseminated under the sponsorship of the National Transportation Research Center, Inc., in the interest of information exchange. NTRCI assumes no liability for the contents or use thereof.

This report was prepared as an account of work sponsored by an agency of the United States Government. Neither the United States Government nor any agency thereof, nor any of their employees, makes any warranty, express or implied, or assumes any legal liability or responsibility for the accuracy, completeness, or usefulness of any information, apparatus, product, or process disclosed, or represents that its use would not infringe privately owned rights. Reference herein to any specific commercial product, process, or service by trade name, trademark, manufacturer, or otherwise does not necessarily constitute or imply its endorsement, recommendation, or favoring by the United States Government or any agency thereof. The views and opinions of authors expressed herein do not necessarily state or reflect those of the United States Government or any agency thereof.

Principal Investigator:

Connie Smith-Holbert, NTRCI

Program Manager:

Joseph Petrolino, NTRCI

Authors:

Bart Watkins, Power Source Technologies, Inc.

David Irick, Power Source Technologies, Inc.

DOE Award \#: DE-EE0004201

Performance Period: October 1, 2010 - December 31, 2011

December, 2011 



\section{Table of Contents}

LIST OF ABBREVIATIONS AND ACRONYMS .................................................................... VII

UNITS OF MEASUREMENT ................................................................................................ IX

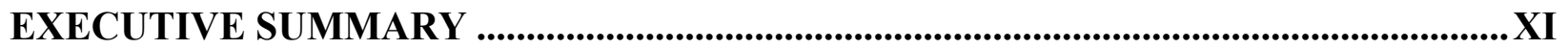

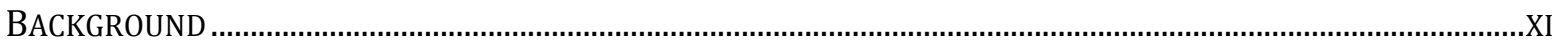

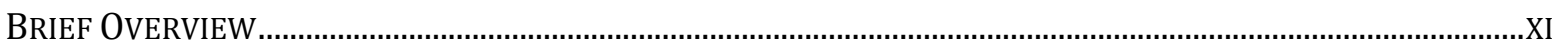

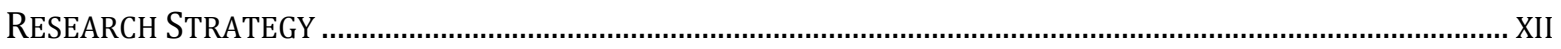

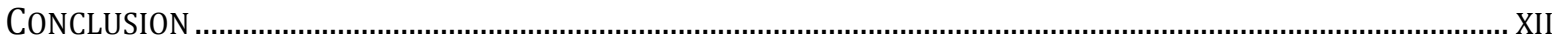

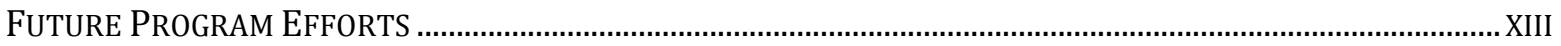

CHAPTER 1 - INTRODUCTION AND BACKGROUND ........................................................ 1

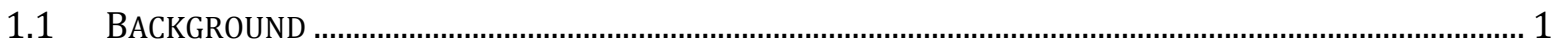

1.1.1 APTUS DesignWorks, Inc. (APTUS) ................................................................................................

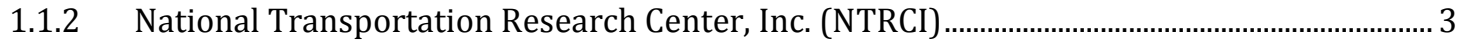

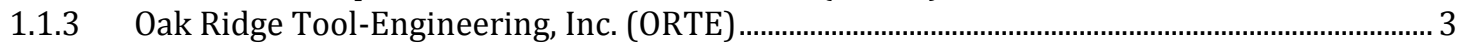

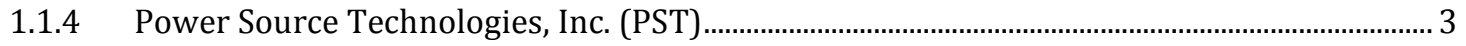

1.1.5 The University of Tennessee (UT) ..................................................................................................

1.2 PROJECT DESCRIPTION............................................................................................................... 3

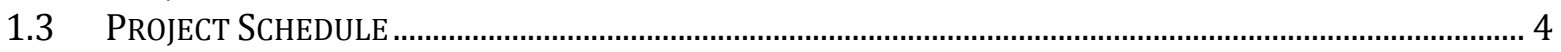

CHAPTER 2 - COMPLETION AND TESTING OF GEN2.5A............................................... 7

2.1 GEN2.5A DESIGN.....................................................................................................................

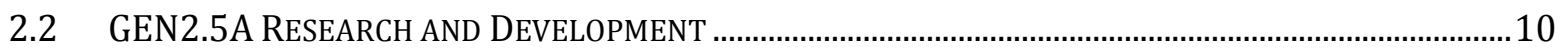

2.2.1 Tip Seal .........................................................................................................................................................10

2.2.2 Flush-Mount Fuel Injector Nozzles .....................................................................................................11

2.2.3 Housing Side Seal Testing and Evaluation ............................................................................................14

2.3 GEN2.5A MANUFACTURING ………………………………………………………………………...19

2.4 GEN2.5A TESTING AND EVALUATION................................................................................................26

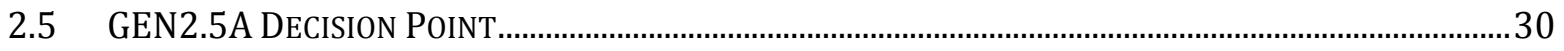

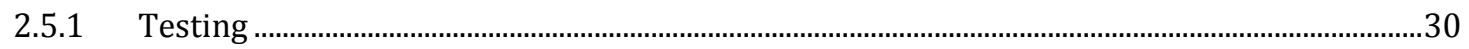

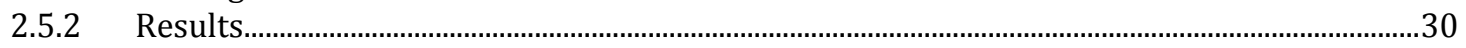

2.5 .3 Conclusion.................................................................................................................................... 31

CHAPTER 3 - COMPLETION AND TESTING OF GEN2.5B ......................................... 33

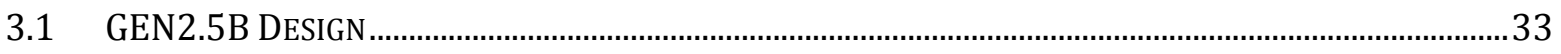

3.1.1 Initial Housing Side Seal System Modification....................................................................................33

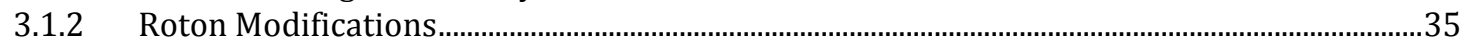

3.1.3 Further Housing Side Seal System Modification ....................................................................................38

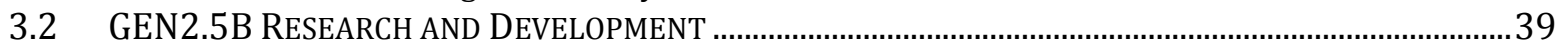

3.3 GEN2.5B MANUFACTURING........................................................................................................... 40

3.4 GEN2.5B TESTING AND EVALUATION...............................................................................................4

3.4.1 First Round of Testing ...........................................................................................................................41

3.4.2 Second Round of Testing ...............................................................................................................42

3.4.3 Third Round of Testing ....................................................................................................................47

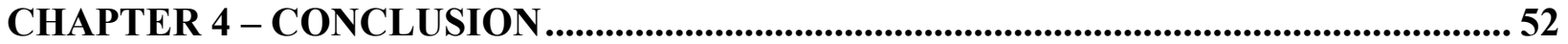

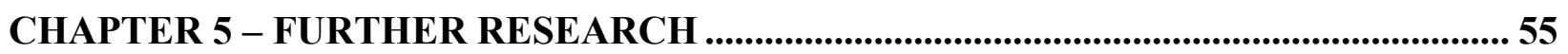

5.1 CHAPTER OVERVIEW.......................................................................................................................5

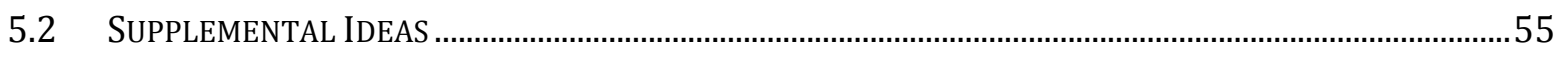

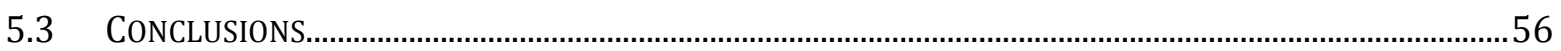


This page intentionally left blank. 


\section{List of Figures}

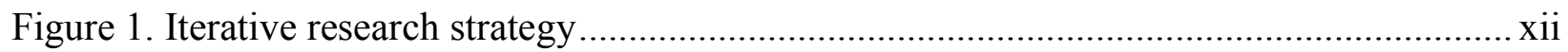

Figure 2. Legacy engine exploded view …………………............................................. 1

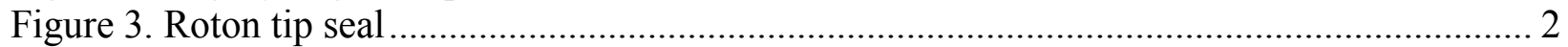

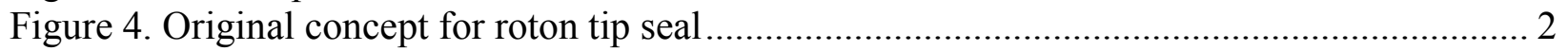

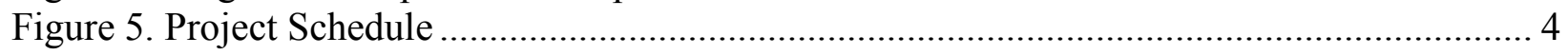

Figure 6. Material removed from large seal....................................................................... 7

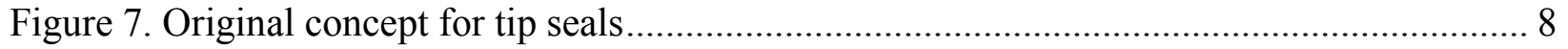

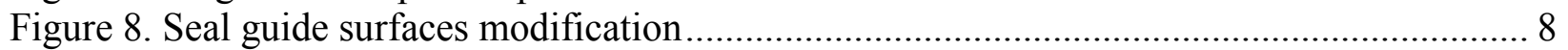

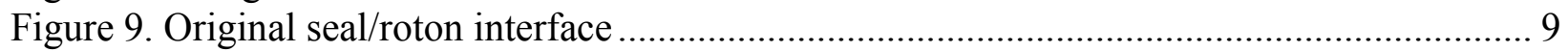

Figure 10. Stroke limiting feature redesign ....................................................................... 9

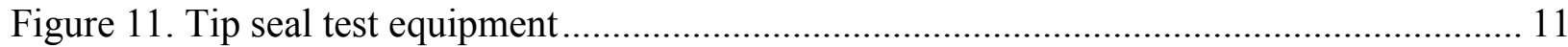

Figure 12. Detail of tip seals in extended (non-contact) position ................................................. 11

Figure 13. Custom modified nozzle: tip built up by precision welding...................................... 12

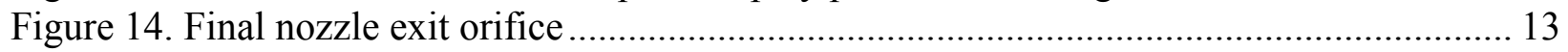

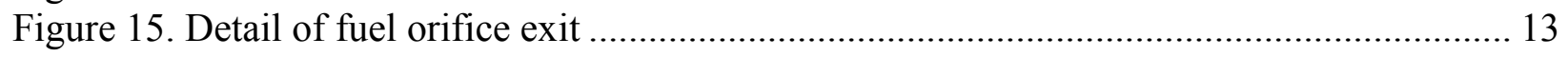

Figure 16. Housing side seal test fixture in original configuration................................................ 15

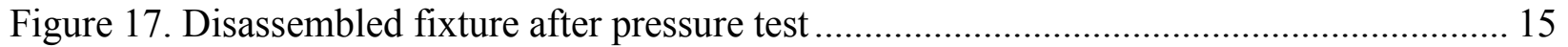

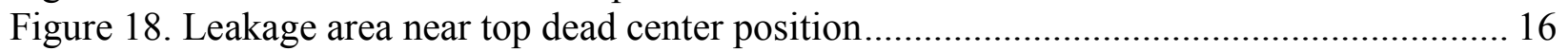

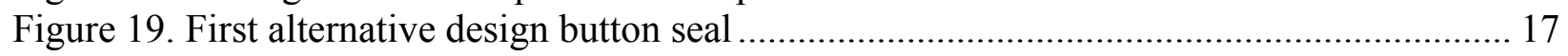

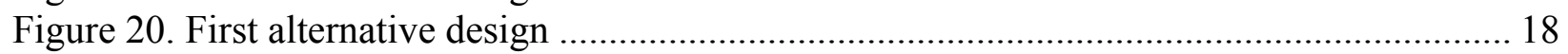

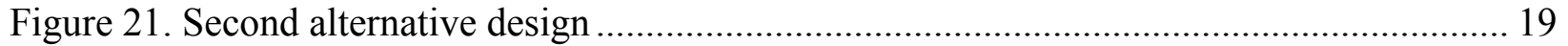

Figure 22. Triangle button seal and two-segment side seals ....................................................... 19

Figure 23. Completed GEN2.5A components ......................................................................... 20

Figure 24. Housing, aspiration plate and rotor shaft installed on assembly fixture...................... 20

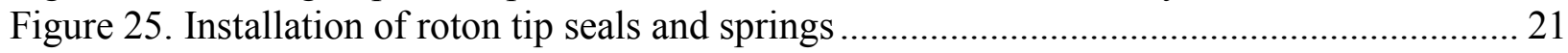

Figure 26. Initial fit check of rotons with housing.................................................................... 21

Figure 27. Rotor and rotons installed in assembly fixture .......................................................... 22

Figure 28. Front bearing plate and planetary gears installed ........................................................ 22

Figure 29. Drive plate and front cover installed ...................................................................... 23

Figure 30. Rear view prior to removal of assembly fixture ..................................................... 24

Figure 31. Rear of engine after removal of assembly fixture …………...................................... 24

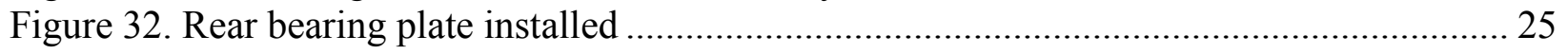

Figure 33. Rear cover installed and assembly complete............................................................ 25

Figure 34. GEN2.5A prepared for dynamometer installation..................................................... 26

Figure 35. GEN2.5A installed on dynamometer prior to testing ................................................ 26

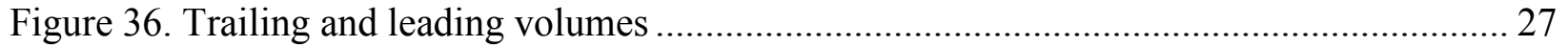

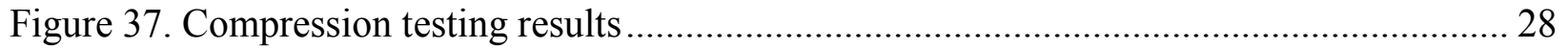

Figure 38. Lubricating oil expelled from engine ………........................................................... 28

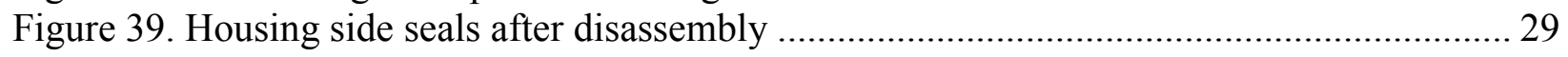

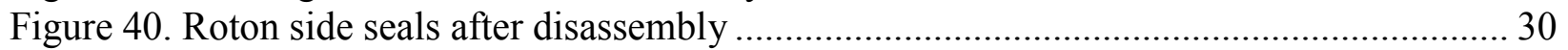

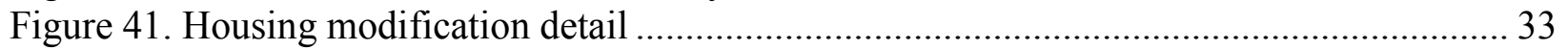

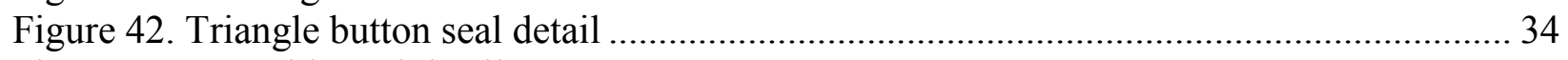

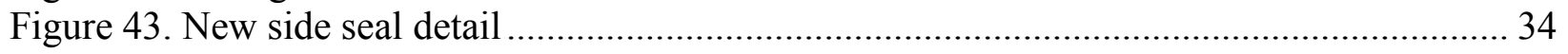


Figure 44. Rotons 1 and 2 pressure port modifications ................................................... 35

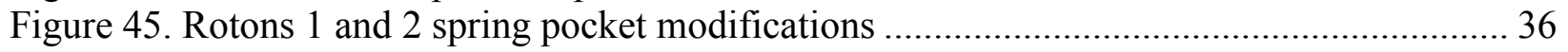

Figure 46. Roton 3 with 1/2" wide combustion pocket extension ............................................ 37

Figure 47. Roton 3 with 1" wide combustion pocket extension ........................................... 37

Figure 48. Roton 3 with 1-1/2" wide combustion pocket extension...................................... 38

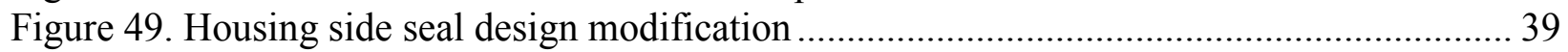

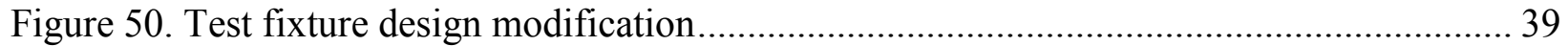

Figure 51. Redesigned roton and housing button seals..................................................... 40

Figure 52. Housing side seal manufacturing.................................................................... 41

Figure 53. Typical compression testing results........................................................... 42

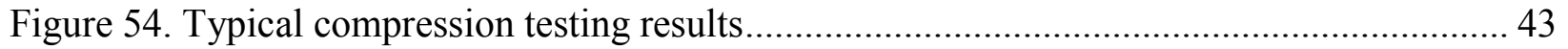

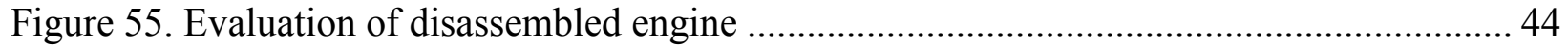

Figure 56. Leakage past the housing side seals in the area of the trailing volume..................... 45

Figure 57. Leakage past the ends of the roton tip seals along the face of the rotons.................. 46

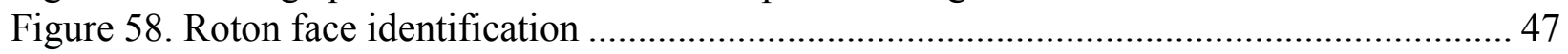

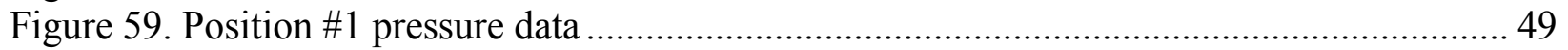

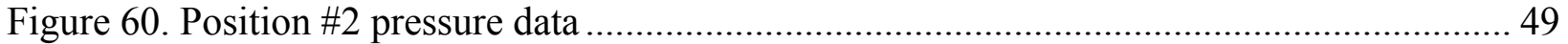

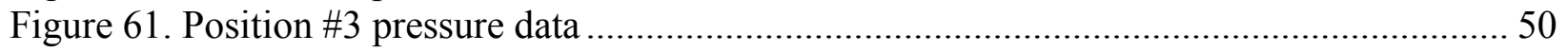




\section{List of Tables}

Table 1. Task Identification and Responsibility .................................................................... 5

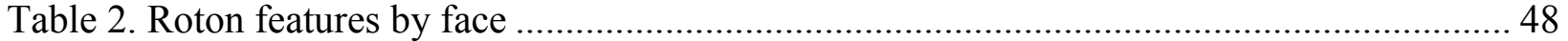

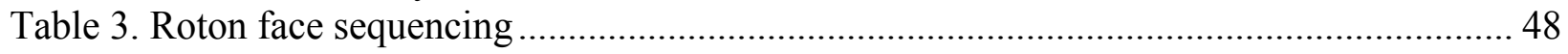


This page intentionally left blank. 


\section{List of Abbreviations and Acronyms}

\begin{tabular}{|l|l|}
\hline \multicolumn{1}{|c|}{$\begin{array}{c}\text { Abbreviation } \\
\text { or Acronym }\end{array}$} & \multicolumn{1}{c|}{ Definition } \\
\hline DOE & US Department of Energy \\
\hline ISO & International Organization for Standards \\
\hline NTRCI & National Transportation Research Center, Inc. \\
\hline ORTE & Oak Ridge Tool Engineering, Inc. \\
\hline PST & Power Source Technologies, Inc. \\
\hline
\end{tabular}


This page intentionally left blank. 


\section{Units of Measurement}

\begin{tabular}{|l|l|}
\hline \multicolumn{1}{|c|}{ Unit } & \\
\hline $\mathrm{kg}$ & kilogram \\
\hline $\mathrm{km} / \mathrm{h}$ & kilometer per hour \\
\hline $\mathrm{kPa}$ & kilopascal \\
\hline $\mathrm{m}$ & meter \\
\hline $\mathrm{m} / \mathrm{s}$ & meter per second \\
\hline $\mathrm{m} / \mathrm{s}^{2}$ & meter per second squared \\
\hline $\mathrm{mm}$ & millimeter \\
\hline $\mathrm{N} \cdot \mathrm{m}$ & Newton-meter \\
\hline $\mathrm{s}$ & second \\
\hline $\mathrm{psi}$ & Pounds per square inch \\
\hline
\end{tabular}


This page intentionally left blank. 


\section{Executive Summary}

Rudolf Diesel first conceived the compression ignition engine in 1892. His original intent was to burn coal dust, but he soon determined that liquid fuels were required. Since then, the diesel engine has not changed much from its original design as a reciprocating internal combustion engine. Enhancements have been made to diesel engine technology to increase efficiency and reduce emissions in recent years; however, these have largely been incremental improvements. The Legacy engine is a completely new design, transitional diesel engine, replacing the reciprocating engine with a rotary engine.

The commercial Legacy engine would provide the marketplace with a more efficient diesel engine. The benefits of Legacy's efficiency would be the reduction in Greenhouse Gas emissions as well as the demand for oil. In a broader sense, it could reduce the United States' dependency on foreign oil, provide a technological advantage in a critical market, and lead to the creation of "green" jobs. The core technology and its deployment uses existing infrastructure which will reduce the cost and time of implementation into the marketplace.

As a new, developing technology, many future opportunities for design optimization may be available. These opportunities would provide continued environmental and economic benefit.

\section{Background}

The Legacy engine is a revolutionary, patented engine that offers significant advances over conventional internal combustion engines in 1) power to weight ratio; 2) multiple fuel acceptance; 3) fuel economy; and 4) environmental compliance. These advances are achieved through a combination of innovative design geometry, rotary motion, aspiration simplicity, and manufacturing/part simplicity.

The tip seal represents the most significant technical challenge for commercialization of the Legacy engine and achievement of the projected engine performance gains. Tip seal design parameters include geometry, materials of construction, tribology, lubrication, fabrication methods and reliability.

PST has developed a solution to the tip seal challenge. This project has focused on the design, evaluation and optimization of the tip seal for the Legacy engine.

\section{Brief Overview}

The PST concept for the roton tip seal was developed into a manufacturable design. The design was evaluated using a custom designed and fabricated seal test fixture and further refined. This design was incorporated into the GEN2.5A prototype and tested for achievable compression pressure. The Decision Point at the end of Phase 1 of the project (described below) was to further optimize the existing tip seal design.

Enhancements to the tip seal design were incorporated into the GEN2.5B prototype and tested and evaluated using the iterative research strategy described below. Compression pressures adequate for compression ignition of diesel fuel were achieved, although not consistently in all combustion volumes. The variation in compression pressures was characterized versus design features. 
As the roton tip seal performance was improved, results pointed toward inadequate performance of the housing side seals. Enhancement of the housing side seal system was accomplished using a custom designed side seal test fixture. The design enhancements developed with the test fixture were also incorporated into the GEN2.5B prototype and tested and evaluated using the iterative research strategy described below.

Finally, to simplify the requirements for the roton tip seals and to enhance the introduction and combustion of fuel, a flush-mount fuel injector was designed, manufactured and demonstrated in the GEN2.5B prototype.

\section{Research Strategy}

The project was structured in two phases. Each phase was focused on the continued development of the tip seal system.

\section{GEN2.5A Testing and Evaluation}

The testing and evaluation is intended to confirm the adequate sealing of the prototype asymmetric tip seal system. The success of Phase 1 will show the GEN2.5A prototype developing sufficient compression pressure to reliably initiate combustion ignition of diesel fuel. The test data will be used for an enhanced design and implementation for GEN2.5B.

\section{GEN2.5B Design Enhancement and Validation}

The design enhancements will be derived from the data taken in GEN2.5A. Upon review the redesign will be implemented on the GEN2.5A engine and effective change and validation of GEN2.5B, which is GEN2.5A redesigned. The redesign will incorporate design changes recommended from Phase 1.

An iterative strategy was taken toward optimizing the tip seal system. The strategy is shown in Figure 1.

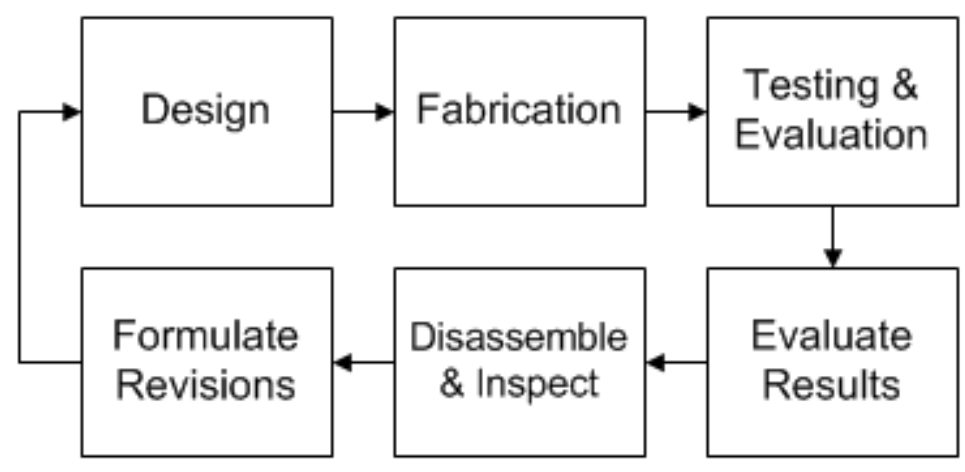

Figure 1. Iterative research strategy

\section{Conclusion}

The key technical challenge to the Legacy engine's commercialization, and the focus of this project, was the development of a viable roton tip seal. Continued development of the Legacy 
engine would not be possible without a solution to this challenge. Validation of the asymmetric tip seal system represents a major milestone in the development of the Legacy engine. Based on the results described in this report, the project has been successful. The asymmetric tip seal system has functioned as intended and achieved compression pressures adequate for compression ignition. The importance of this achievement cannot be overstated in terms of the continuing development of the Legacy engine.

\section{Future Program Efforts}

The development of a functioning tip seal, completed during this project, allows for the further research required for the continuing development of the Legacy engine. Key areas of required research and development include:

- Induction and exhaust optimization

- Combustion Optimization

- Thermal management

- Subsystem Development
- Controls
○ Fuel injection

Successful completion of research and development in these areas will lead to validation of the predicted improvements in efficiency and will provide the foundation necessary for continued development and eventual commercialization the Legacy engine. 
This page intentionally left blank. 


\section{Chapter 1 - Introduction and Background}

The commercial Legacy engine would provide the marketplace with a more efficient diesel engine, replacing the conventional reciprocating engine with a rotary engine. The benefits of Legacy's efficiency would be the reduction in Greenhouse Gas emissions as well as the demand for oil. In a broader sense, it could reduce the United States' dependency on foreign oil, provide a technological advantage in a critical market, and lead to the creation of "green" jobs. The core technology and its deployment uses existing infrastructure which will reduce the cost and time of implementation into the marketplace.

As a new, developing technology, many future opportunities for design optimization may be available. These opportunities would provide continued environmental and economic benefit.

\subsection{Background}

The Legacy engine, depicted in Figure 2, is a revolutionary, patented engine that offers significant advances over conventional internal combustion engines in 1) power to weight ratio; 2) multiple fuel acceptance; 3) fuel economy; and 4) environmental compliance. These advances are achieved through a combination of innovative design geometry, rotary motion, aspiration simplicity, and manufacturing/part simplicity.

\section{Rotating Components}

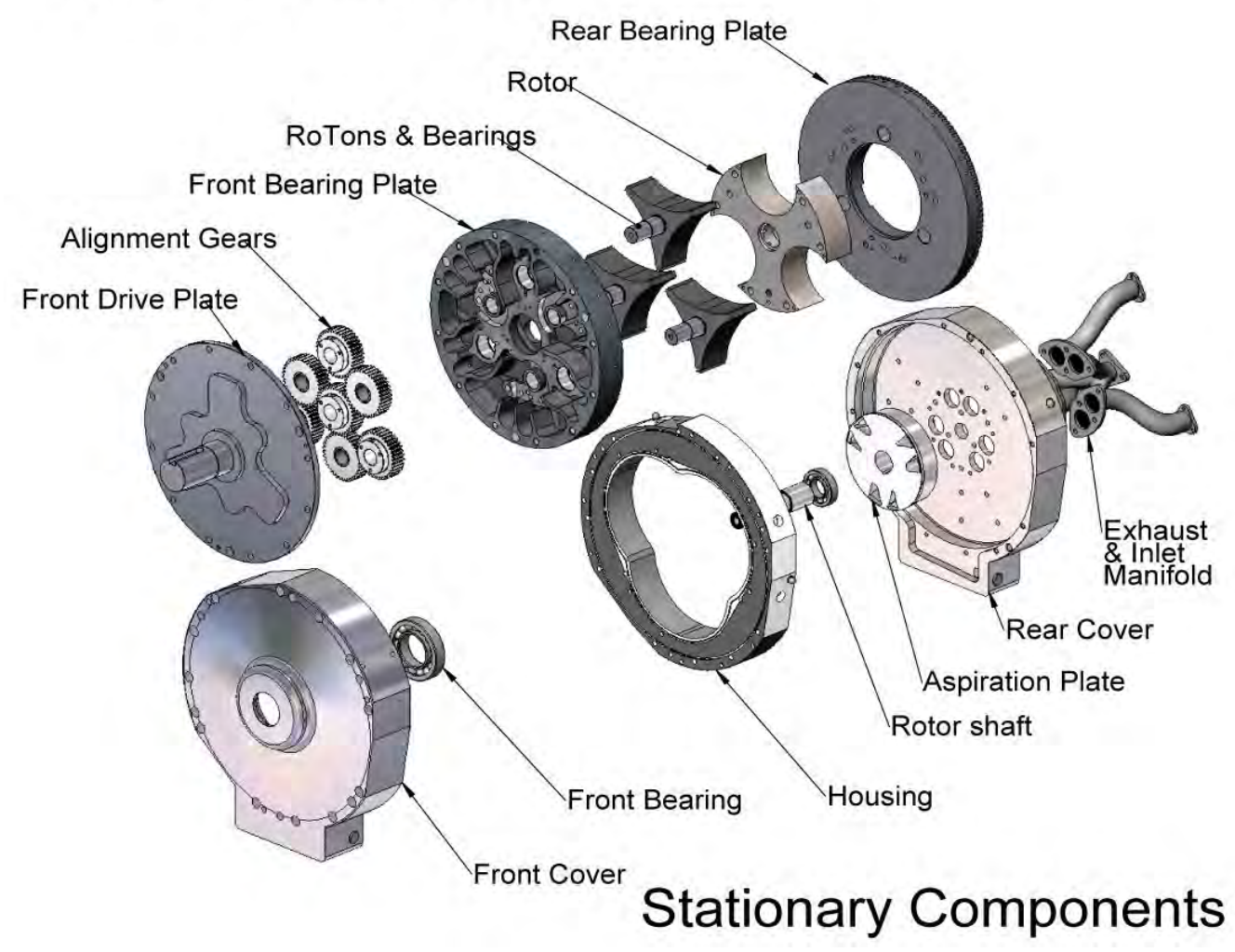

Figure 2. Legacy engine exploded view 
The roton tip seal, shown in Figure 3, represents the most significant technical challenge for commercialization of the Legacy engine and achievement of the projected engine performance gains. Tip seal design parameters include geometry, materials of construction, tribology, lubrication, fabrication methods and reliability.

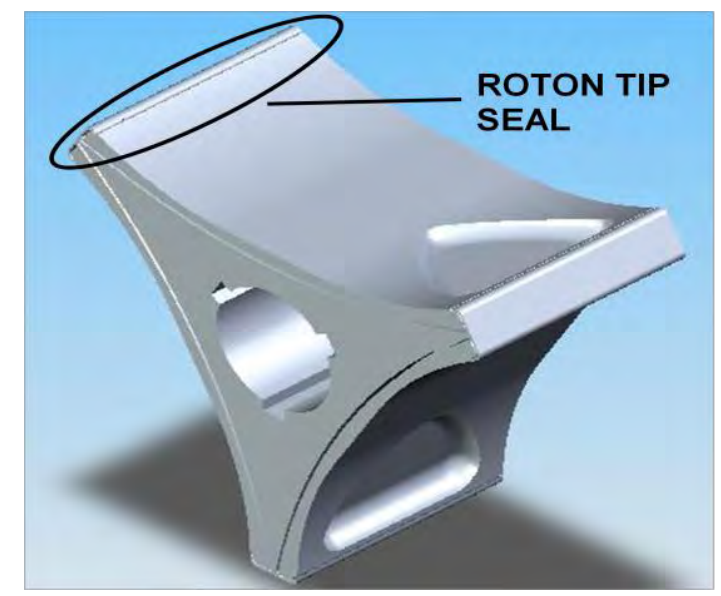

Figure 3. Roton tip seal

The Legacy engine incorporates a radically new configuration and combustion concept, and accordingly, seal configuration cannot be derived or extrapolated from existing seal geometry design solutions in current reciprocating or rotary engines.

PST has developed a solution to the tip seal challenge. The original concept for the tip seal is shown in Figure 4. This project has focused on the design, evaluation and optimization of the tip seal for the Legacy engine.
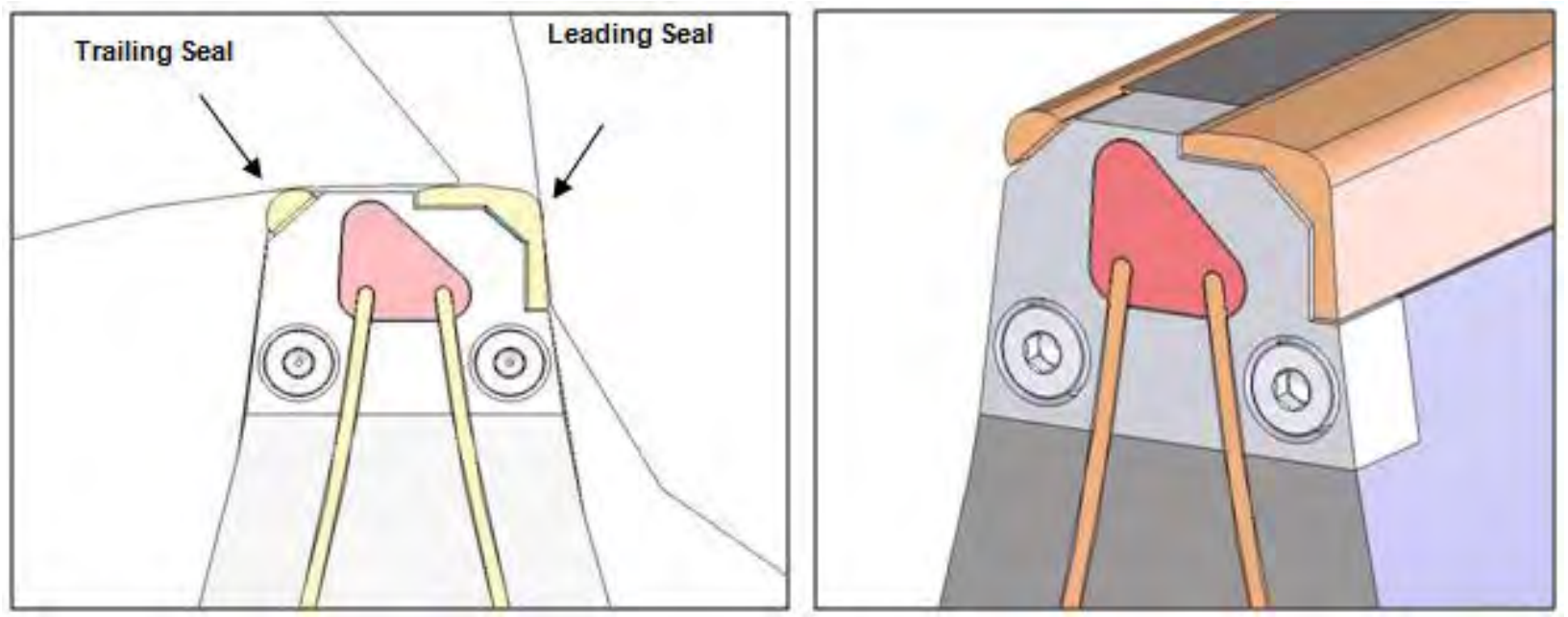

Figure 4. Original concept for roton tip seal 
Project Team

1.1.1 APTUS DesignWorks, Inc. (APTUS)

APTUS was responsible for engineering design of all of the components and design modifications. APTUS was also responsible for configuration control of the design documents.

\subsubsection{National Transportation Research Center, Inc. (NTRCI)}

NTRCI was responsible for overall project management, sub-contract management, cost management and reporting.

\subsubsection{Oak Ridge Tool-Engineering, Inc. (ORTE)}

ORT-E was responsible for fabricating, purchasing, or modifying all components required to build the prototypes as identified by the parts list provided by APTUS/PST.

\subsubsection{Power Source Technologies, Inc. (PST)}

PST acted as the technical lead for the project. PST had technical oversight of the design, engineering, testing, data collection, analysis and reporting.

\subsubsection{The University of Tennessee (UT)}

UT provided the project with professional assistance in automotive engineering, related to the evaluation and testing of the Legacy engine.

\subsection{Project Description}

This project tests and evaluates a new type of tip seal for a rotary diesel "Legacy" engine. The results of this work allows for the continuing development of the Legacy engine. Once the tip seals have been validated, continued research and development will result in a commercially viable Legacy engine.

The research objective of this effort is to develop an enhanced tip seal for Legacy engine that is reliable and durable. This process is split into two phases:

\section{GEN2.5A Testing and Evaluation}

The testing and evaluation is intended to confirm the adequate sealing of the prototype asymmetric tip seal system. The success of Phase 1 will show the GEN2.5A prototype developing sufficient compression pressure to reliably initiate combustion ignition of diesel fuel. The test data will be used for an enhanced design and implementation for GEN2.5B.

\section{GEN2.5B Design Enhancement and Validation}

The design enhancements will be derived from the data taken in GEN2.5A. Upon review the redesign will be implemented on the GEN2.5A engine and effective change and validation of GEN2.5B, which is GEN2.5A redesigned. The redesign will incorporate design changes recommended from Phase 1. 


\subsection{Project Schedule}

This project was conducted in Fiscal 2011 and the first three month of Fiscal 2012. Figure 5 is the project schedule. The tasks are identified and their lead organizations are named in Table 1 below.

\begin{tabular}{|c|c|c|c|c|c|c|c|c|c|c|c|c|c|c|c|}
\hline \multirow{2}{*}{ Tasks } & \multicolumn{15}{|c|}{ Month of the Project } \\
\hline & $10 / 10$ & $11 / 10$ & $12 / 10$ & $01 / 11$ & $02 / 11$ & $03 / 11$ & $04 / 11$ & $05 / 11$ & $06 / 11$ & $07 / 11$ & $08 / 11$ & $09 / 11$ & $10 / 11$ & $11 / 11$ & $12 / 11$ \\
\hline \multicolumn{16}{|l|}{1} \\
\hline \multicolumn{16}{|l|}{2} \\
\hline \multicolumn{16}{|l|}{3} \\
\hline \multicolumn{16}{|l|}{4} \\
\hline \multicolumn{16}{|l|}{5} \\
\hline \multicolumn{16}{|l|}{6} \\
\hline \multicolumn{16}{|l|}{7} \\
\hline \multicolumn{16}{|l|}{8} \\
\hline \multicolumn{16}{|l|}{9} \\
\hline \multicolumn{16}{|l|}{10} \\
\hline \multicolumn{16}{|l|}{11} \\
\hline \multicolumn{16}{|l|}{12} \\
\hline \multicolumn{16}{|l|}{13} \\
\hline \multicolumn{16}{|l|}{14} \\
\hline \multicolumn{16}{|l|}{15} \\
\hline \multicolumn{16}{|l|}{16} \\
\hline \multicolumn{16}{|l|}{17} \\
\hline \multicolumn{16}{|l|}{18} \\
\hline \multicolumn{16}{|l|}{19} \\
\hline \multicolumn{16}{|l|}{20} \\
\hline \multicolumn{16}{|l|}{21} \\
\hline \multicolumn{16}{|l|}{22} \\
\hline \multicolumn{16}{|l|}{23} \\
\hline 24 & & & & & & & & & & & & & & & \\
\hline
\end{tabular}

Figure 5. Project Schedule 
Table 1. Task Identification and Responsibility

\begin{tabular}{|l|l|l|}
\hline Task & Task Description & Responsible Organization \\
\hline Task 1 & Program Management & NTRCI \\
\hline Task 2 & Design Review & PST \\
\hline Task 3 & Hardware Evaluation & PST \\
\hline Task 4 & Design of GEN2.5A & APTUS \\
\hline Task 5 & Manufacturing Planning & PST \\
\hline Task 6 & Fabrication and Procurement & ORTE \\
\hline Task 7 & Tip Seal Evaluation & APTUS \\
\hline Task 8 & Assembly of GEN2.5A & PST \\
\hline Task 9 & GEN2.5A Testing and Evaluation & UT \\
\hline Task 10 & Decision Point & PST \\
\hline Task 11 & Design of GEN2.5B & APTUS \\
\hline Task 12 & Fabrication and Procurement & ORTE \\
\hline Task 13 & Assembly of GEN2.5B & PST \\
\hline Task 14 & GEN2.5B Testing and Evaluation & UT \\
\hline Task 15 & GEN2.5B Decision Point & PST \\
\hline Task 16 & Revise design of GEN2.5B & APTUS \\
\hline Task 17 & Fabrication and Procurement & ORTE \\
\hline Task 18 & Assembly of GEN2.5B & PST \\
\hline Task 19 & GEN2.5B Testing and Evaluation & UT \\
\hline Task 20 & Revise design of GEN2.5B & APTUS \\
\hline Task 21 & Fabrication and Procurement & ORTE \\
\hline Task 22 & Assembly of GEN2.5B & PST \\
\hline Task 23 & GEN2.5B Testing and Evaluation & UT \\
\hline Task 24 & Final Project Reporting & NTRCI \\
\hline
\end{tabular}


This page intentionally left blank. 


\section{Chapter 2 - Completion and Testing of GEN2.5A}

\subsection{GEN2.5A Design}

The design review conducted by PST led to the modification and enhancement of the Tip Seal design and the fuel injection system originally proposed for the GEN2.5A.

All engine component detail drawings were completed. A process was created through a collaboration internet service for submitting completed drawings for approval. The drawing submittal/approval system also keeps a record of each component's revision history.

Drawings were updated as needed to support change requests during manufacturing. Engine assembly drawings, instructions and documentation were created to support Gen 2.5A engine assembly.

\section{Tip Seal}

\section{Sealing Surface Shape}

The sealing surface geometry works in conjunction with the Housing and Rotor geometry to provide correct surface transition and seal articulation. Changes were made to the shape to trim some excess material from the side extension of the large seal as shown in Figure 6. This yields lower seal mass which should accomplish improved seal response to housing surface variation and reduced engine wear.

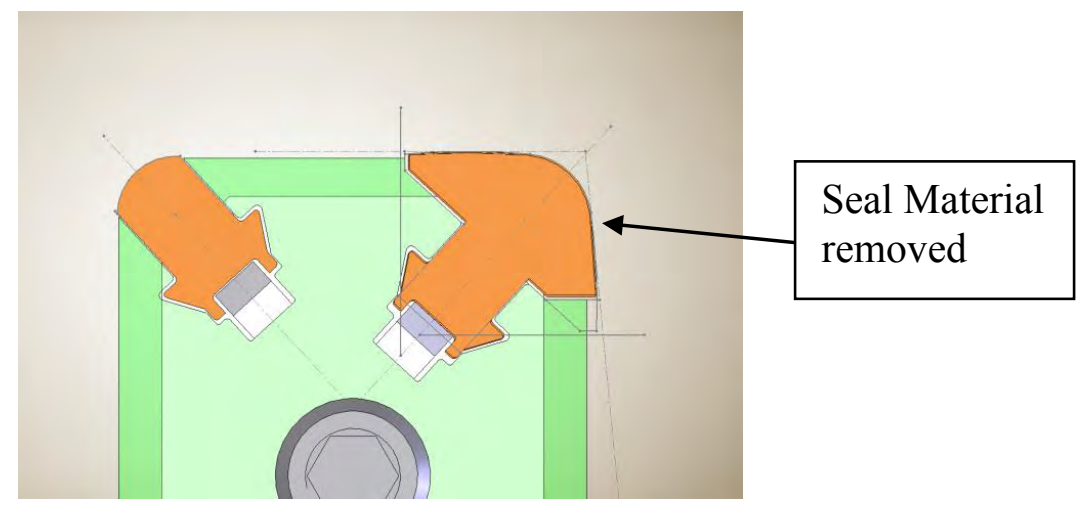

Figure 6. Material removed from large seal

\section{Seal Guide Surfaces}

The originally proposed seal design, shown in Figure 7, included 3 small parallel guide pins that extended into small guide holes in the roton to provide orientation control for the seal as it articulates in and out of the roton tip. The combination of pin contact and the contact between the seal and roton established the sliding interface. The purpose of the pins was to separate the interface contact points as much as possible without compromising the structural integrity of the roton tip. 


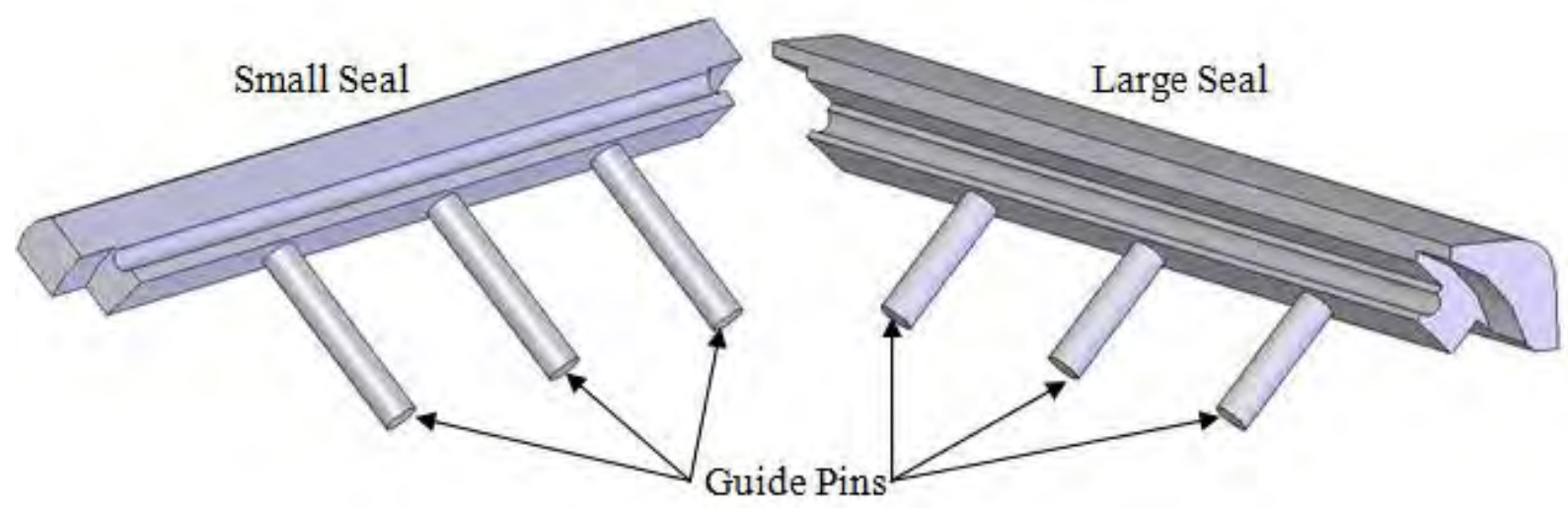

Figure 7. Original concept for tip seals

During manufacturing planning, the 3 parallel pins were judged to be likely to cause binding of the seals in the roton. The fit of the guide pins in the guide holes must be sufficient to prevent the pins from binding in the holes. The achievable tolerance on location of the pins on the seals and the guide holes in the rotons required a greater clearance tolerance between the pins and holes than what was required to prevent cocking. A single-piece seal shape was developed that could accomplish acceptable normal force separation in a much more manufacturable design. The final shape, shown in Figure 8, maximizes contact separation while maintaining sufficient roton tip integrity. The proposed seal shape can be easily manufactured.

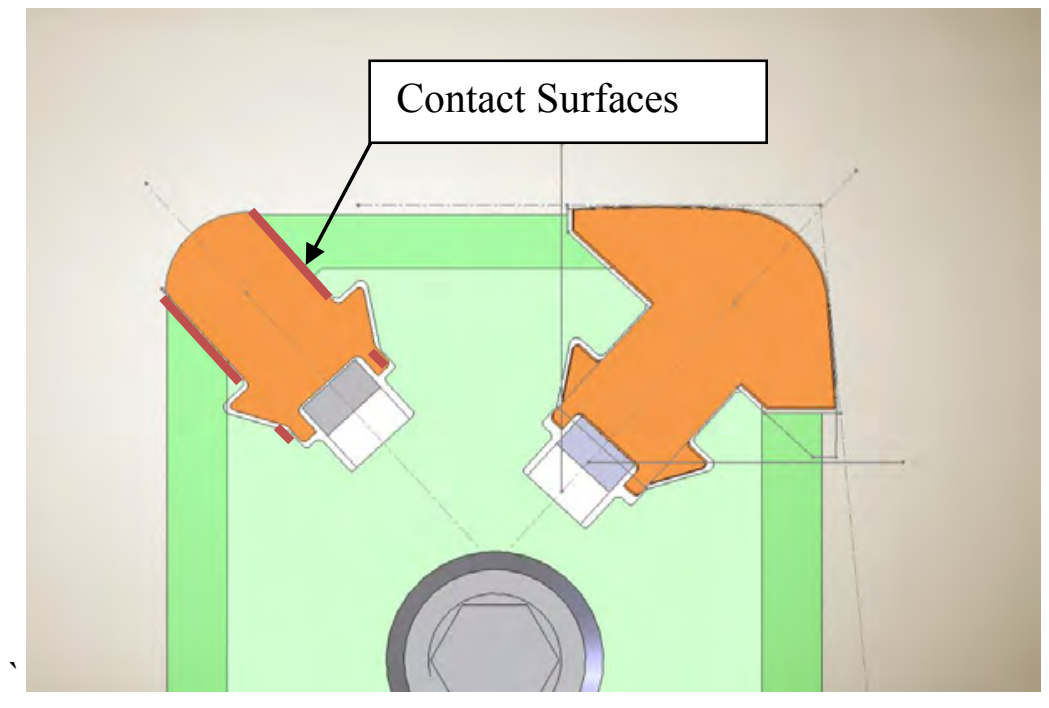

Figure 8. Seal guide surfaces modification

\section{Seal Stroke Limiting Feature}

The originally proposed seal/ roton interface, shown in Figure 9, included a lengthwise groove for retaining the seal in the roton using a section of standard drill rod. The seal could be inserted along its articulation axis and then locked in place with the rod. The rod would be undersized relative to the groove diameter, allowing the desired seal articulation. 


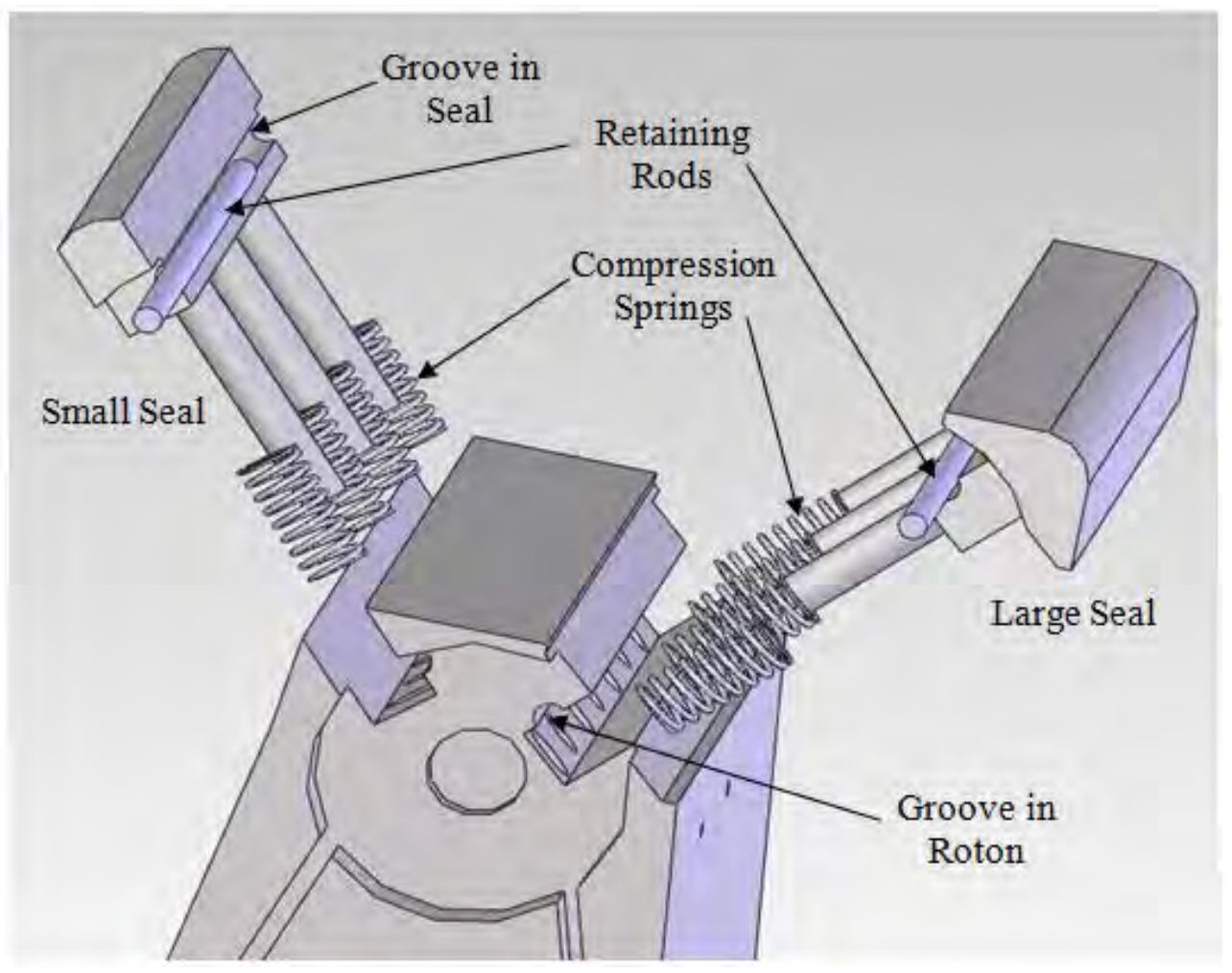

Figure 9. Original seal/roton interface

This arrangement became unnecessary since the proposed seal guide surface change described above no longer requires the seal to be inserted along the axis of articulation. The new design, shown in Figure 10, allows the seal to be inserted along the direction of its length, and therefore the stroke limiting feature(s) can be integrated into the basic seal and roton shapes as shown. The "ears" on the seals slide into grooves machined into the roton and are captured within these grooves to limit movement in the outward direction.

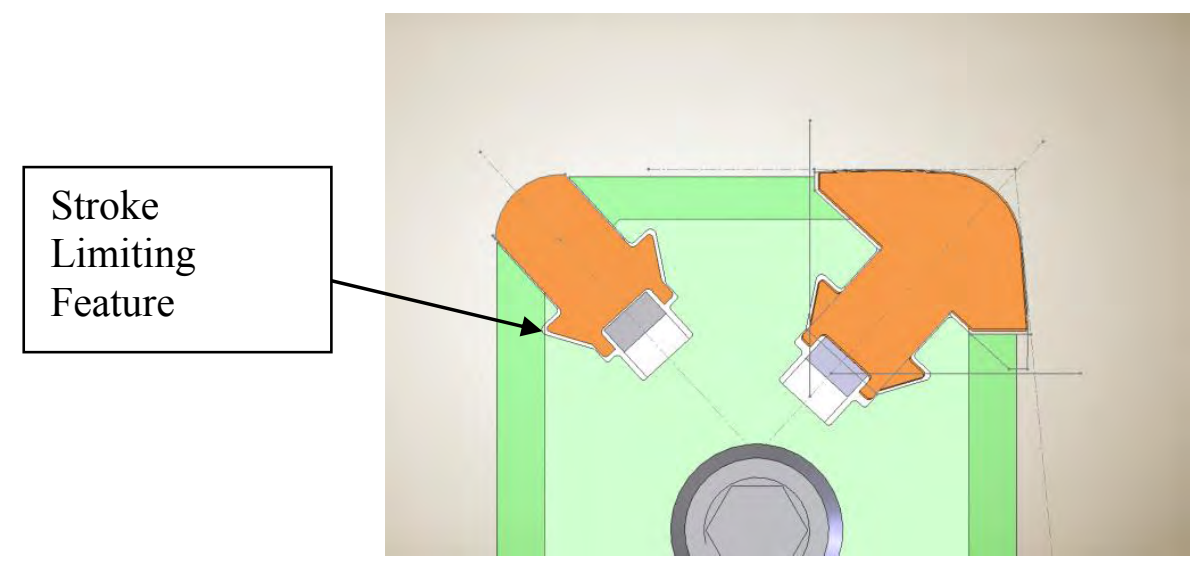

Figure 10. Stroke limiting feature redesign 


\section{Seal Extension Spring}

The originally proposed seal/ roton interface required the use of multiple small compression coil springs to provide seal extension force. The changes above allow more flexibility in the selection of seal extension spring. The original concept design used four compression springs under each seal. With the elimination of the guide pins, and the ability to assemble the seals in the rotons by sliding along its length, a single leaf-style spring borrowed from the Mazda 13B rotary engine tip seal assembly could be used. Using a single leaf spring in place of multiple compression springs simplifies the roton manufacturing by eliminating the spring pocket features. The leaf spring is inserted lengthwise in the same manner as the seals, which also simplifies the assembly process. Finally, using the leaf spring eliminates components from the parts count, which increases reliability by decreasing the modes of possible failure.

\subsection{GEN2.5A Research and Development}

\subsubsection{Tip Seal}

The fit of the tip seals in the roton tip was a concern. The required clearance between the tip seals and the feature they fit into in the roton affects the operation of the tip seals in two ways. Too little clearance leads to increased friction as the seal articulates into and out of the roton. Too great clearance leads to rocking of the tip seals in the roton, which could cause inefficient sealing and increased wear. To mitigate this risk and evaluate the optimum clearance between the roton and the tip seals, a tip seal test rig, shown in Figure 11, was designed and fabricated. The test rig consisted of a rotating drum to replicate the housing contour and a fixed roton surrogate into which the tips seals were inserted, as shown in Figure 12. The test rig provided visual access to the tip seal for dynamc analysis using a high speed video camera. Three sizes of tip seals were produced for evaluation in the test rig: nominal dimension, .001 undersized and .001 oversized. The three sizes were evaluated in the test rig by operating the rig and recording high speed video of the operation of the seals.

Evaluation of tip seals using the test rig was completed. The tests demonstrated that the mechanical operation of the tip seals was as expected and satisfactory. Evaluation of the oversize and under size tip seals showed no significant difference in performance compared to the nominal size seals. This result provides insight into the manufacturing tolerances required for producing the tip seals. 


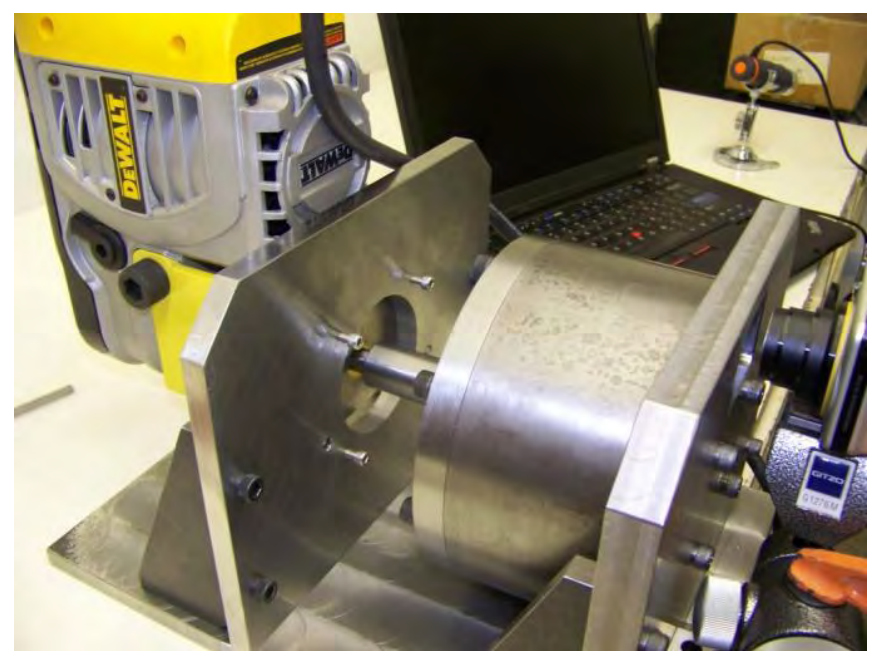

Figure 11. Tip seal test equipment

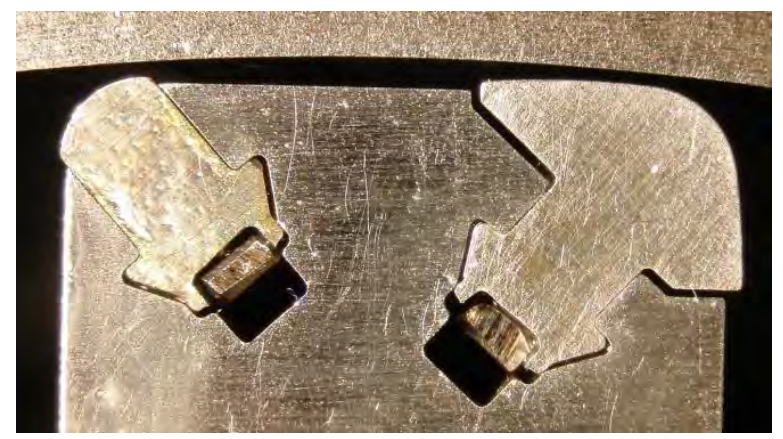

Figure 12. Detail of tip seals in extended (non-contact) position

\subsubsection{Flush-Mount Fuel Injector Nozzles}

Conventional fuel injectors are designed to provide a fuel spray pattern that mimics a hollow cone to provide a combustible mixture in the combustion chamber formed by the piston top and cylinder head in a conventional engine. The features of the injector nozzle that provide this spray pattern protrude into the combustion chamber of a conventional engine. This protrusion cannot be accommodated in the Legacy engine since the rotor and rotons pass the fuel injector while in contact with the housing. Previous prototypes have utilized conventional fuel injectors and nozzles by providing a machined feature in the housing wall to recess the normally protruding feature into the housing to eliminate interference with the rotor and rotons. While this recess allowed the use of conventional fuel injectors, it provided a leakage path for the compressed air before injection and the combustion gases after injection. Development of the flush-mount fuel injector was undertaken to eliminate this sealing issue.

Significant simplification of the housing manufacturing can also be accomplished by creation of a custom flush-mounted fuel injector nozzle. Such a nozzle eliminates the need to manufacture precise features into the inside and outside of the Housing to accommodate a typical piston engine injector shape. Creating the flush-mount nozzle involves significant challenges, but these hurdles are perceived to involve less risk and uncertainty than machining and EDMing the more 
complex housing features required to use conventional injector nozzles. The housing features would require machining graphite electrodes to the desired shape and using plunge-edm to produce the features in the housing; both of these processes are high risk for prototype development. These features would be machined at the near-completion point in the housing manufacturing process. Mis-machining the housing would require a lengthy and risky repair at best, and starting over on a replacement at worst. Nozzles are readily available, and low cost; therefore, developing the flush-mount nozzle was considered low risk with respect to schedule and cost.

While the flush-mount nozzle could be readily manufactured by a fuel injector manufacturer, developing it for this project required modifying existing conventional injector nozzles. This modification required welding additional material onto the existing nozzle, machining the resulting nozzle to the required size and contour to match the housing, and producing the small holes to the size and orientation required for the GEN2.5B.

A welding vendor was identified for welding up the injector tip; this effort proved successful in that the material required was built up without distortion of the internal geometry of the injector nozzle. A welded nozzle is shown in Figure 13. The welded nozzles were machined to the required outside shape and contour by ORTE. A manufacturer capable of producing very small orifices was also identified that was capable of producing the required fuel orifices in the machined nozzles. Figure 14 shows the two orifices required in the nozzle, and Figure 15 shows a detailed view of one orifice illustrating the shallow angle of exit required for the Legacy engine geometry. A test part was produced for evaluation; the results were satisfactory, and the vendor completed six fuel injectors for the GEN2.5A.

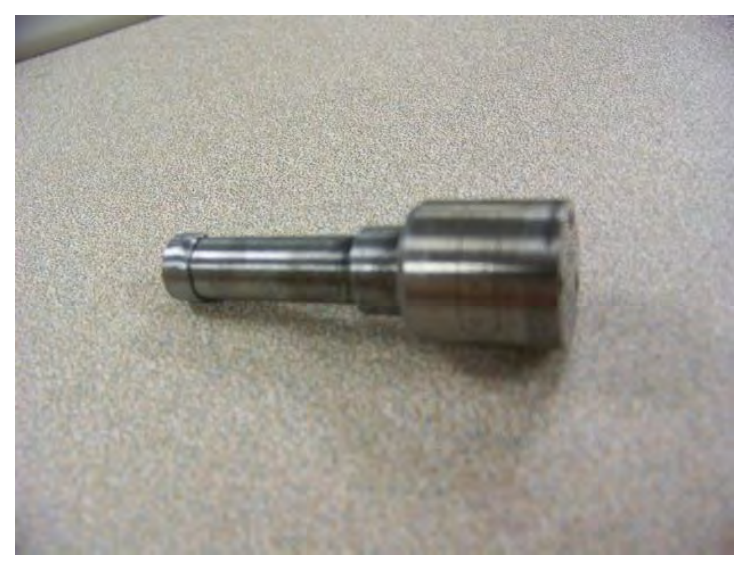

Figure 13. Custom modified nozzle: tip built up by precision welding. 


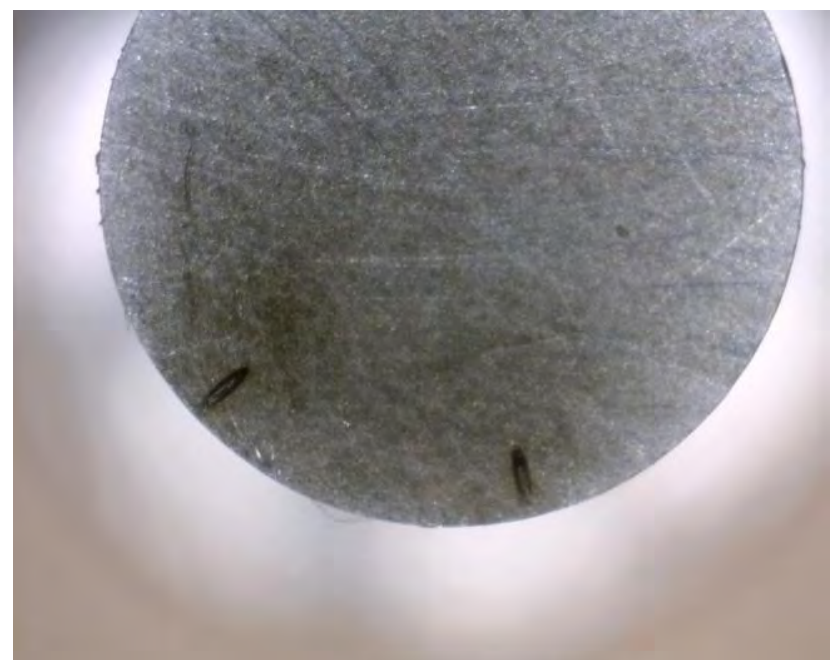

Figure 14. Final nozzle exit orifice

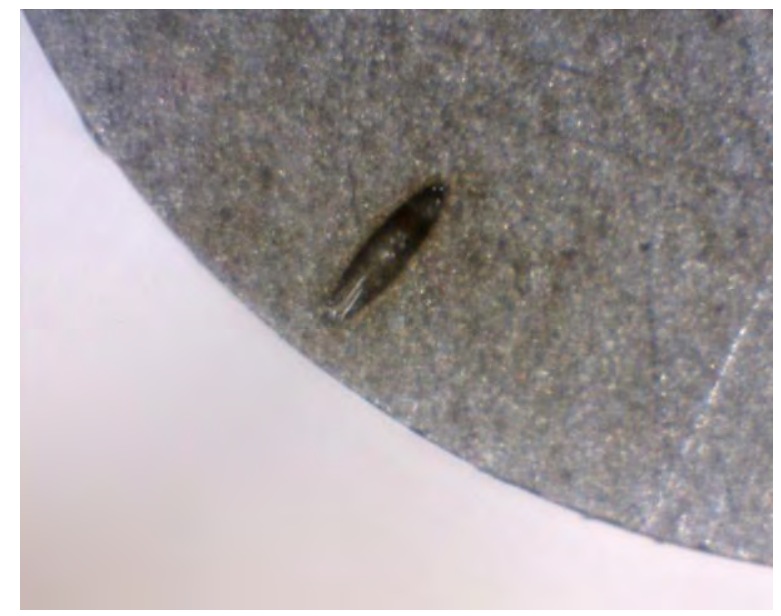

Figure 15. Detail of fuel orifice exit

Testing of the fuel injection system was performed to confirm that the welding and machining of the nozzle holes did not affect the functionality of the injectors. The four modified injectors were tested using the high-pressure common rail injection system used on the engine; however, the testing was performed on the bench to observe the injectors. The fuel pressure was limited to $3000 \mathrm{psi}$, which is the injection pressure for the original fuel system for these injectors. The prototype engine control module developed for the Legacy engine provides for a simulated engine speed input, which allows the fuel injection system to be operated under simulated conditions.

Each modified injector was tested separately utilizing the following procedure:

1. Connect the injector to the fuel rail. The other two fuel outlets on the fuel rail were blocked.

2. With the control cable disconnected, pressurize the fuel rail to $3000 \mathrm{psi}$.

3. Monitor the injector for any leakage. 
4. De-pressurize the fuel rail.

5. Swab the injector tip with a paper towel to detect any fuel accumulation at the nozzle holes.

6. Connect the control cable and install the injector into a fuel containment tube to capture the fuel.

7. Set the simulated engine speed to $600 \mathrm{rpm}$, pressurize the fuel rail and enable the injector driver for the injector being tested.

8. Observe that fuel is being sprayed from the injector into the fuel containment tube.

9. Disable the injector driver, de-pressurize the fuel rail and disconnect the control cable.

10. Remove the injector from the fuel containment tube and wipe dry.

11. Repeat steps 2-5.

One of the four modified injectors was found to not seal closed in step 3, resulting in leakage. The remaining three passed all of the test steps and were deemed satisfactory for engine operation.

\subsubsection{Housing Side Seal Testing and Evaluation}

The housing side seal effort was undertaken as a result of compression testing of GEN2.5A. The inadequate performance of the housing side seal system, described below in the GNE2.5A Testing and Evaluation section, prevented further evaluation of the asymmetric roton tip seal system, including combustion testing. Therefore, resolution of the housing side seal system issues is integral to the further evaluation of the asymmetric roton tip seal system.

To address the housing side seal issues, a test fixture was designed and fabricated to evaluate the performance of the existing side seal system and investigate alternative designs. The fixture was designed to initially replicate the housing side seal geometry in the GEN2.5A. The fixture is shown in its original configuration in Figure 16. The top plate of the fixture is removed to show internal details. A housing side seal from GEN2.5A was used in the initial testing. A straight seal fabricated from the same material as the housing side seals was used to complete the pressurized volume. Button seals were included to complete the seal as in the GEN2.5A. The seal springs from GEN2.5A were used for this initial test. Shims were used to space the top plate .004" from the bottom plate to simulate the clearance between the housing and the bearing plates. 


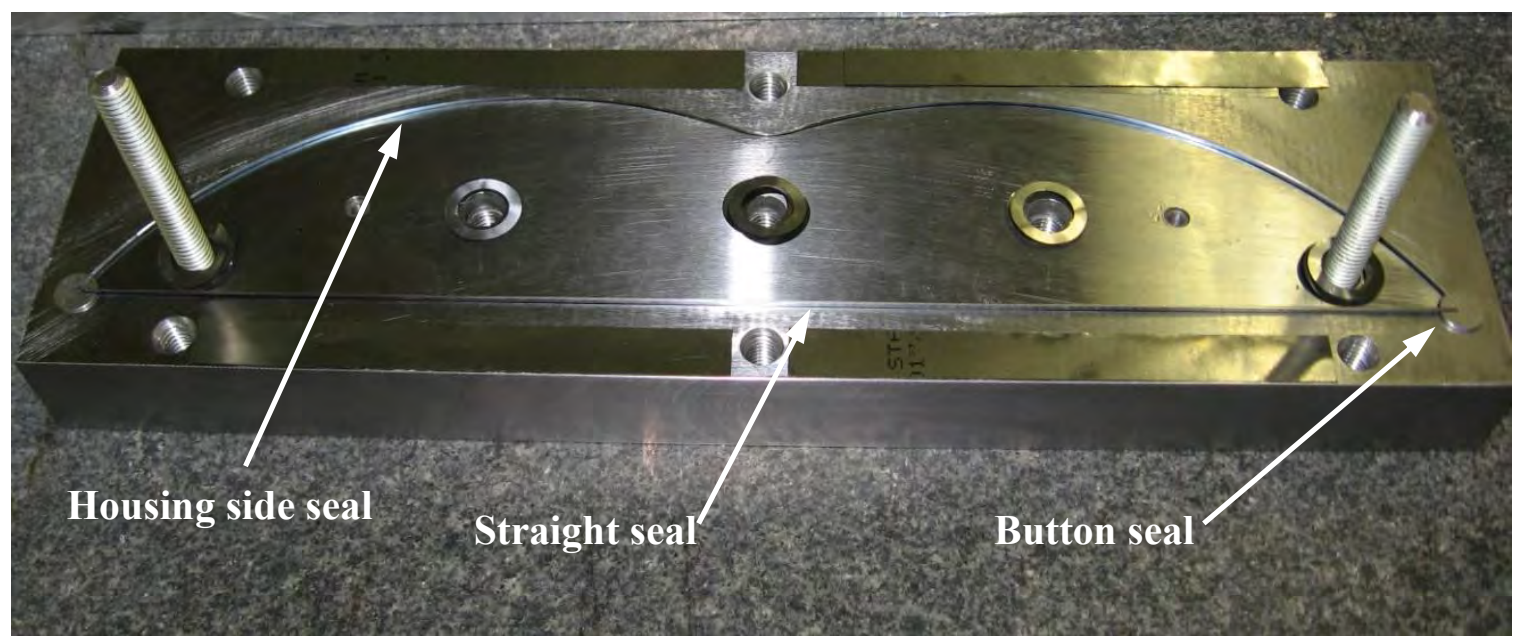

Figure 16. Housing side seal test fixture in original configuration

The top plate was installed and the sealed volume was pressurized with nitrogen. Leakage was observed at approximately 75 psig confirming the results of the dynamometer compression testing. White lithium grease was pasted on the inside of the seals as a leakage indicator. Using this technique, it was confirmed that the major leakage occurs at the top dead center region as shown in Figure 17 and Figure 18.

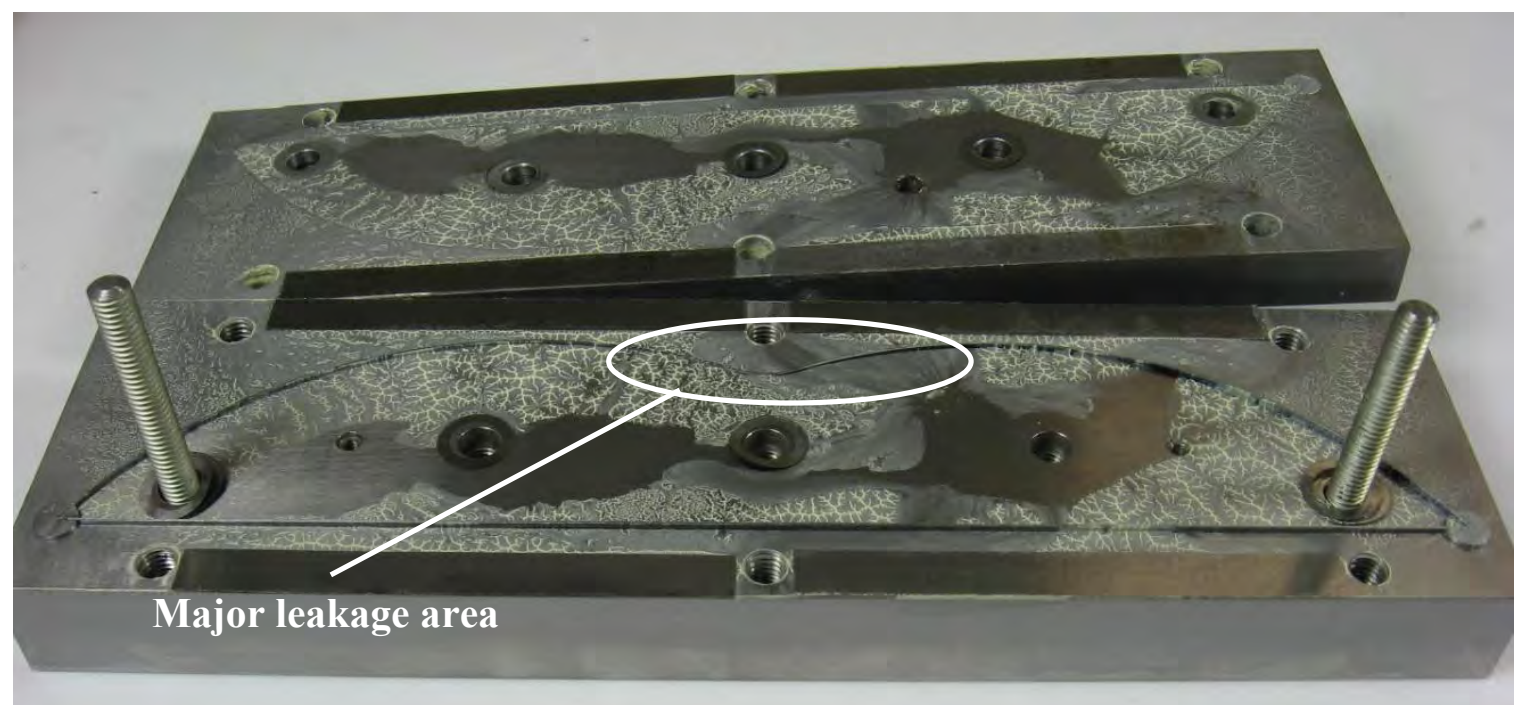

Figure 17. Disassembled fixture after pressure test 


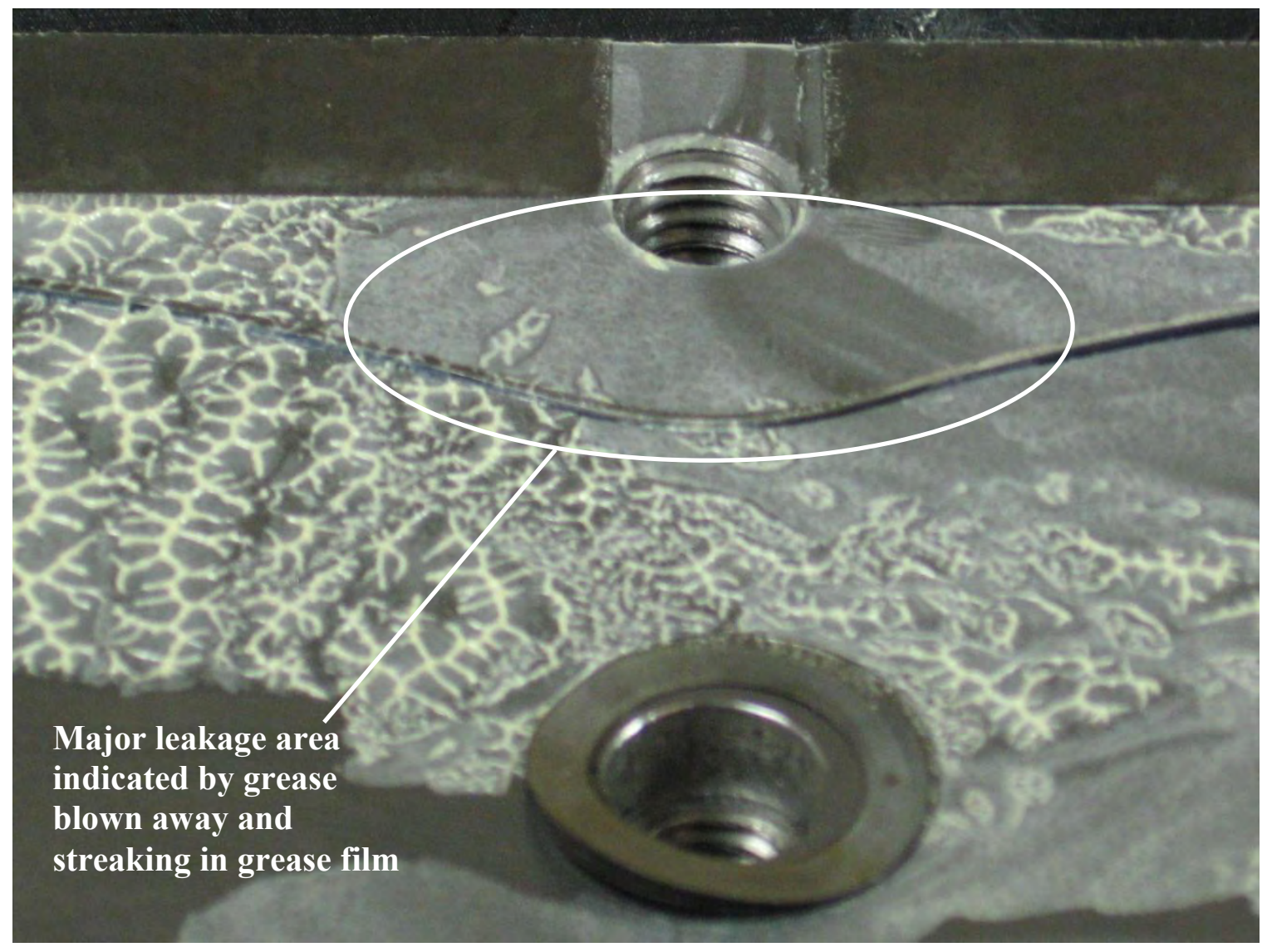

Figure 18. Leakage area near top dead center position

The first alternative design evaluated was the addition of a button seal with a spring underneath it under the side seal in the top dead center region. Due to the close proximity of the seal to the interior edge of the housing in the engine, this button seal has a small ledge to support the side seal as shown in Figure 19. 

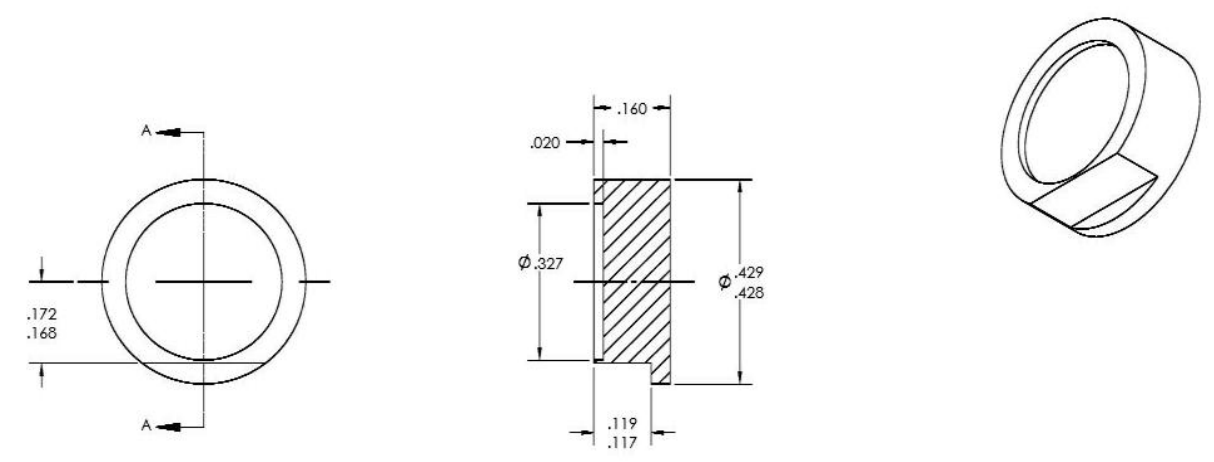

SECTION A-A

Figure 19. First alternative design button seal

This design did not improve the performance; leakage occurred at approximately the same pressure, 75 psig. A second set of wave springs were added under the side seal and the straight seal, but there was no improvement. The major leakage again occurred at the top dead center area as indicated by the lithium grease indicator as shown in Figure 20. 


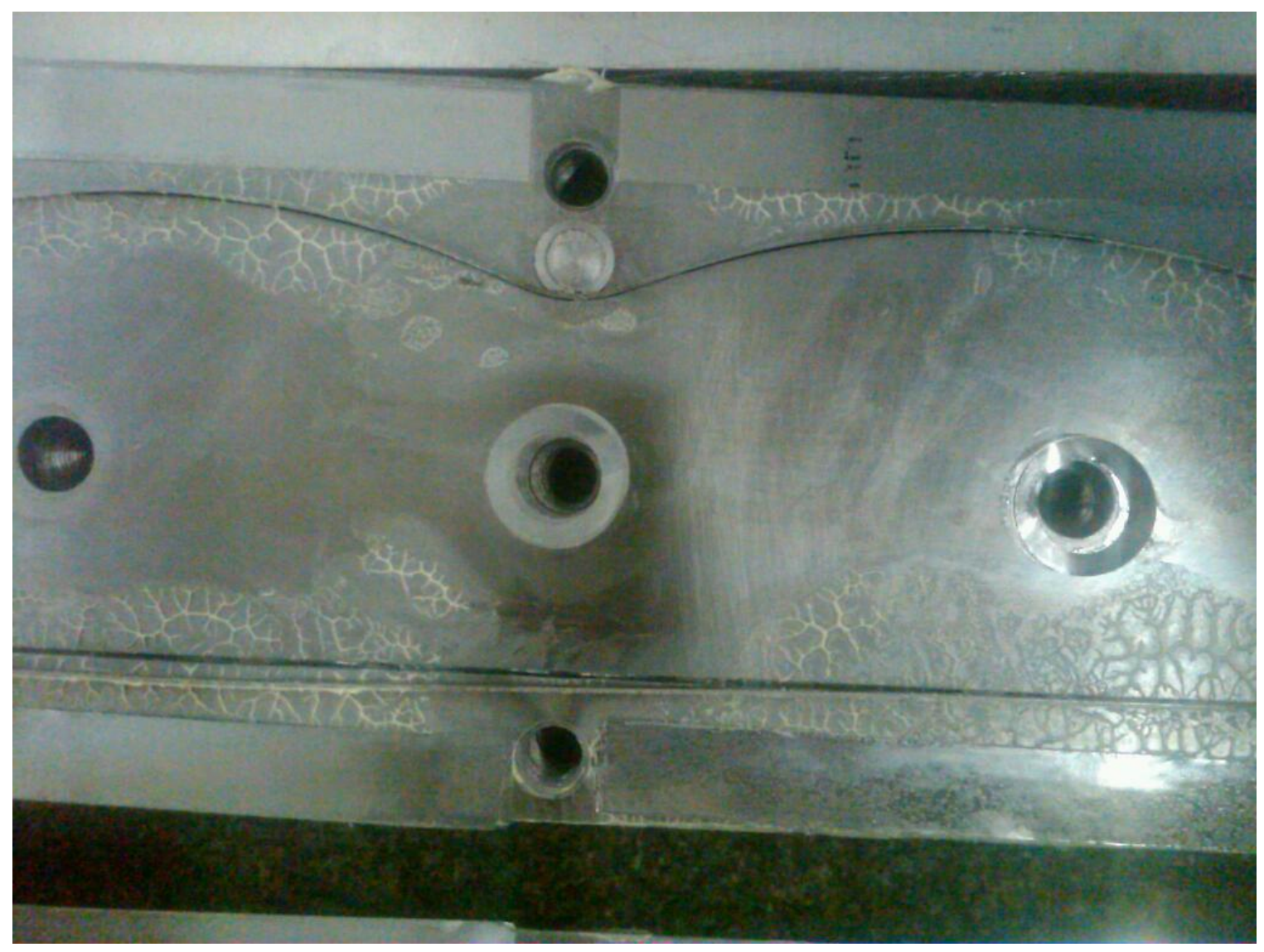

Figure 20. First alternative design

The second alternative design evaluated was a complete redesign of the housing sealing system. The one-piece side seal design was abandoned in favor of a two-segment seal with a triangle shaped button seal located at the top dead center position. The button seal incorporated a pocket machined in the face to reduce the contact area and thus the friction. This new design is shown in Figure 21 and Figure 22. The original side seals were fabricated from spring steel wire that was bent to the desired geometry. This wire had slightly rounded edges from the original drawing and rolling operations. Maintaining the flatness required for the seals while achieving the desired geometry was not possible with this material and manufacturing process. To eliminate these issues, a new side seal material was specified and a new manufacturing process was developed. The new side seals were made from ductile iron that was ground flat and to a thickness that corresponded to the desired seal height. The desired seal geometry was then obtained by EDM machining each seal separately from the flat ground ductile iron stock. 


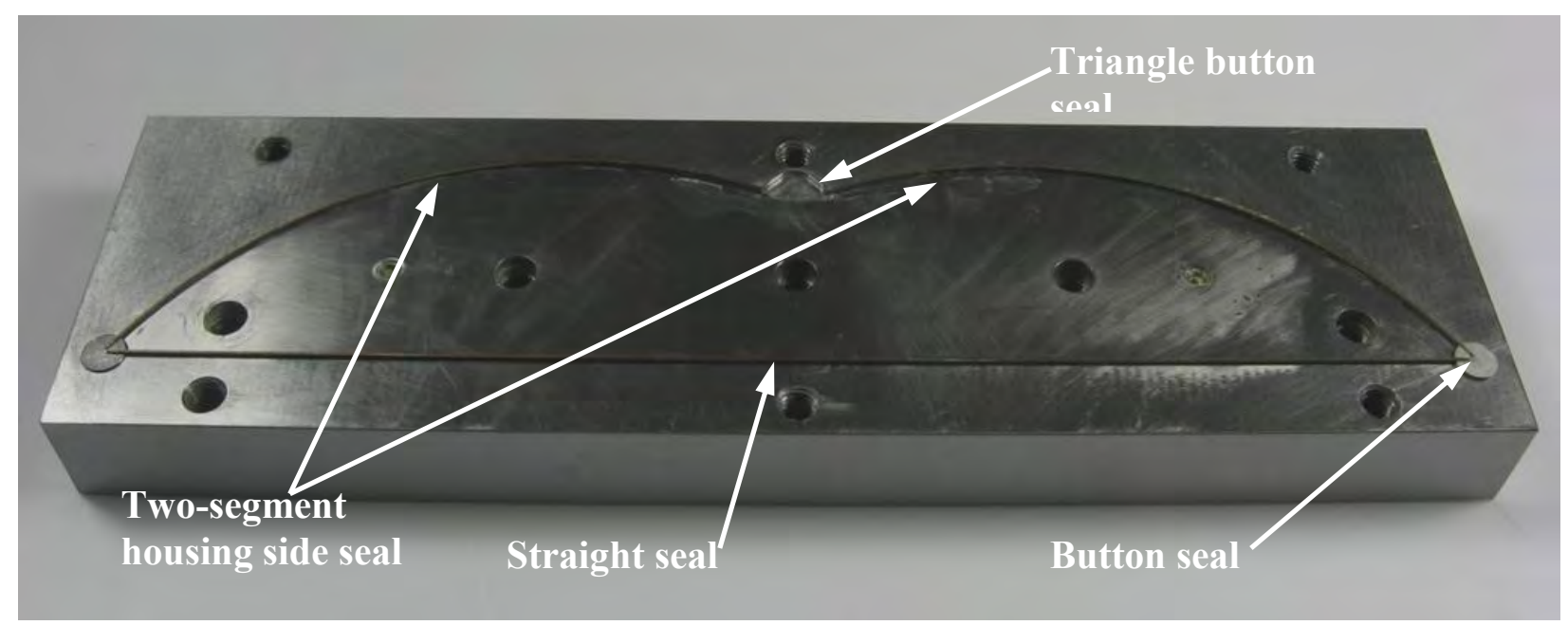

Figure 21. Second alternative design

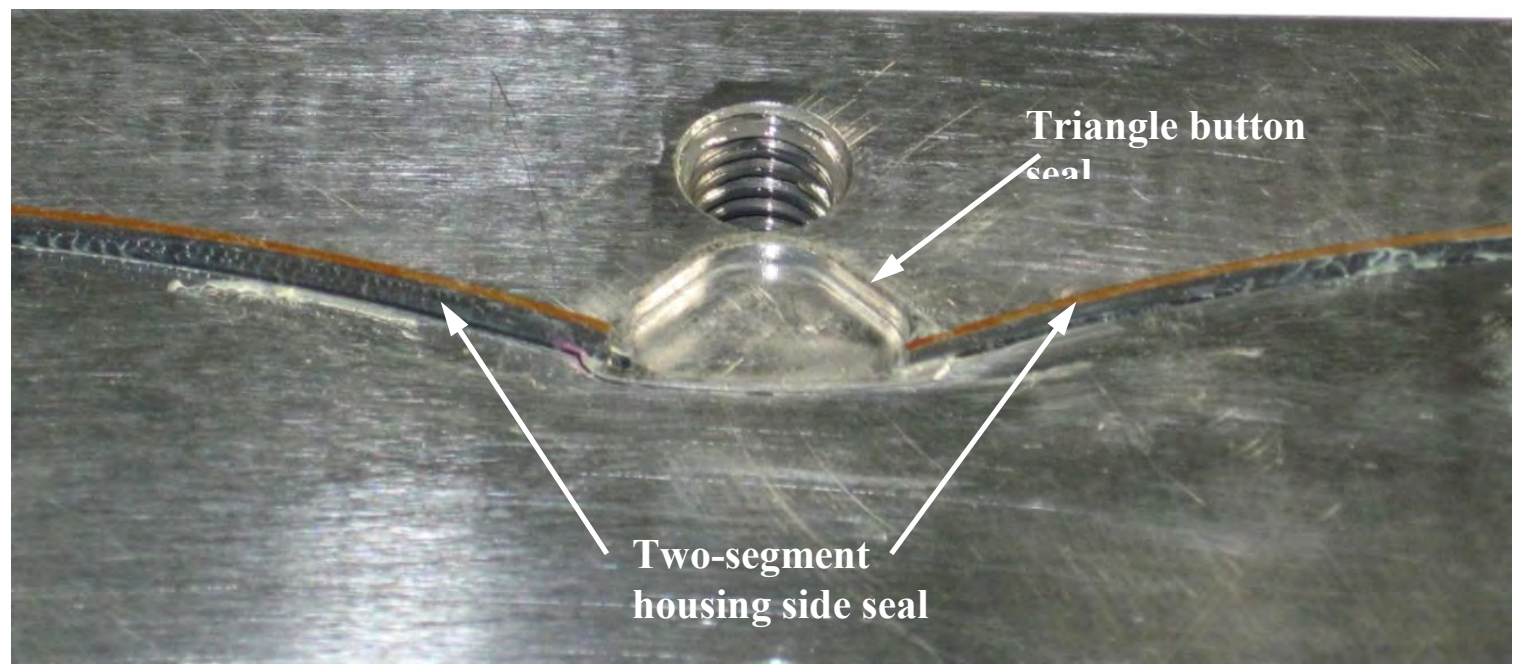

Figure 22. Triangle button seal and two-segment side seals

This design also used two wave springs under each side seal (four under the longer straight seal). A pressure of $250 \mathrm{psig}$ was applied before any leakage was observed. This pressure was obtained, of course, in a static test. The additional hydrodynamic sealing provided by the oil film between the seals and the rotating bearing plates should allow the sealing system to perform as required for combustion testing of the GEN2.5B.

\subsection{GEN2.5A Manufacturing}

Component manufacturing was completed. All of the manufactured components for the GEN2.5A are shown below in Figure 23. 


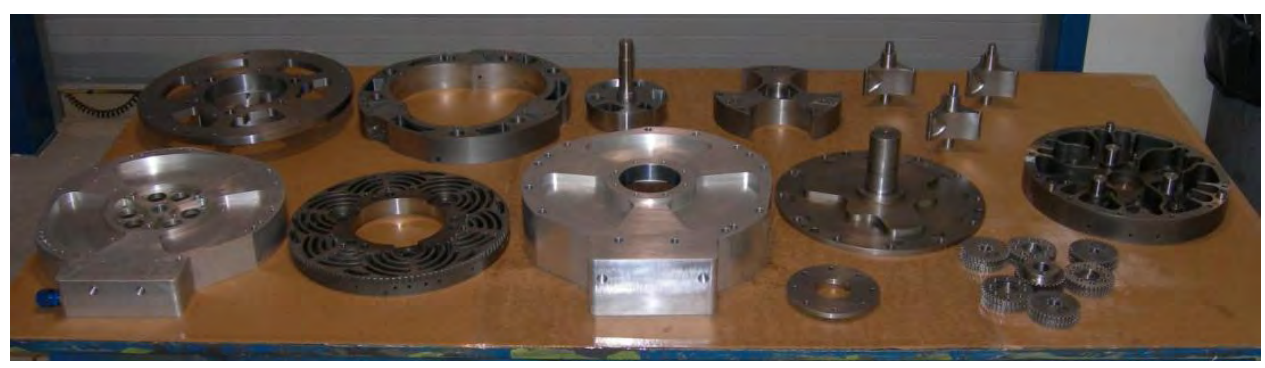

Figure 23. Completed GEN2.5A components

The sequence of assembly for the GEN2.5A is shown in the following figures. The assembly fixture eliminates the need for in-process measurements and fit-up.

The first step in the assembly process is attaching the housing, aspiration plate and rotor shaft to the setup plate as shown in Figure 24. The setup plate contains locating holes for dowel pins that ensure proper orientation of the components.

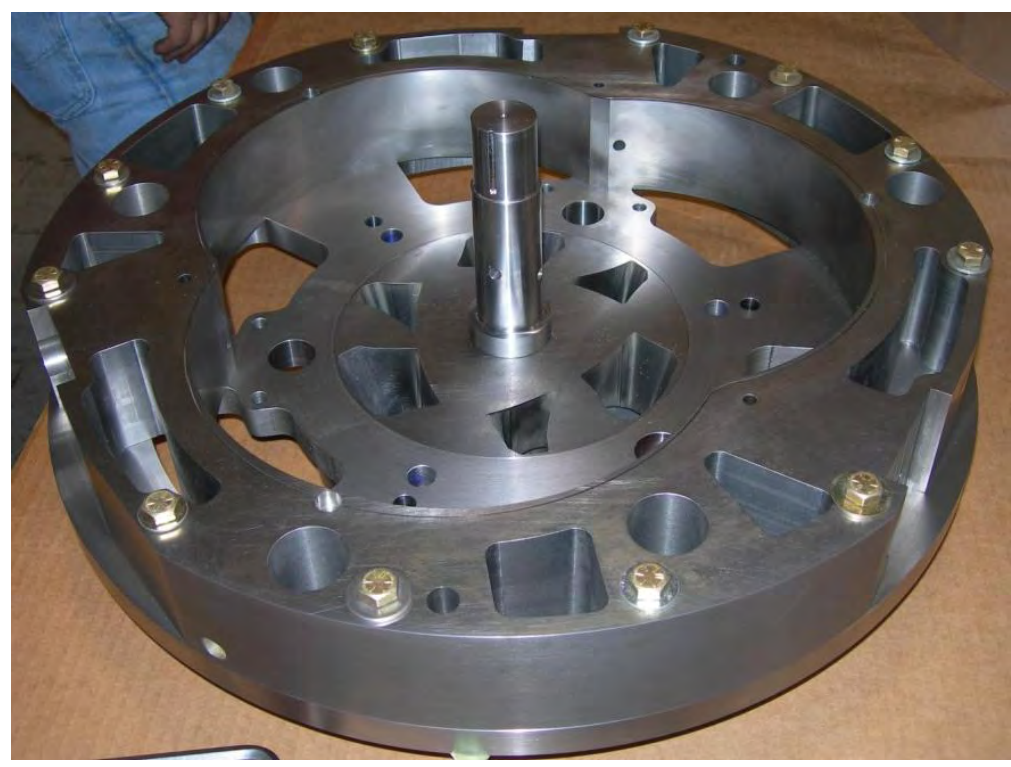

Figure 24. Housing, aspiration plate and rotor shaft installed on assembly fixture

In preparation for installing the rotons, the tip seals and leaf springs are inserted into the rotons as shown in Figure 25. 


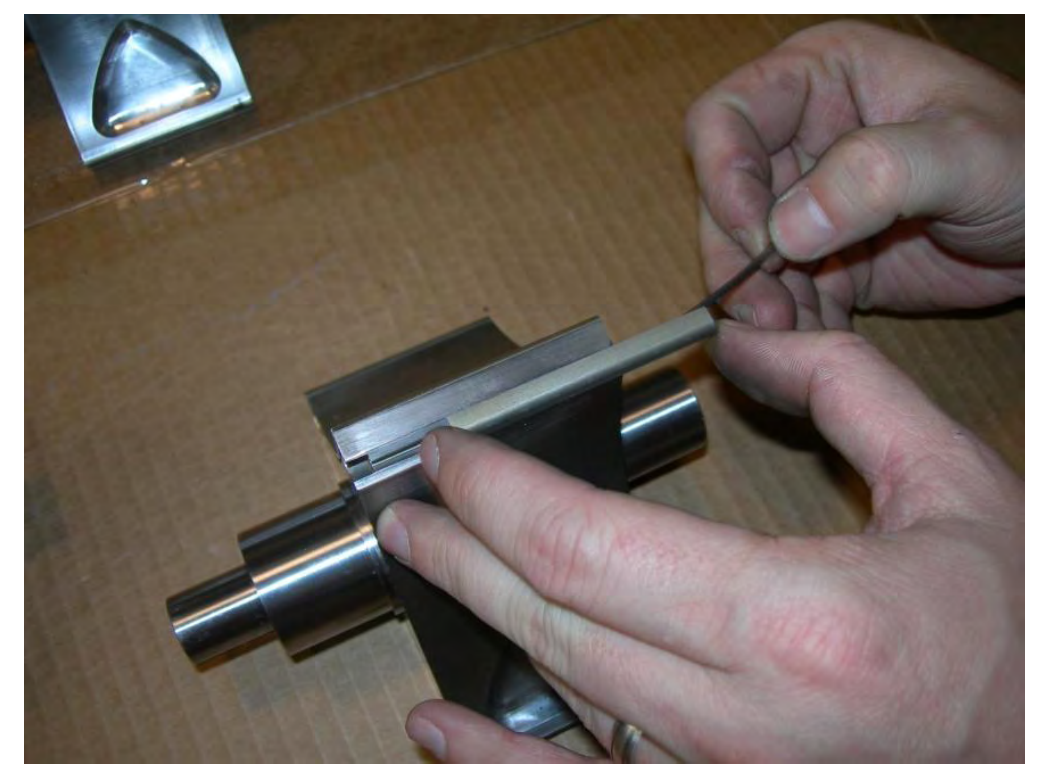

Figure 25. Installation of roton tip seals and springs

The rotons are then installed onto the setup plate and positioned. Figure 26 shows the three rotons in their respective top dead center orientations.

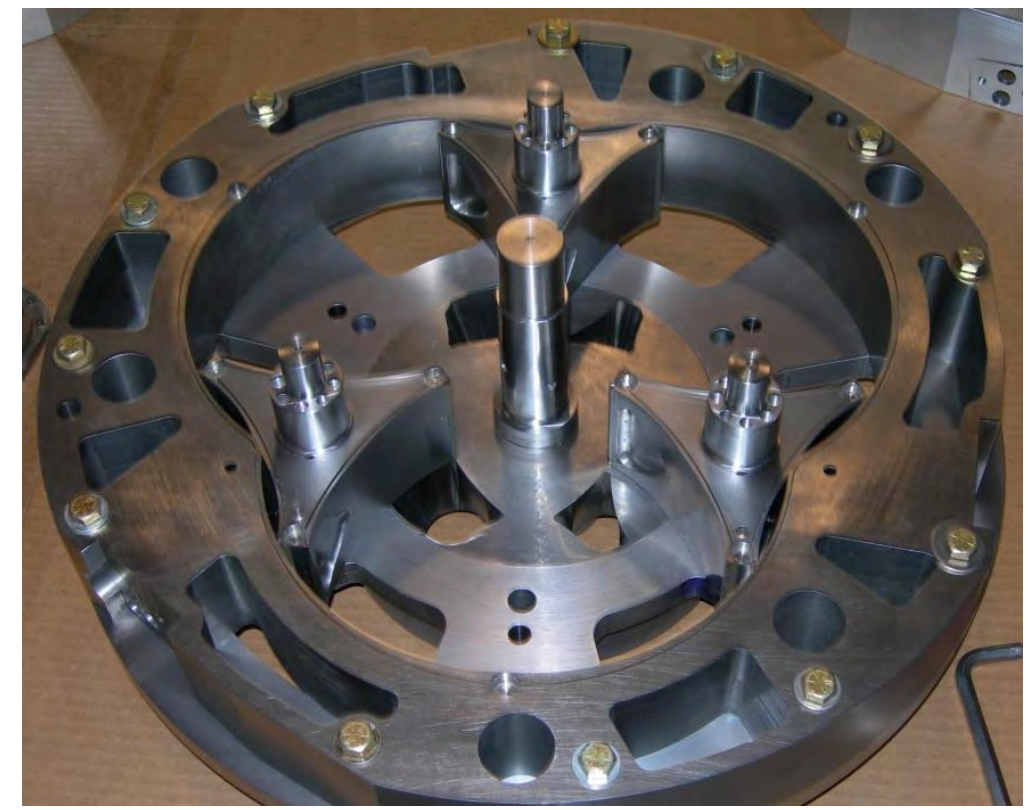

Figure 26. Initial fit check of rotons with housing

The rotor is then installed, as shown in Figure 27. It and the three rotons are secured to the setup plate with bolts installed from the rear. The side seals are installed in the front of the housing and rotons at this point in the process. 


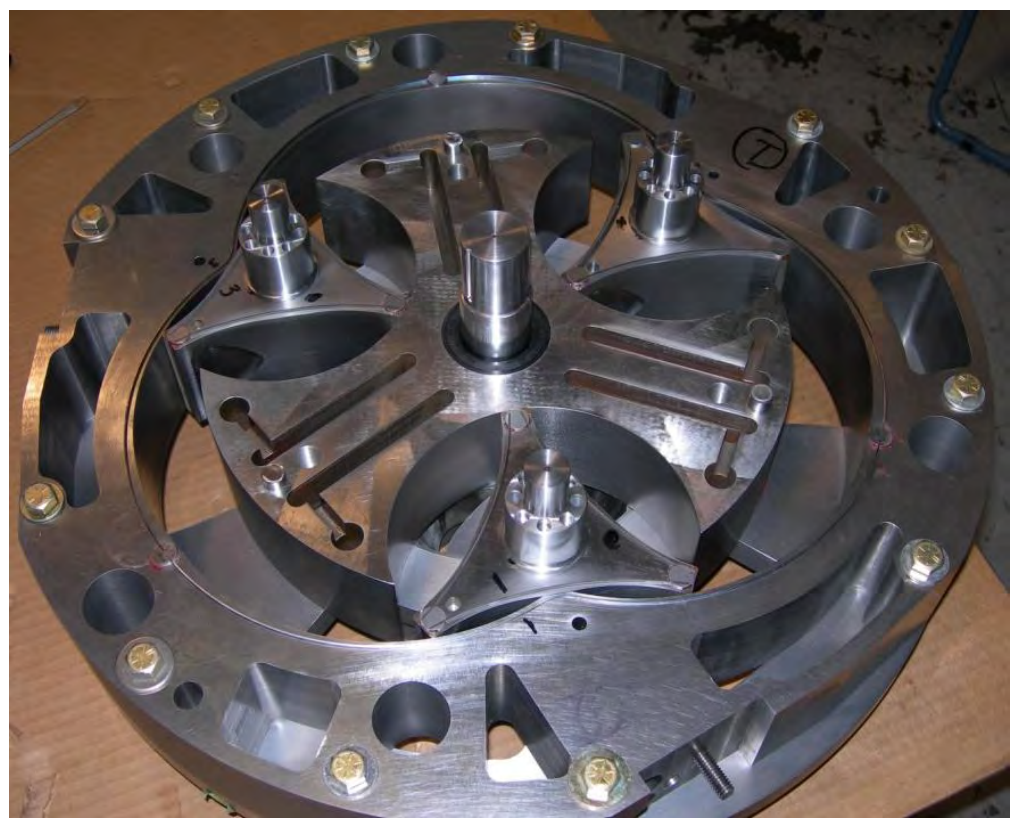

Figure 27. Rotor and rotons installed in assembly fixture

Figure 28 shows the front bearing plate and planetary gears installed. The front bearing plate is bolted to the rotor. The gears are positioned, and bolted to the roton shafts. During the initial assembly, the split gears were preloaded against each other. The assembly was then setup on a jig grinder and the dowel pin holes through the gears were final machined to ensure that the proper gear preload was maintained when the engine was later disassembled and reassembled.

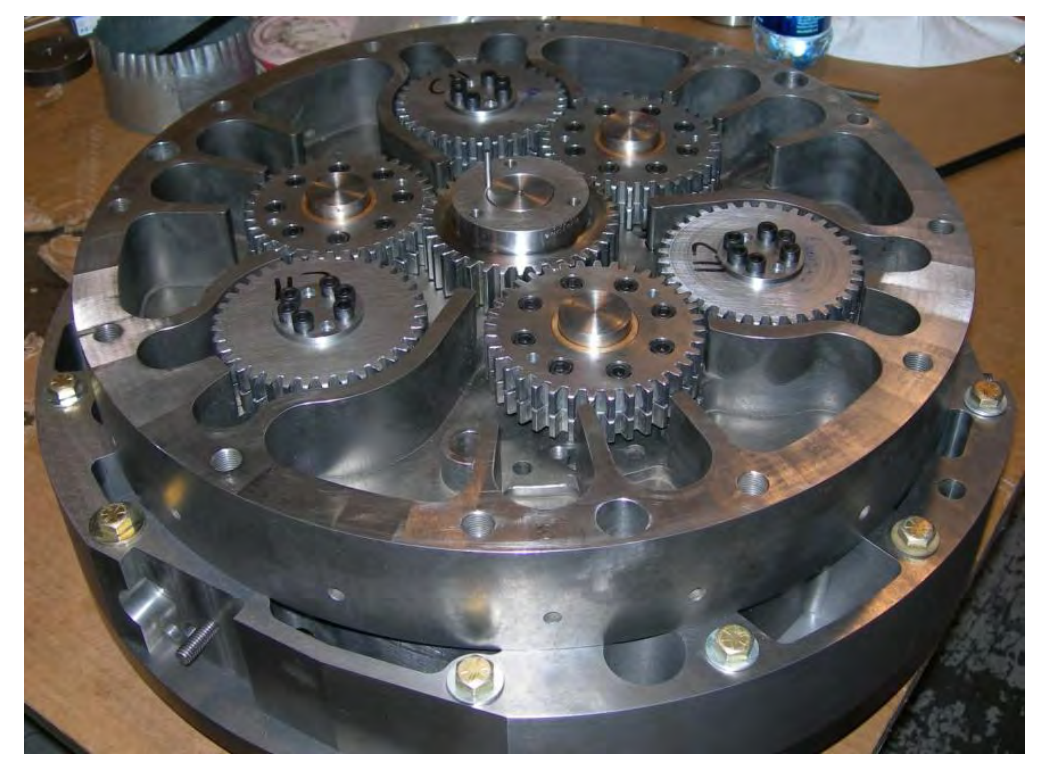

Figure 28. Front bearing plate and planetary gears installed

The drive plate and front cover were then assembled as shown in Figure 29. The front cover is secured to the setup plate for turning the assembly over. 


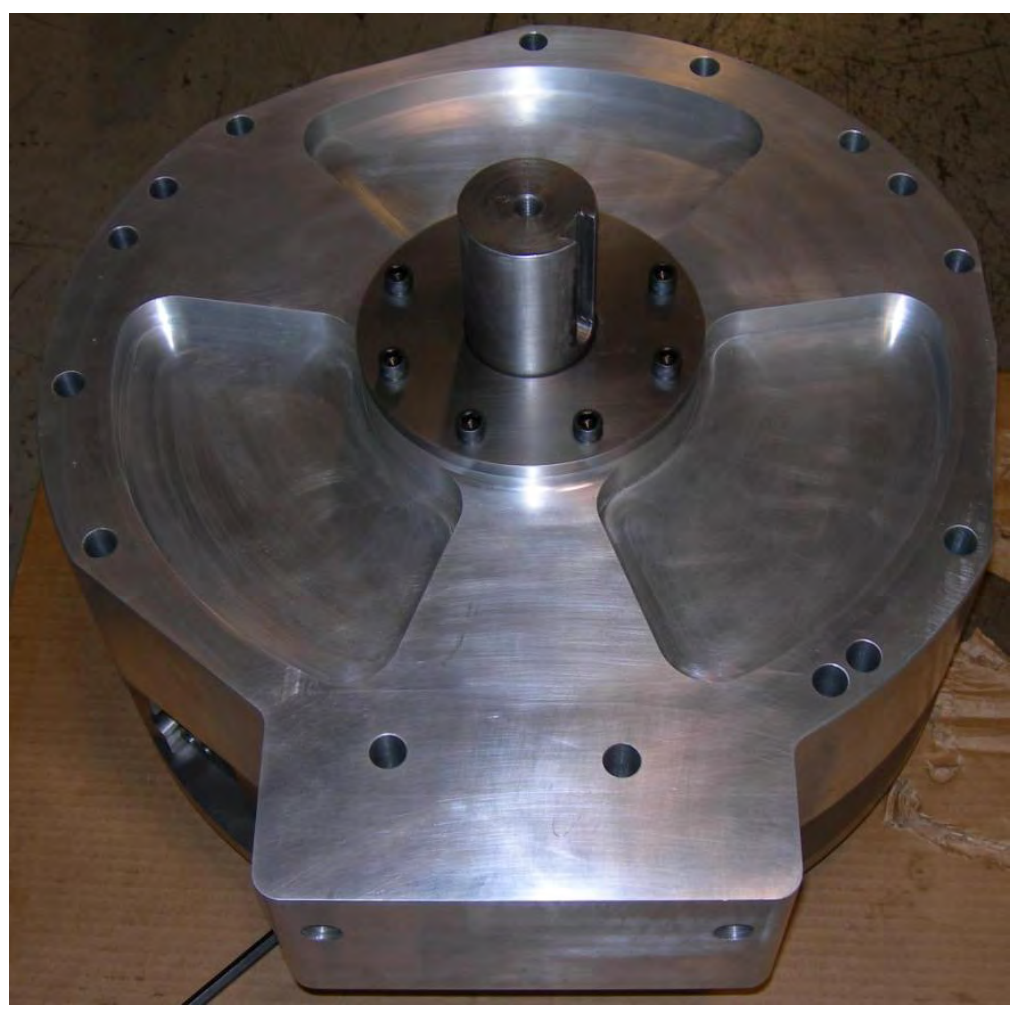

Figure 29. Drive plate and front cover installed

Figure 30 shows the assembly prior to removing the setup plate and continuing the assembly procedure. Figure 31 shows the assembly with the setup plate removed. The engine assembly is now completely constrained in the correct position without the setup plate. 


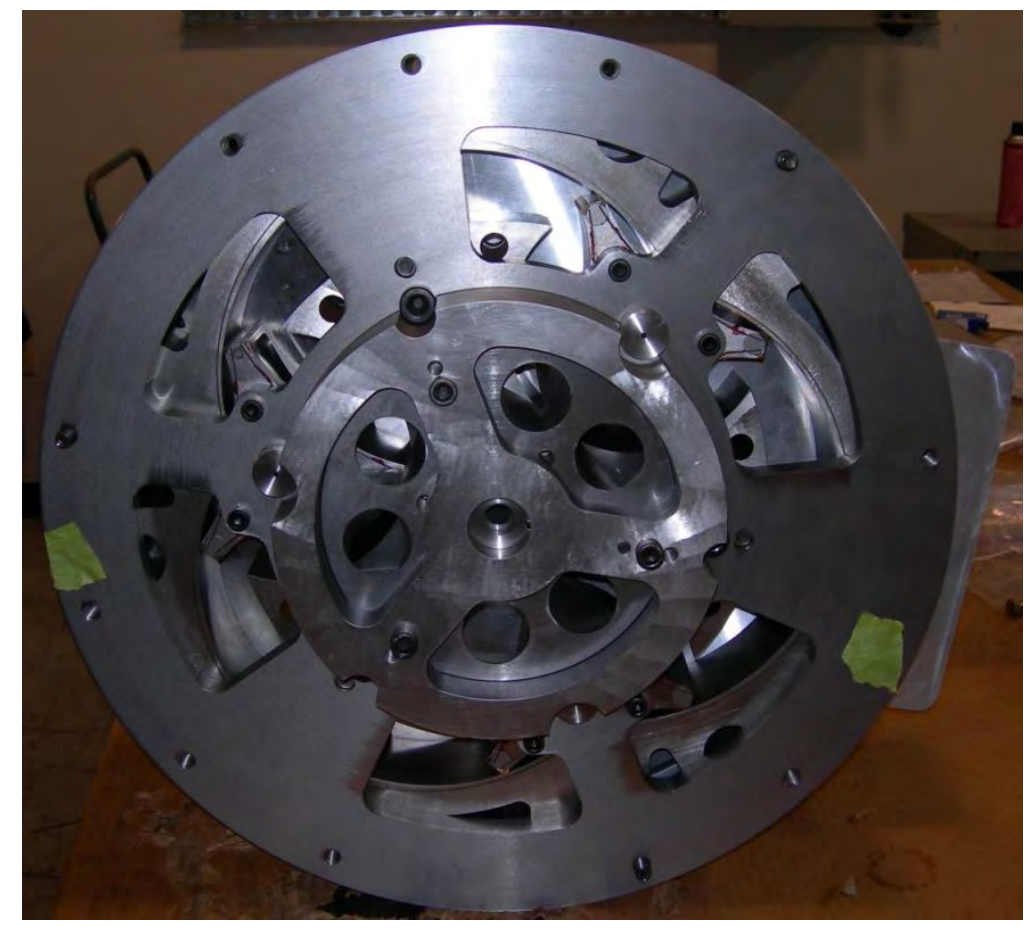

Figure 30. Rear view prior to removal of assembly fixture

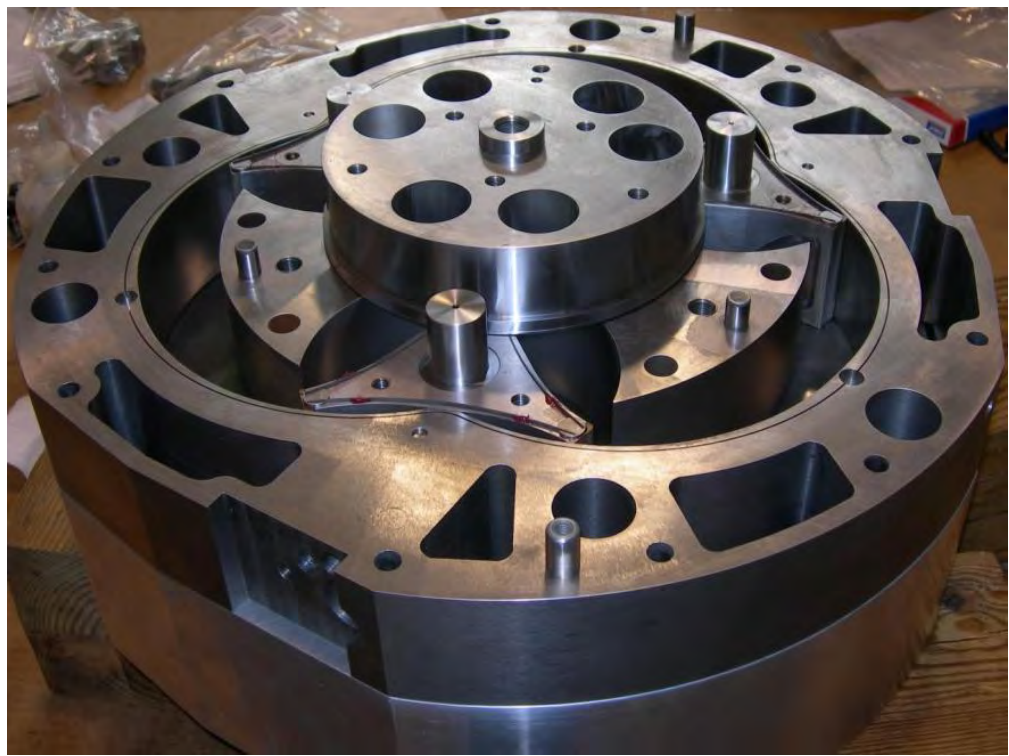

Figure 31. Rear of engine after removal of assembly fixture

After the sides seals are installed in the rear of the housing and rotons, the rear bearing plate is installed as shown in Figure 32. The rear cover is then installed, completing the assembly as shown in Figure 33. 


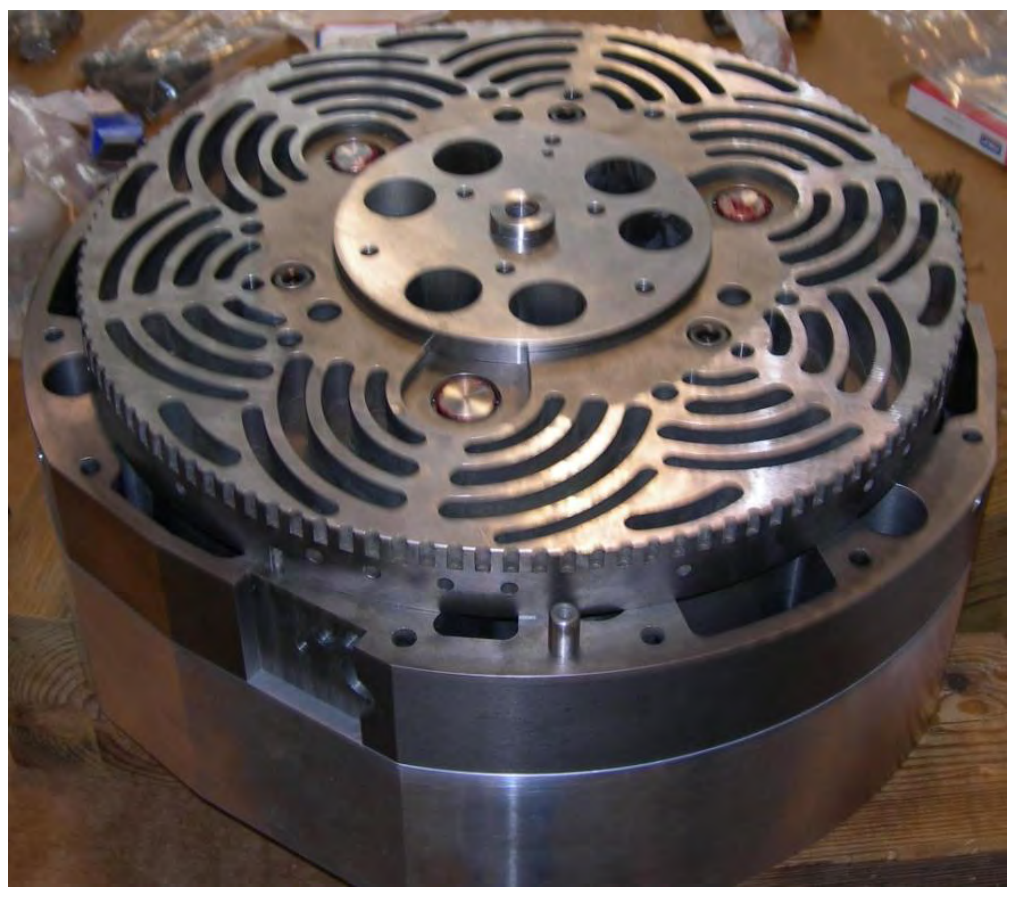

Figure 32. Rear bearing plate installed

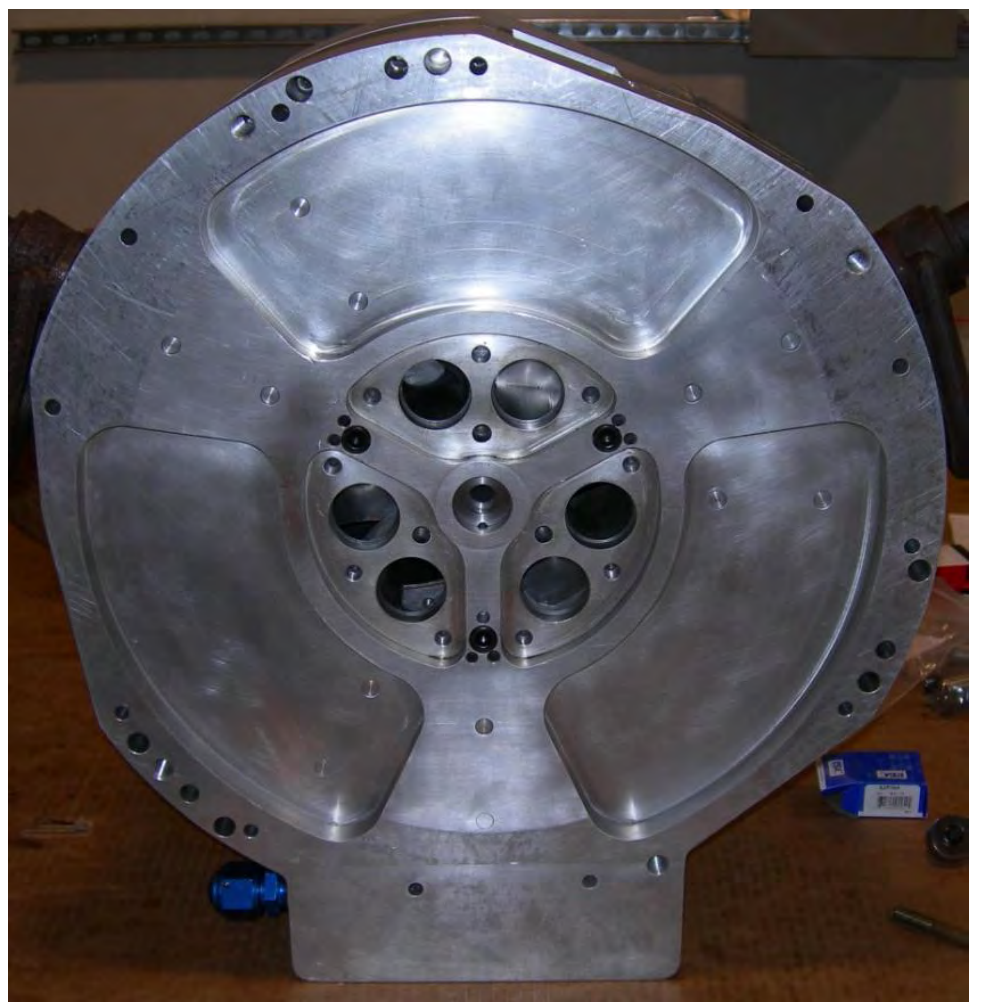

Figure 33. Rear cover installed and assembly complete 


\subsection{GEN2.5A Testing and Evaluation}

The assembled GEN2.5A was installed on the engine dynamometer, as shown in Figure 34 and Figure 35, in the UT Advanced Powertrains, Controls and System Integration laboratory for testing.

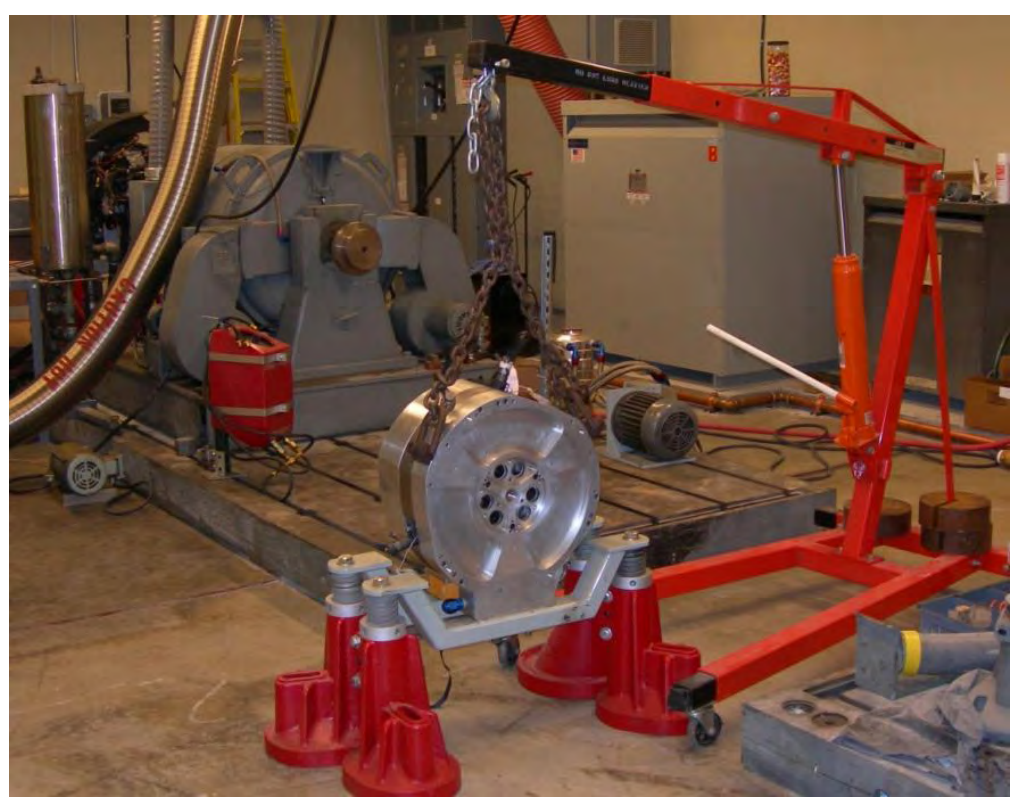

Figure 34. GEN2.5A prepared for dynamometer installation

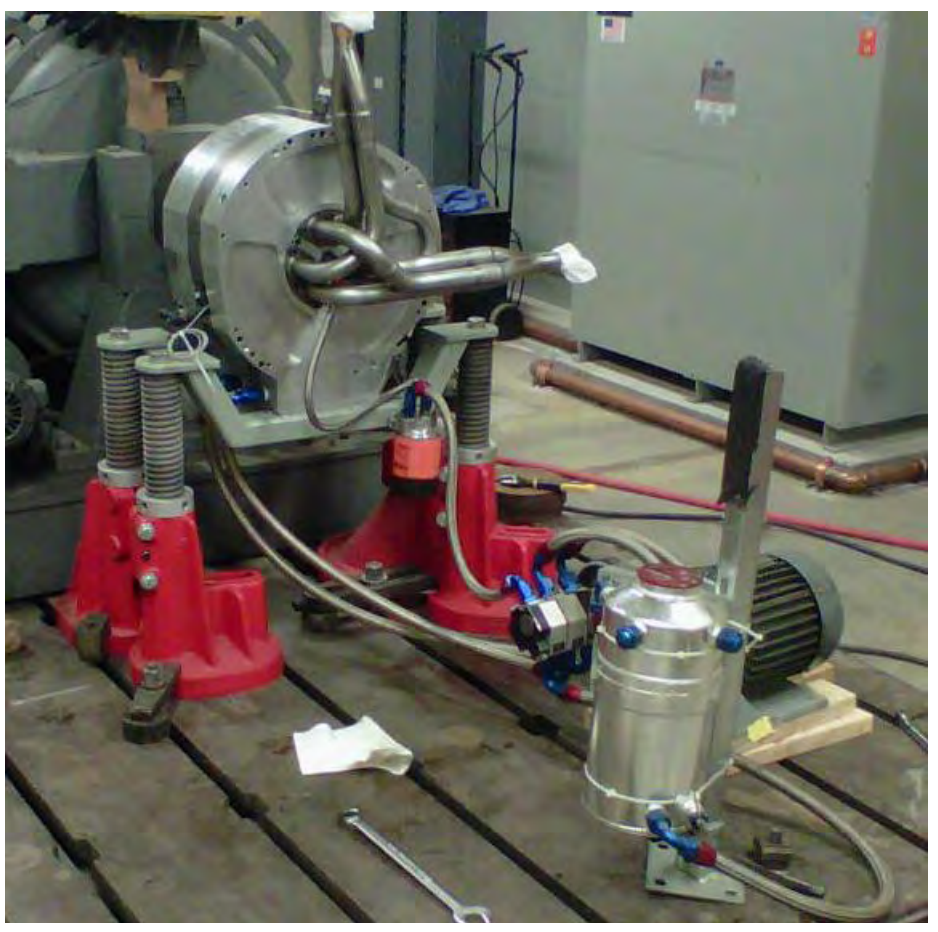

Figure 35. GEN2.5A installed on dynamometer prior to testing 


\section{Compression Testing}

Compression testing was conducted by motoring the GEN2.5A at rotational speeds of 200 and $400 \mathrm{rpm}$. The results were:

- The compression pressures recorded were significantly lower than expectedapproximately 70 psig was achieved during the tests. A typical pressure trace from the compression testing is shown in Figure 37. The pressure trace shows the pressure in the trailing volume. The trailing volume is identified in Figure 36.

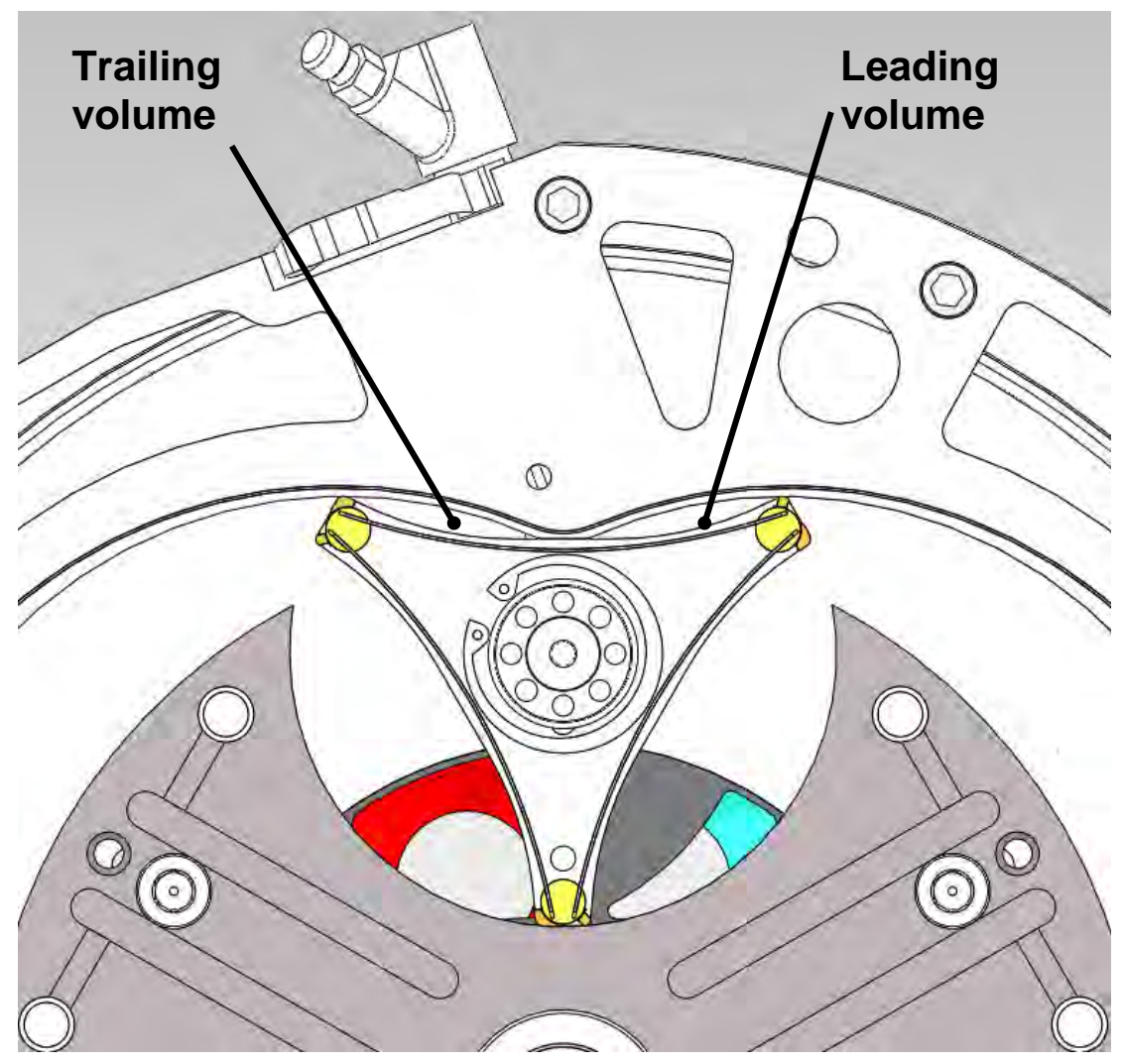

Figure 36. Trailing and leading volumes 


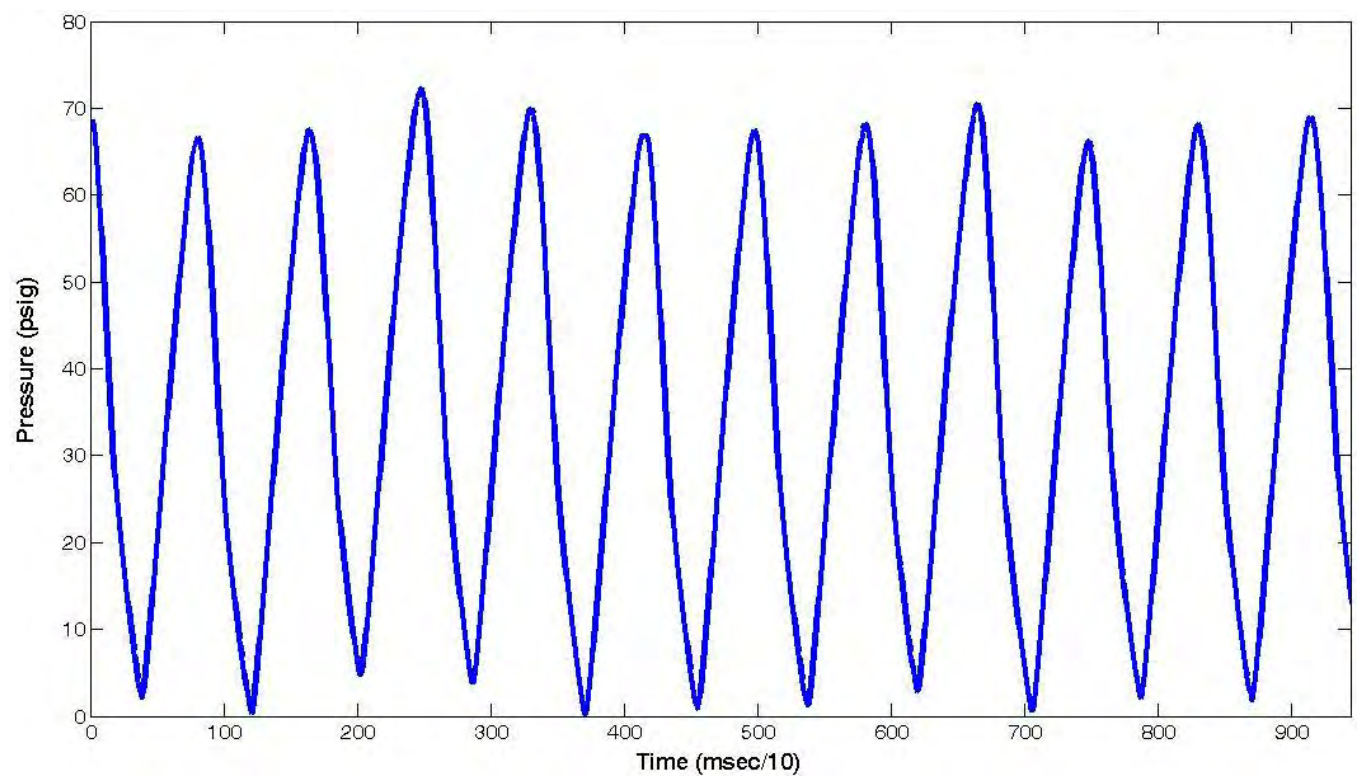

Figure 37. Compression testing results

A pressure build-up inside the engine housing occurred. This caused lubricating oil to be expelled from the engine through a vent in the housing as shown in Figure 38.

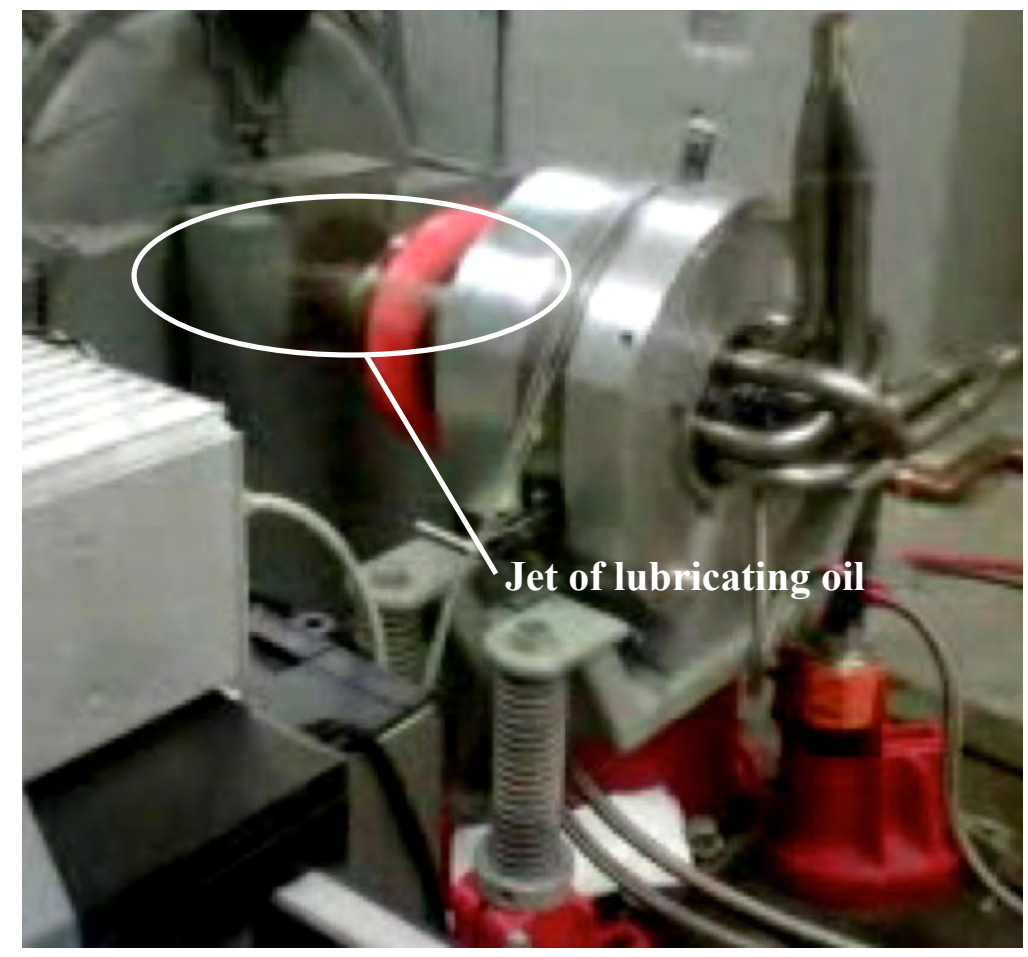

Figure 38. Lubricating oil expelled from engine

- Based on observations, it was determined that pressure was escaping past the housing side seals. Once the engine was disassembled, it was discovered that the middle of each housing side seal was fully compressed as shown in Figure 39. The housing side seal 
springs were not extending the middle portion of the side seal as intended. This portion of the housing side seal is in the area near top-dead-center; therefore, it is exposed to the highest pressure during the cycle.

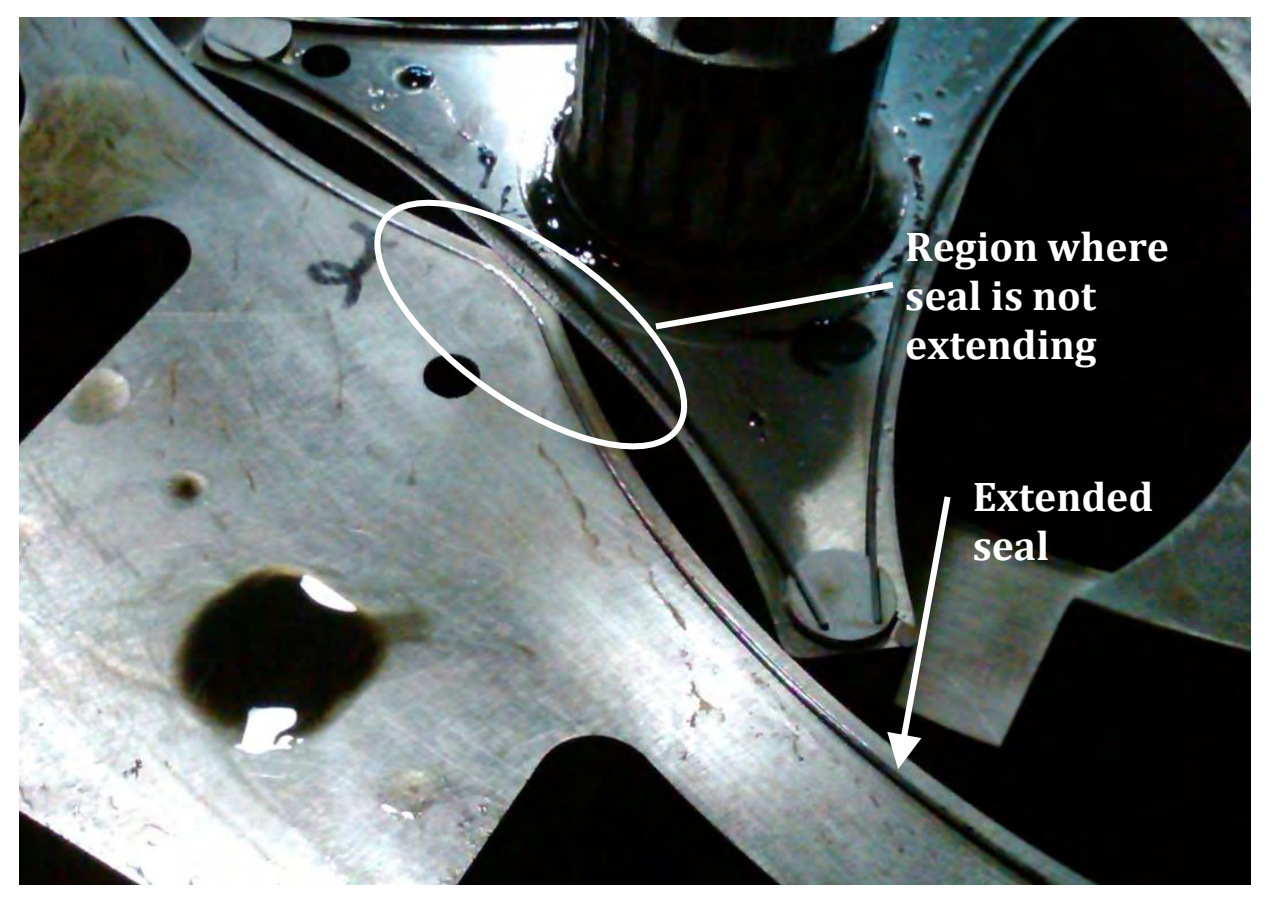

Figure 39. Housing side seals after disassembly

- Based on the volume of air escaping the engine through the vent, the roton seals were assumed to be functioning properly and pumping air (rather than compressing against a sealed working volume). Upon disassembly of the engine, all of the roton tip seals and side seals were moving freely as designed. The roton side seals are shown in Figure 40 at their full extension in their free state. 


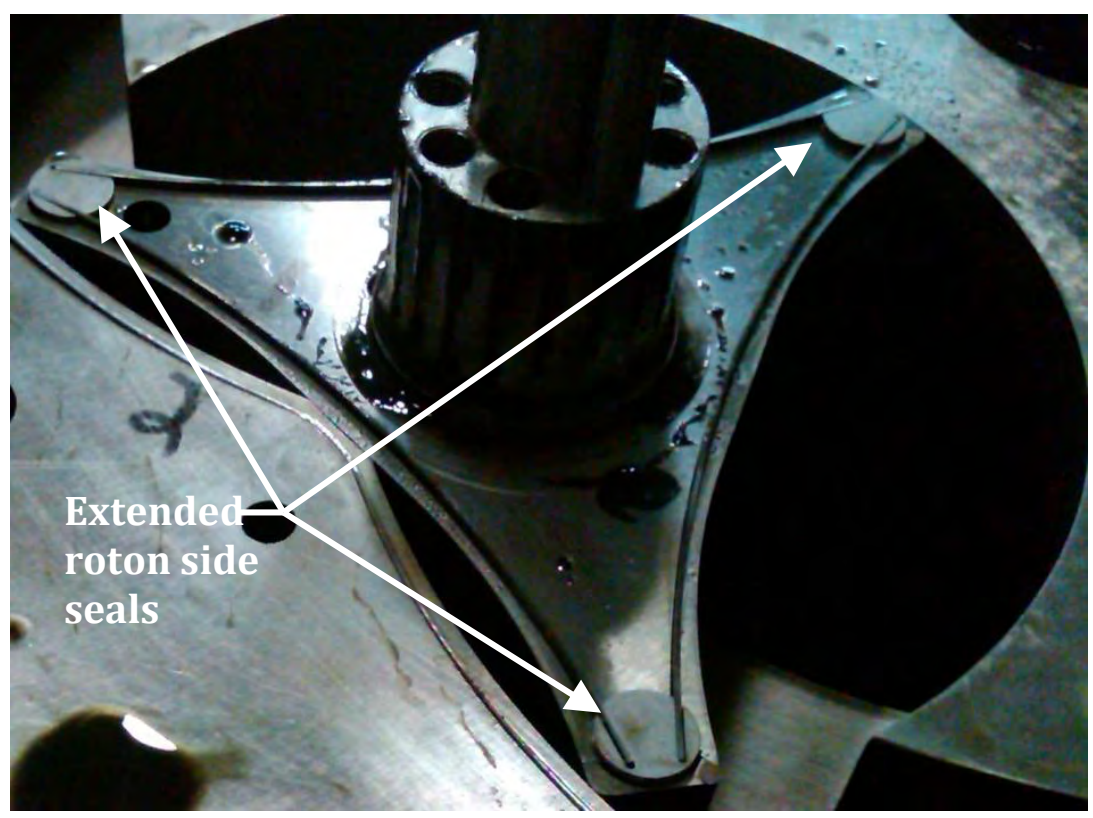

Figure 40. Roton side seals after disassembly

\subsection{GEN2.5A Decision Point}

\subsubsection{Testing}

Motoring at rotational speeds of 200 and $400 \mathrm{rpm}$ at the UTK APCSI Laboratory

\subsubsection{Results}

The following summarizes the results of the GEN2.5A testing and evaluation:

1. The compression pressures recorded were significantly lower than expectedapproximately $75 \mathrm{psi}$ was achieved during the tests.

2. A pressure build-up inside the engine housing occurred. This caused lubricating oil to be expelled from the engine through a vent in the housing.

3. Based on observations, it was determined that pressure was escaping past the housing side seals. Once the engine was disassembled, it was discovered that the middle of each housing side seal was fully compressed as shown below. The housing side seal springs are not extending the middle portion of the side seal as intended. This portion of the housing side seal is in the area near top-dead-center; therefore, it is exposed to the highest pressure during the cycle.

4. Based on the volume of air escaping the engine through the vent, the roton seals were assumed to be functioning properly and pumping air (rather than compressing against a sealed working volume). Upon disassembly of the engine, all of the roton tip seals and side seals were moving freely as designed. The roton side seals are shown in Figure 40 at their full extension in the free state. 


\subsubsection{Conclusion}

PST determined that the side seal between the housing and bearing plates did not function as anticipated, which was confirmed when the GEN2.5A was disassembled. The side seals, at top dead center, were stuck in the grooves that contain them allowing for pressure to leak over them and into the housing. However, based on the high pressure that would be necessary to expel the lubricating oil as witnessed during the tests, the roton tip and side seals seem to be functioning as anticipated.

Based on the results of the compression testing PST has determined that optimization of the current tip seal system is the best approach to GEN2.5B design. The housing side seal issues described above will also be addressed in the GEN2.5B. 
This page intentionally left blank. 


\section{Chapter 3 - Completion and Testing of GEN2.5B}

\subsection{GEN2.5B Design}

\subsubsection{Initial Housing Side Seal System Modification}

This seal system design developed in the housing side seal test fixture was incorporated into the GEN2.5B, and the housing drawings were revised to include the pockets for the triangle button seals. Drawings were also issued for the new side seals and the triangle button seal; details are shown in Figure 41, Figure 42 and Figure 43.

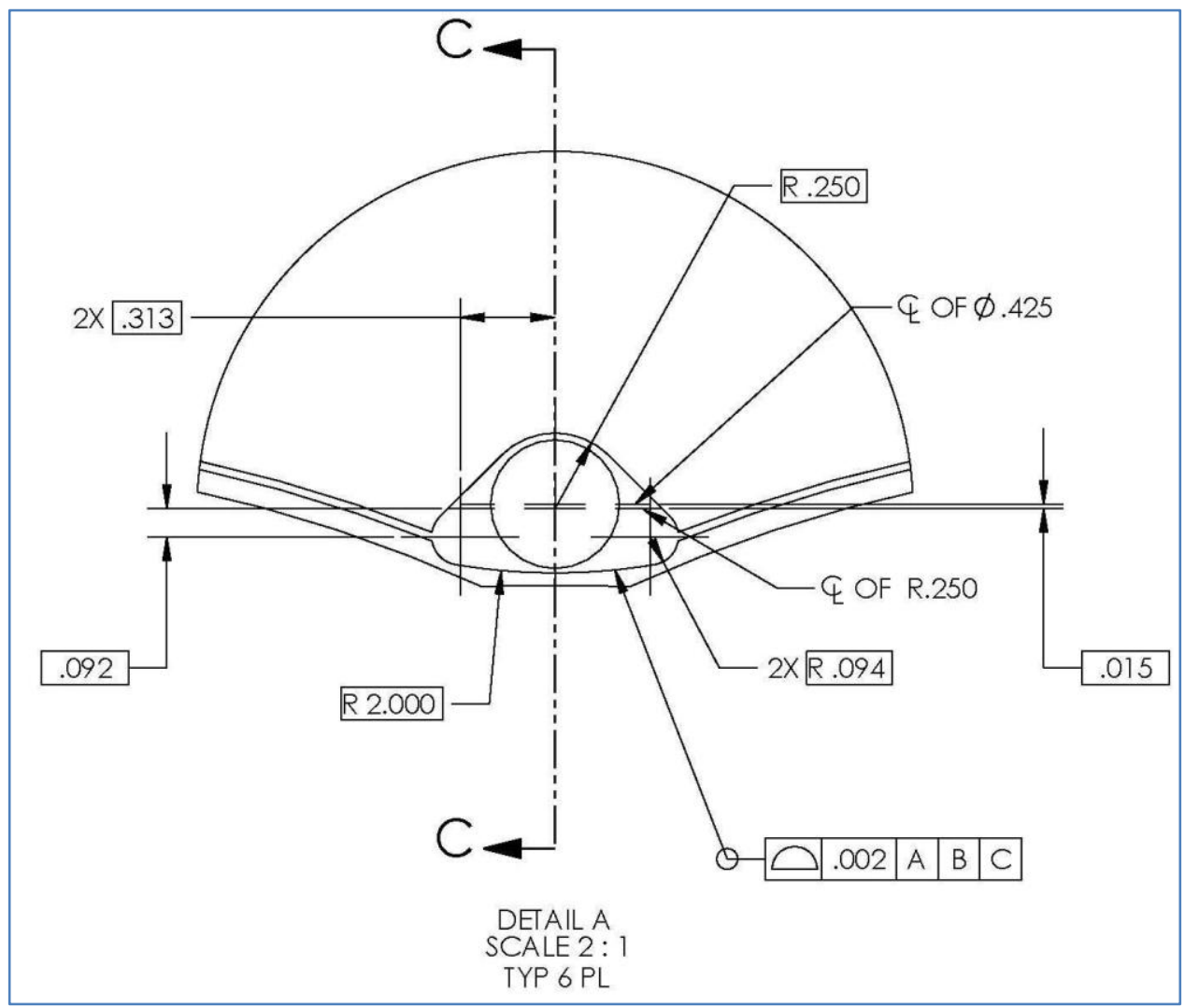

Figure 41. Housing modification detail 


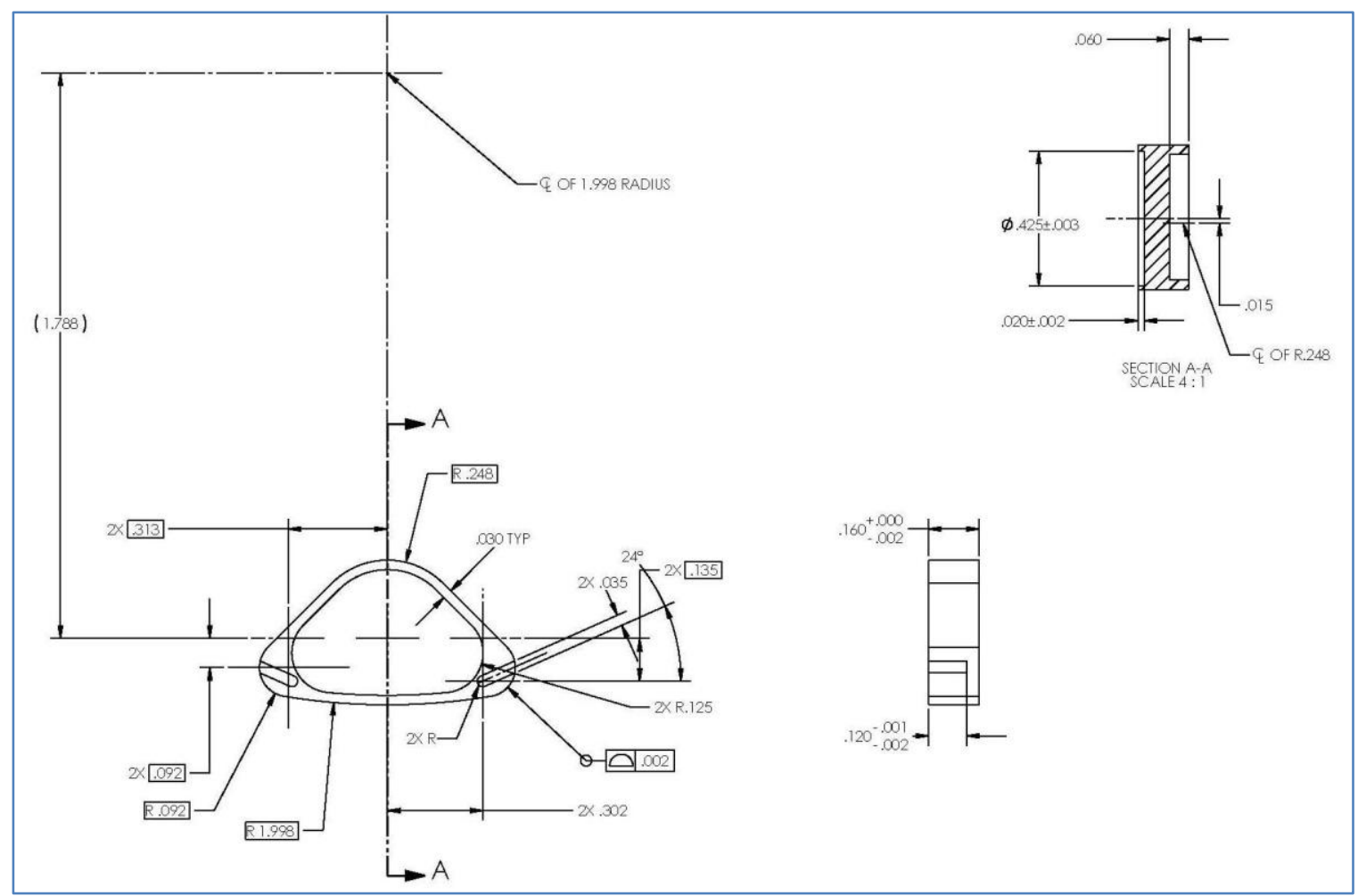

Figure 42. Triangle button seal detail

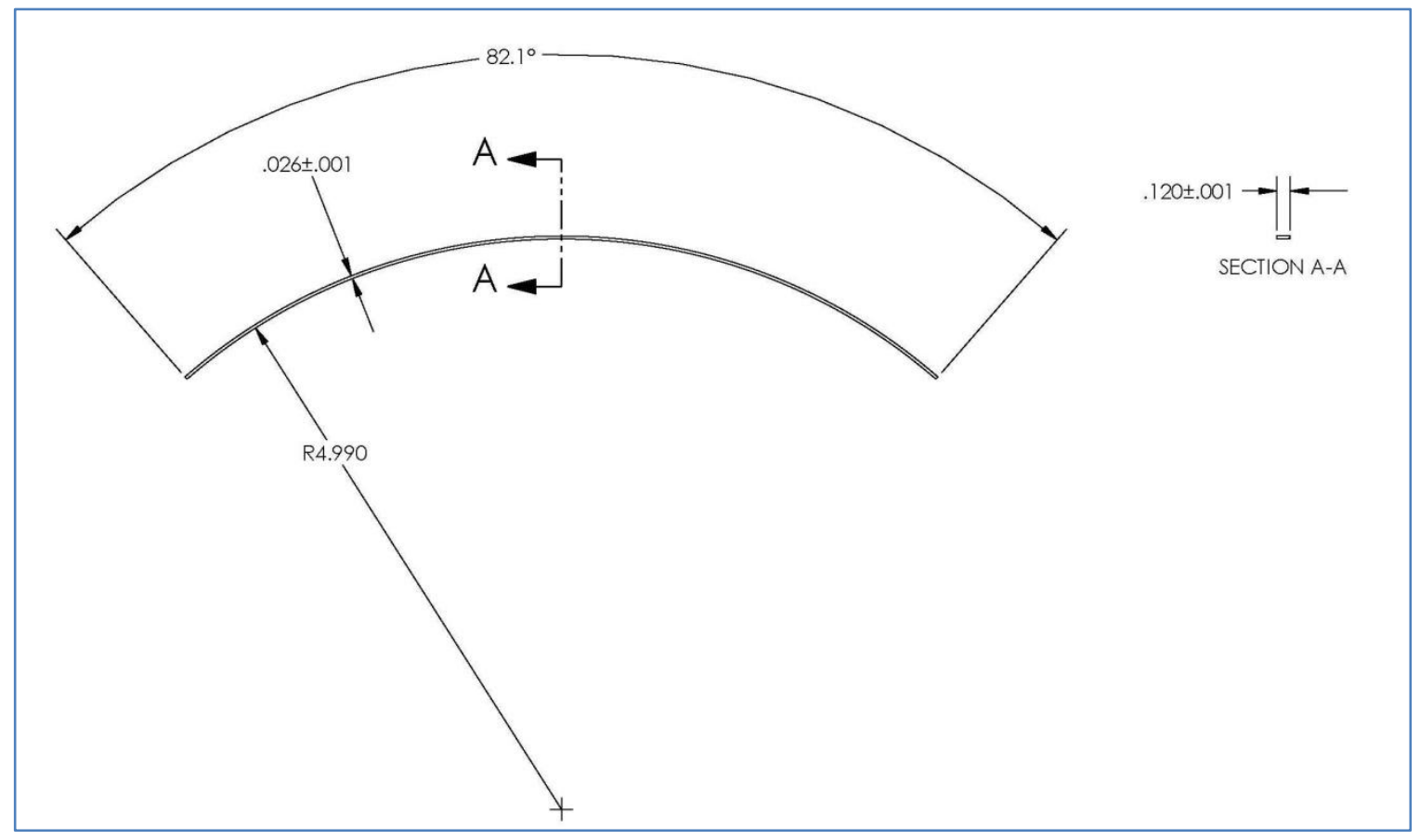

Figure 43. New side seal detail 


\subsubsection{Roton Modifications}

The evaluation of the results obtained in the first round of testing led to design modifications as described in section 3.4.1 below. The combustion pocket was extended to provide more flow area between the trailing and leading volumes. The ports under the tip seals were enlarged to provide more sealing force on the tip seals.

Each roton face can be tracked during the compression testing; therefore, the effect of each modification to the rotons can be individually evaluated. To maximize the information obtained from the listed modifications, each of the three rotons were modified independently. Roton 1 received larger combustion pressure ports on two of the three faces. It will also receive pockets to accept extra tip seal springs, but will not use the extra tip seal springs. Roton 2 received the same modifications as the first roton, but it will use the additional tip seal spring. The modifications to rotons 1 and 2 are shown in Figure 44 and Figure 45.

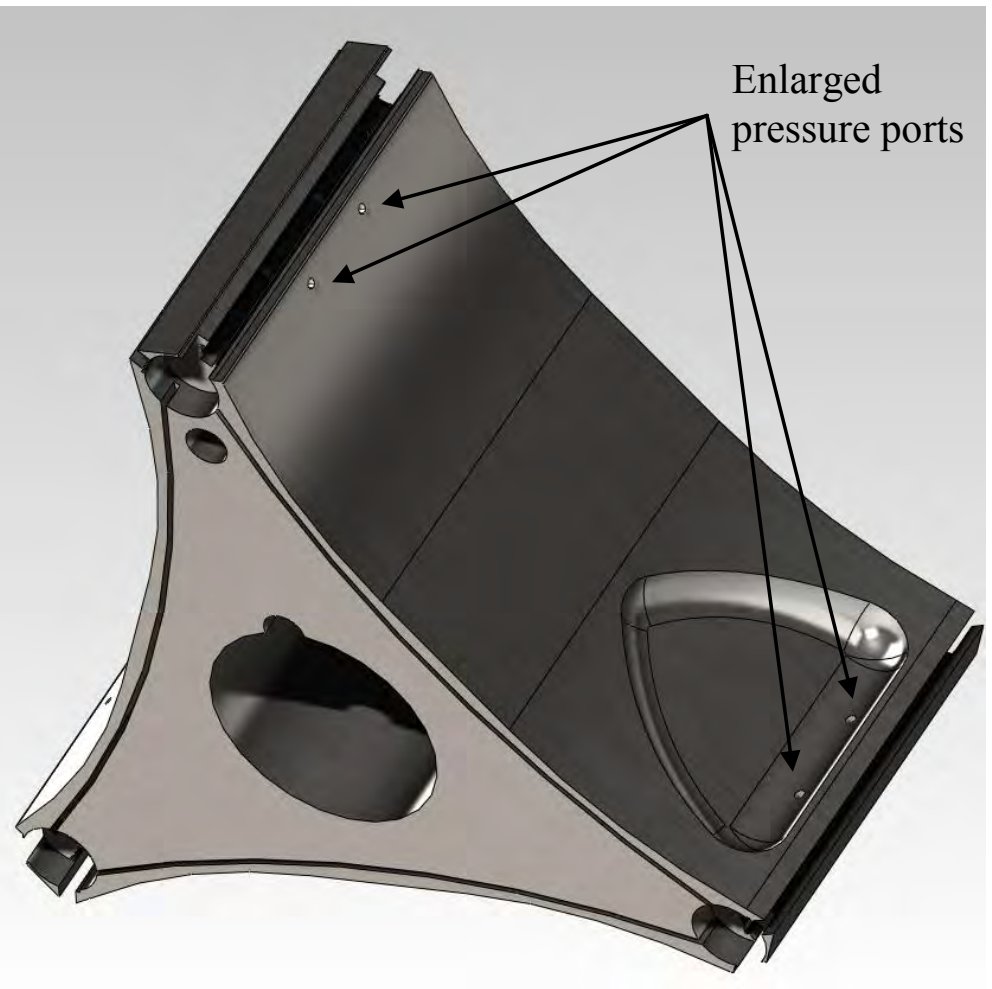

Figure 44. Rotons 1 and 2 pressure port modifications 


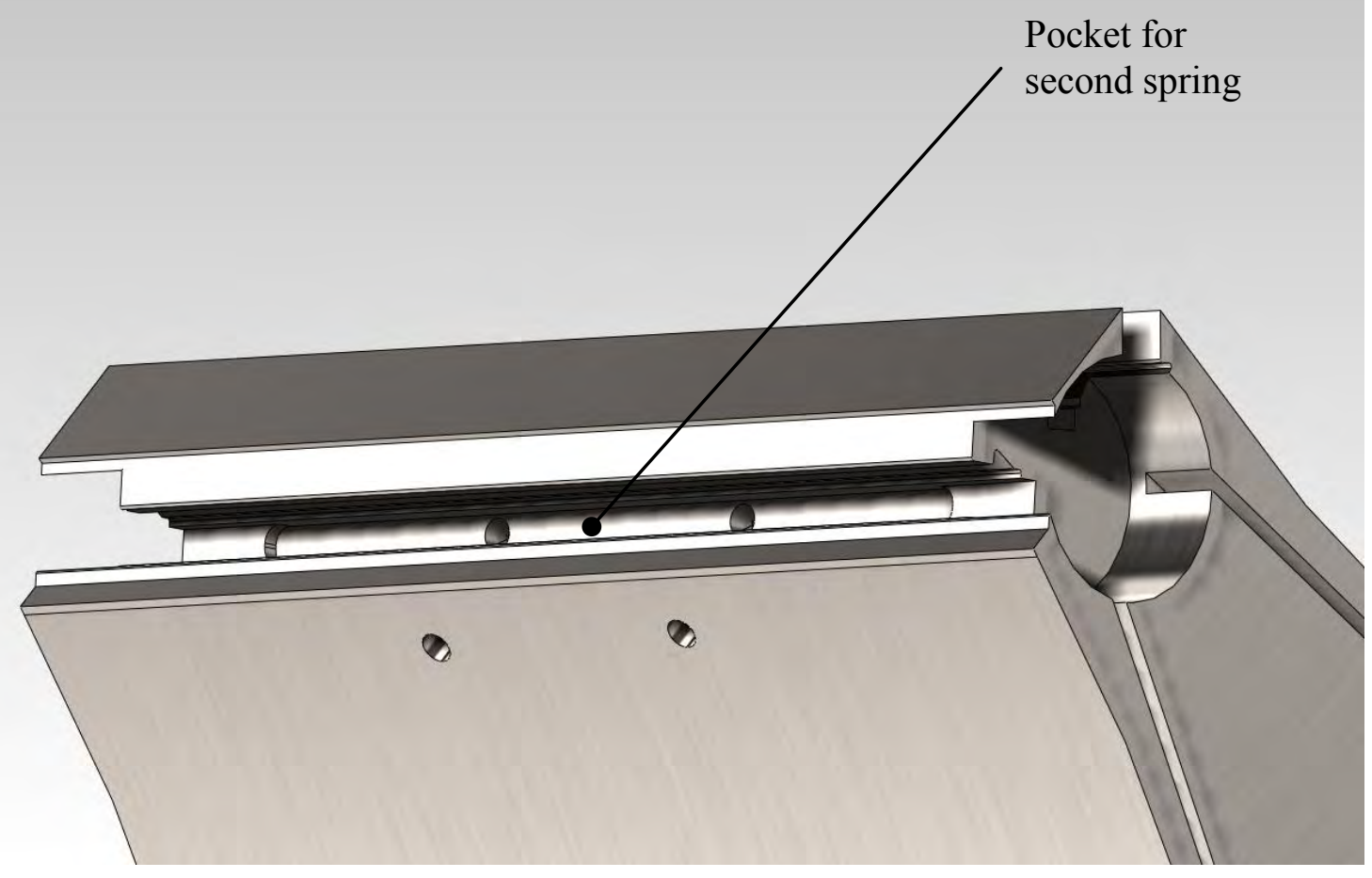

Figure 45. Rotons 1 and 2 spring pocket modifications

Roton 3 had the combustion pocket extended on all three faces. No other modifications will be incorporated in roton 3. These modifications are shown in Figure 46, Figure 47 and Figure 48. 


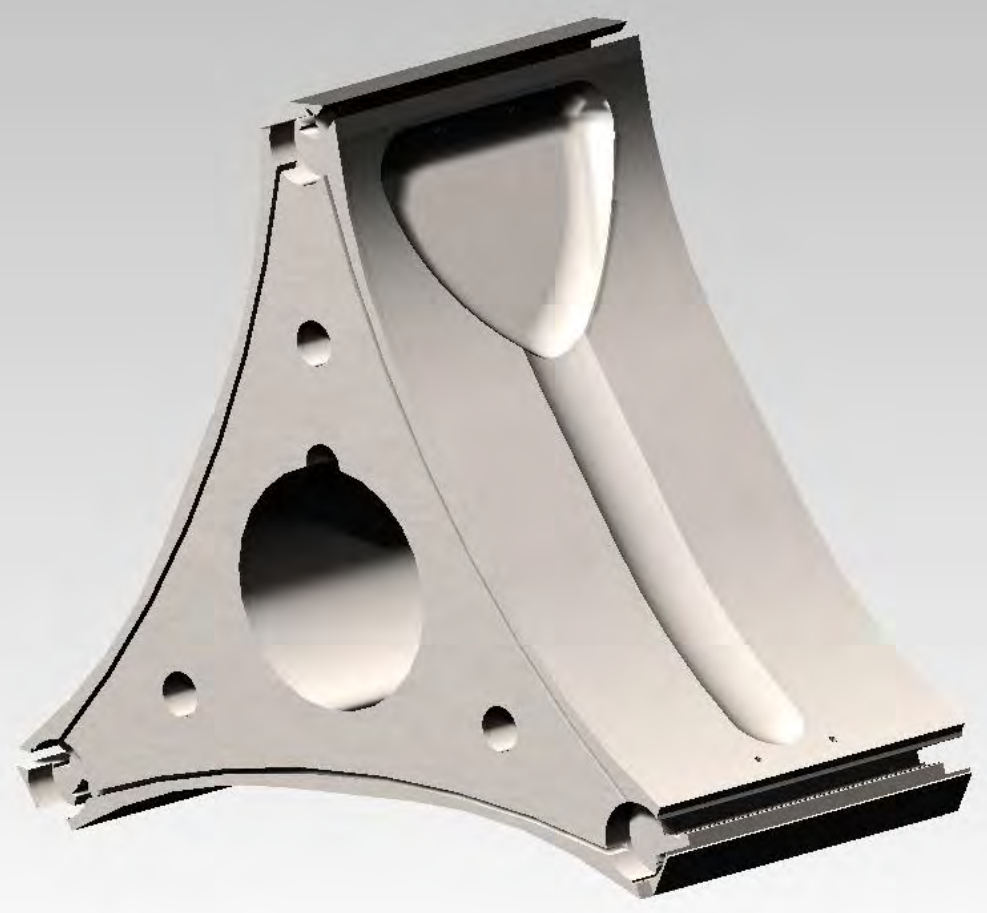

Figure 46. Roton 3 with 1/2" wide combustion pocket extension

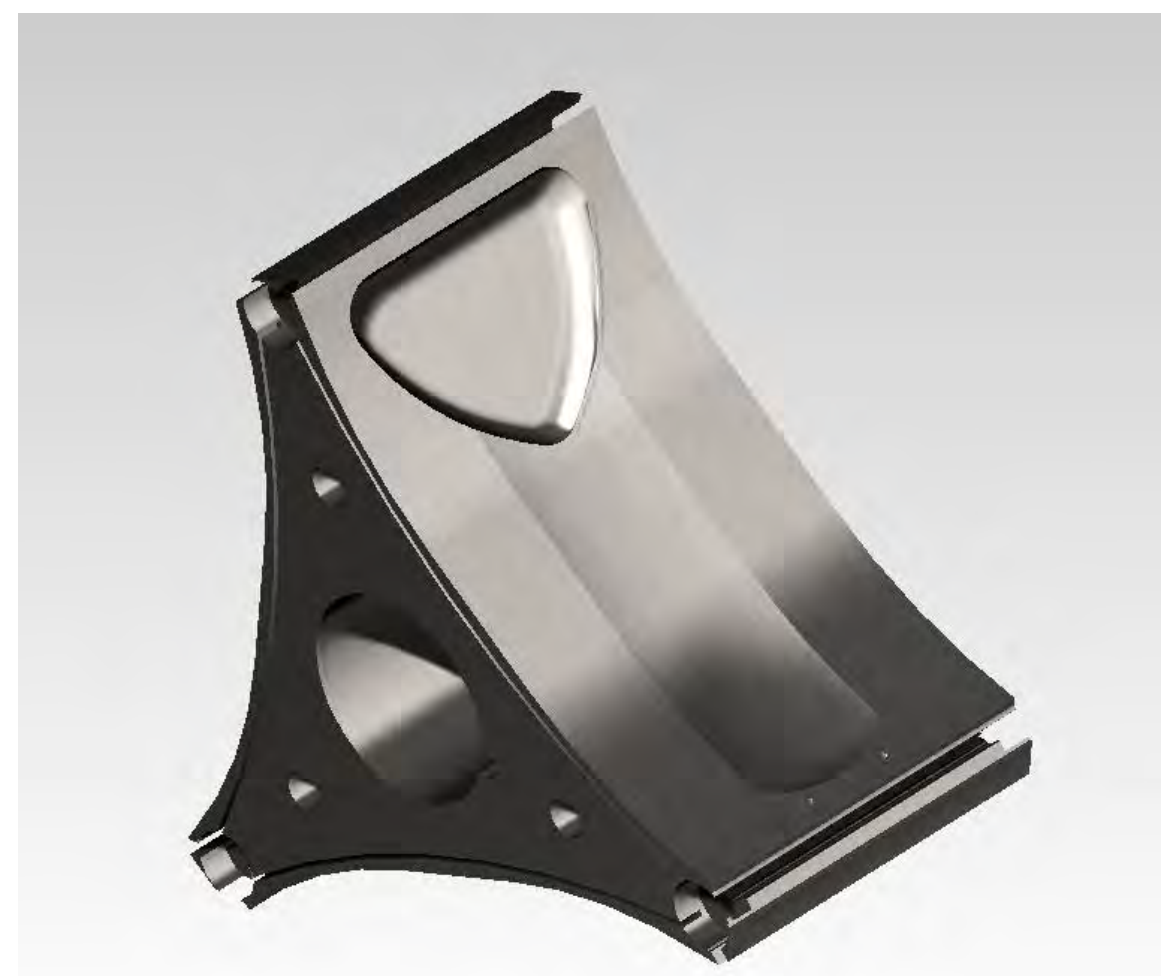

Figure 47. Roton 3 with 1" wide combustion pocket extension 


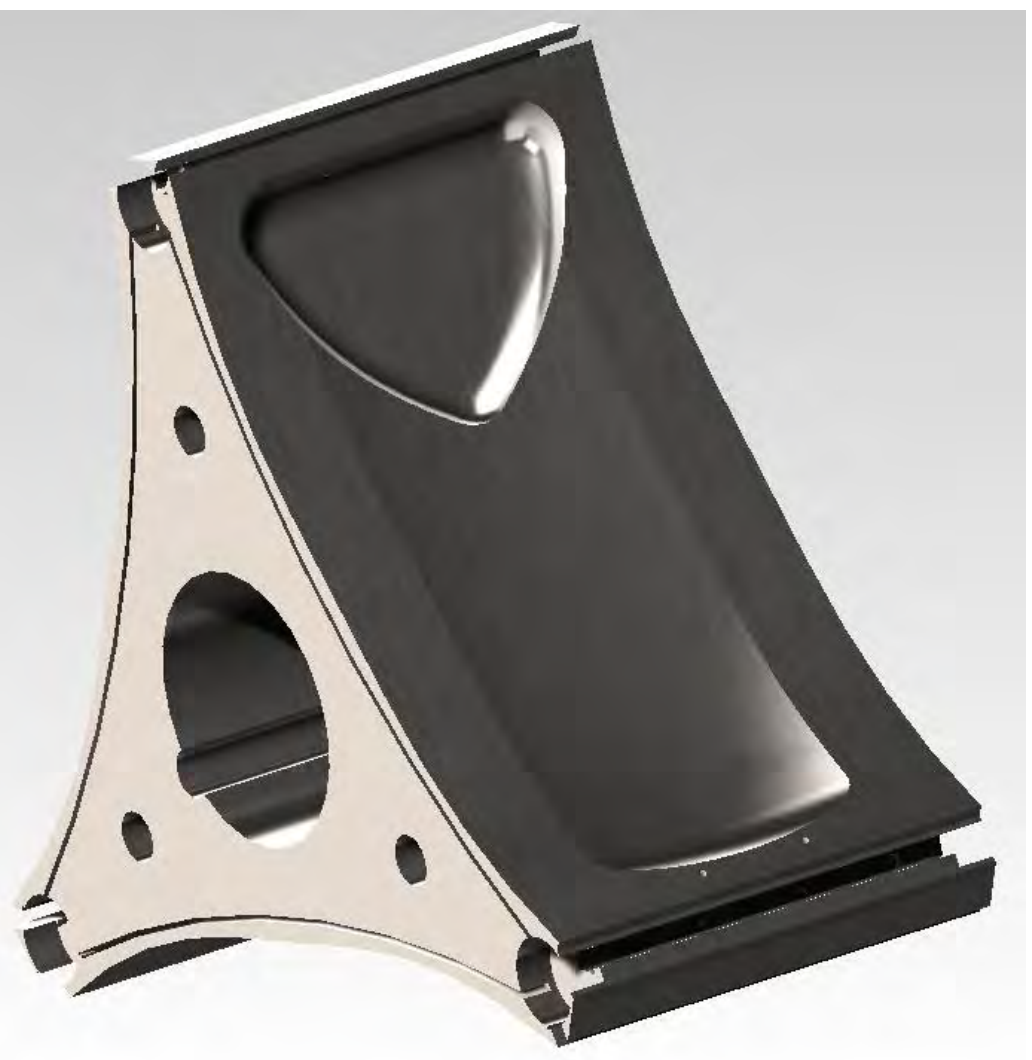

Figure 48. Roton 3 with 1-1/2" wide combustion pocket extension

\subsubsection{Further Housing Side Seal System Modification}

These testing and evaluation results for this design modification, described below in the GEN2.5B Testing and Evaluation section, led to the decision to further modify the housing side seal system to include a second pressure boundary. Figure 49 shows the additional side seal which provides the second pressure boundary in the housing. 


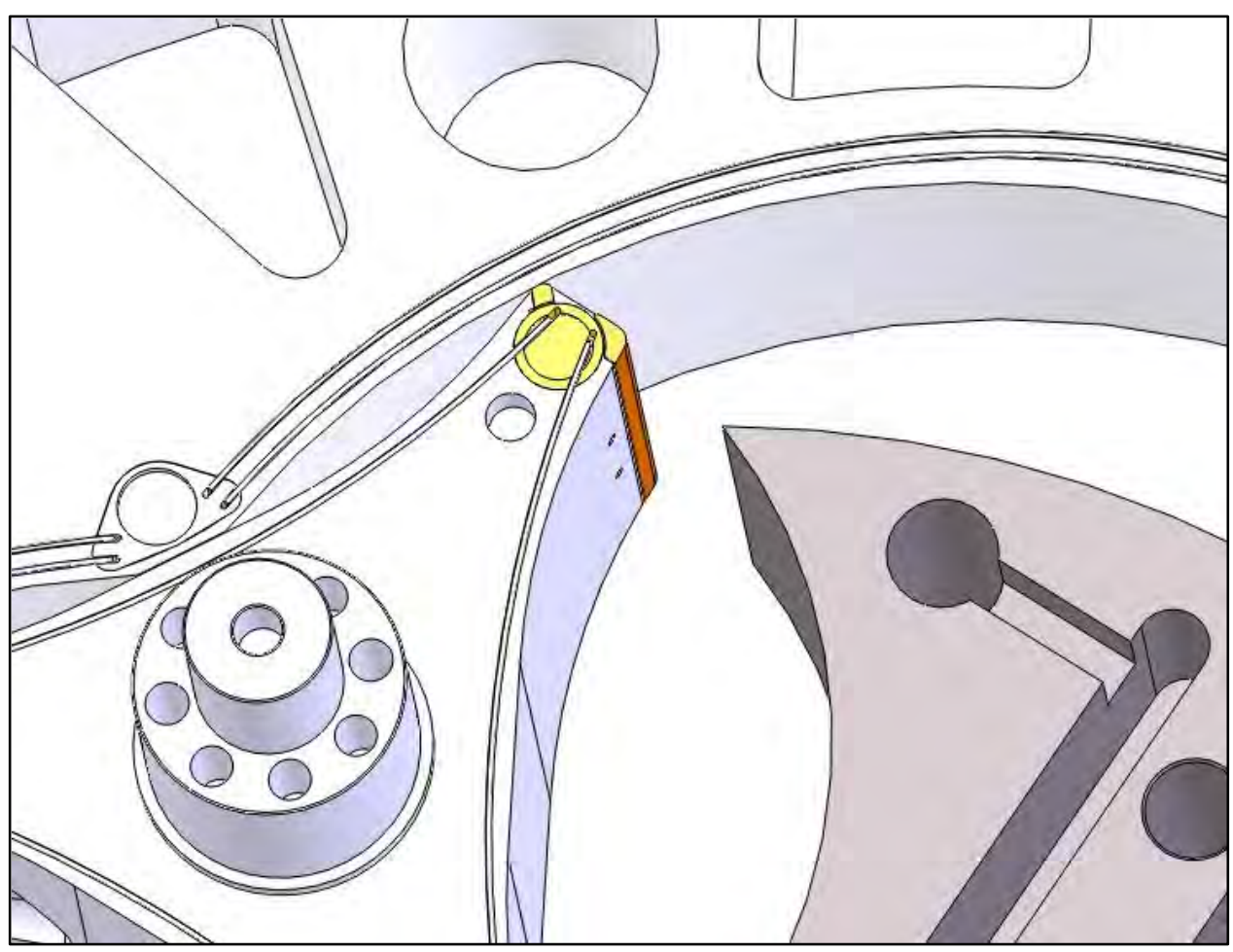

Figure 49. Housing side seal design modification

\subsection{GEN2.5B Research and Development}

The second pressure boundary design modification was evaluated in the housing side seal test fixture so that the maximum sealing pressure could be readily evaluated. Figure 50 shows the design modification incorporated into the side seal test fixture.

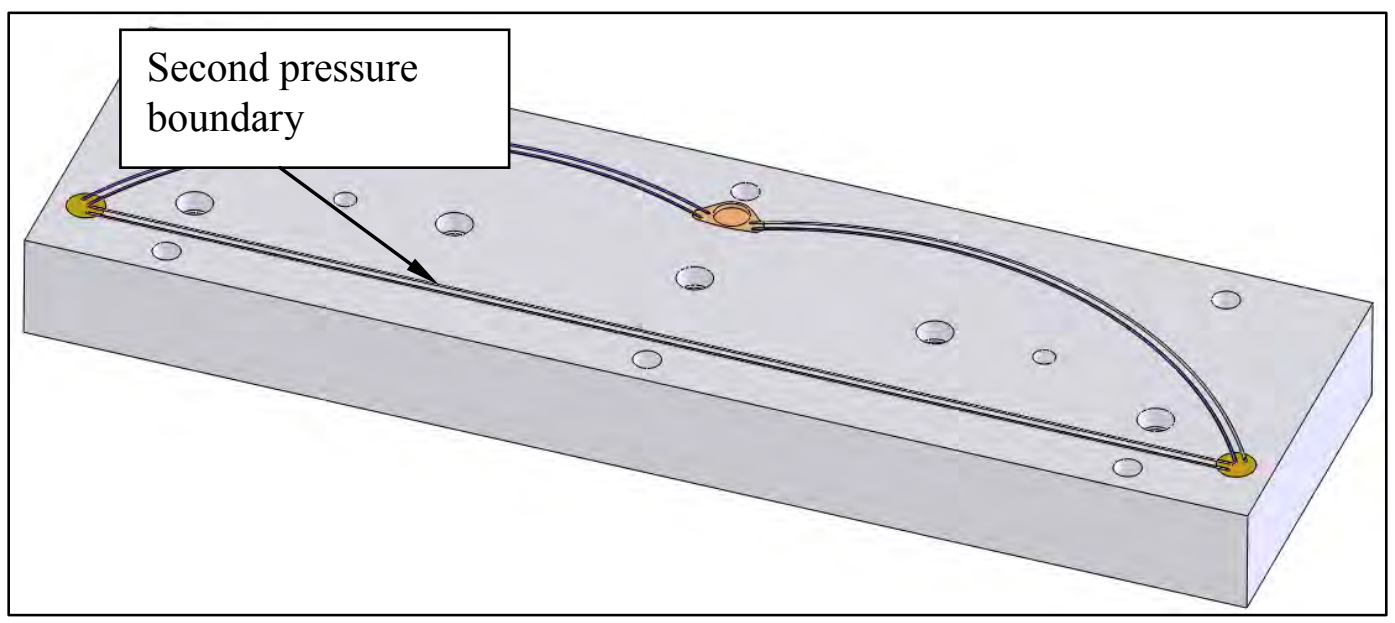

Figure 50. Test fixture design modification 


\subsection{GEN2.5B Manufacturing}

Figure 51 shows the redesigned button seals for the rotons and the housing incorporated in the GEN2.5B.

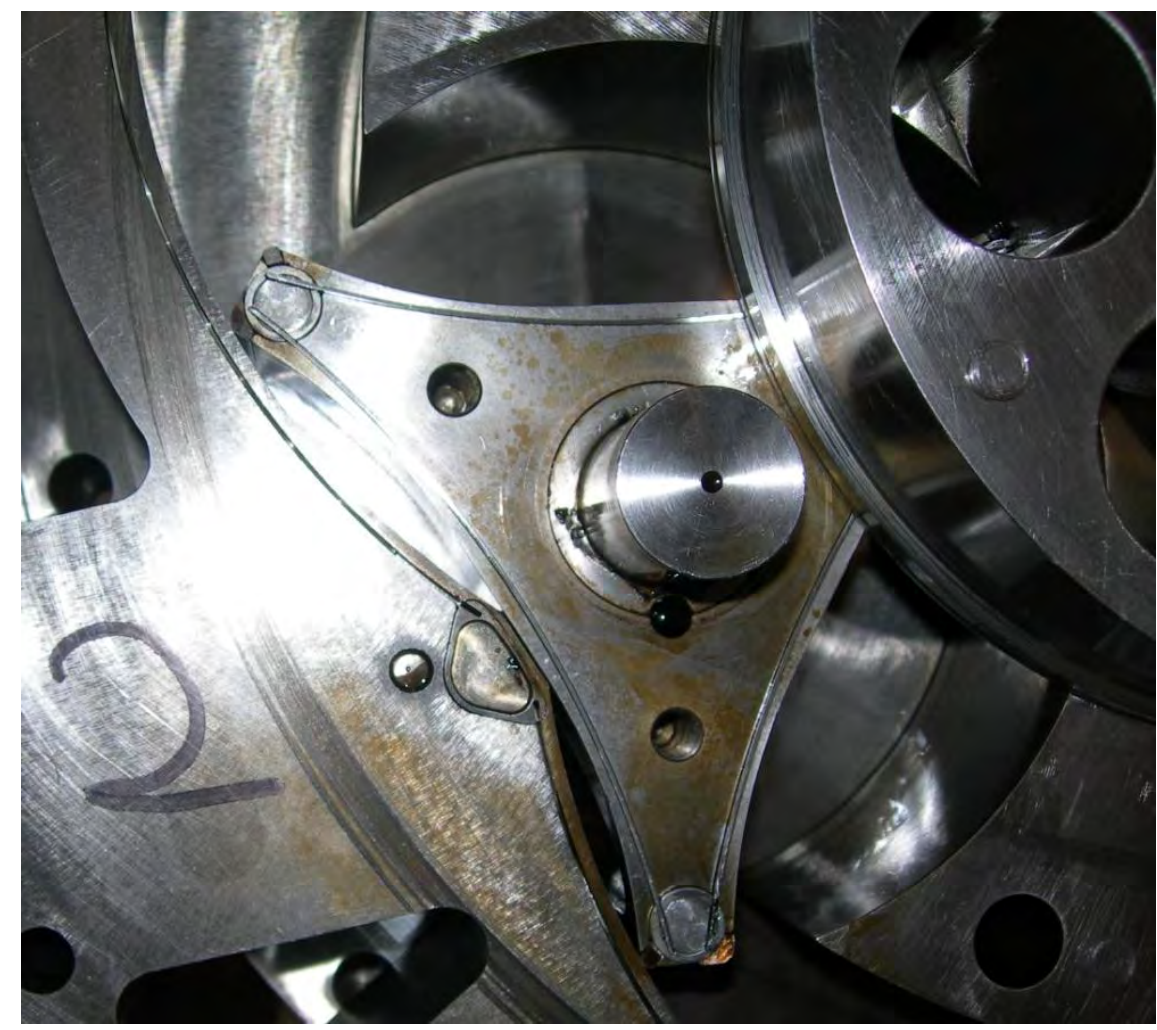

Figure 51. Redesigned roton and housing button seals

The process of designing a second housing seal into the engine also helped to reveal a potential cost savings for manufacturing the housing. The side seal pockets previously machined into the housing were very time consuming and costly due to their narrow width and deep cross section. To fit two side seals into the engine housing, a wider groove is cut as shown in Figure 52. The wider groove allows the use of a larger, more conventional cutting tool. An insert is placed into the groove to separate the two seals. 


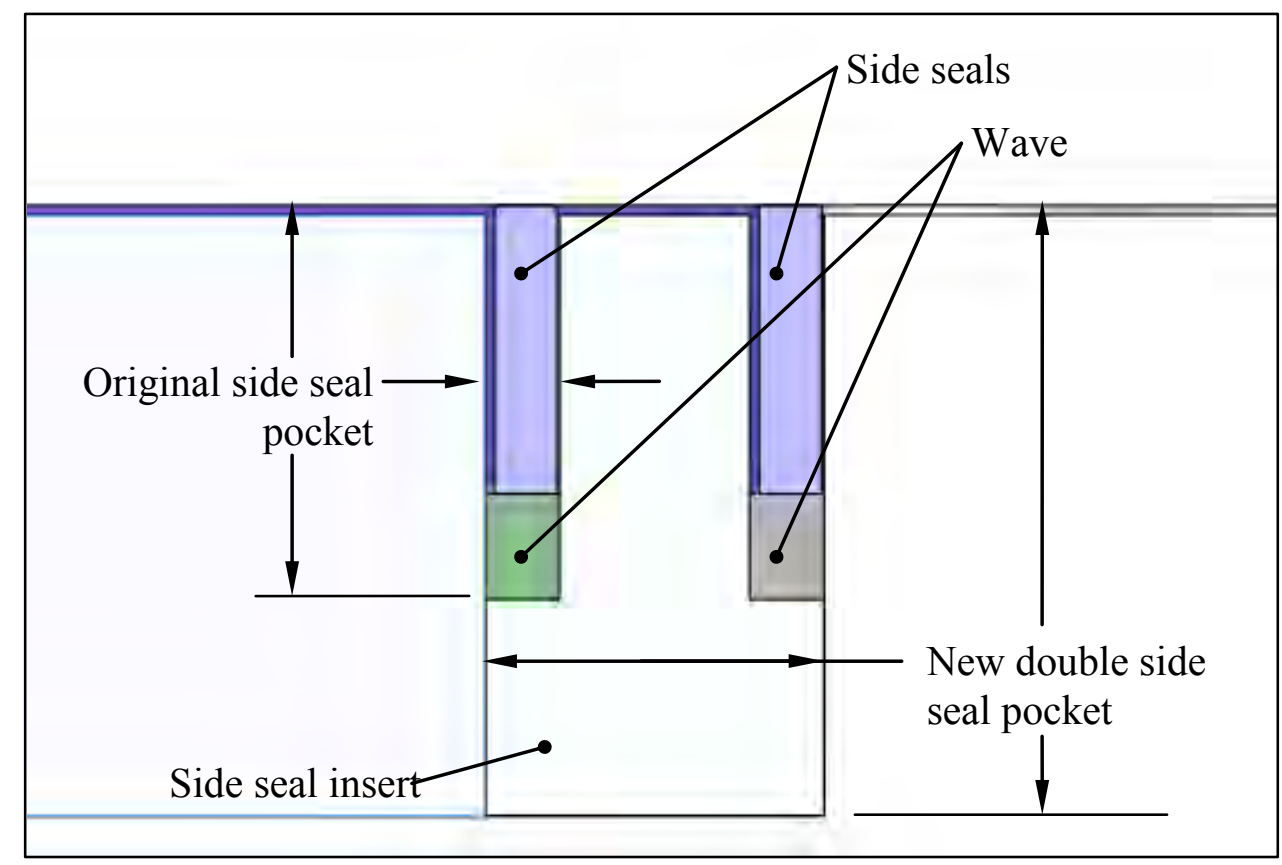

Figure 52. Housing side seal manufacturing

\subsection{GEN2.5B Testing and Evaluation}

\subsubsection{First Round of Testing}

The GEN2.5B was assembled after the modification to the housing for incorporation of the new side seal system. Two rounds of compression testing were performed to evaluate the effect of the new housing side seal system on the maximum compression pressure. Typical results of the compression testing are shown in Figure 53. 


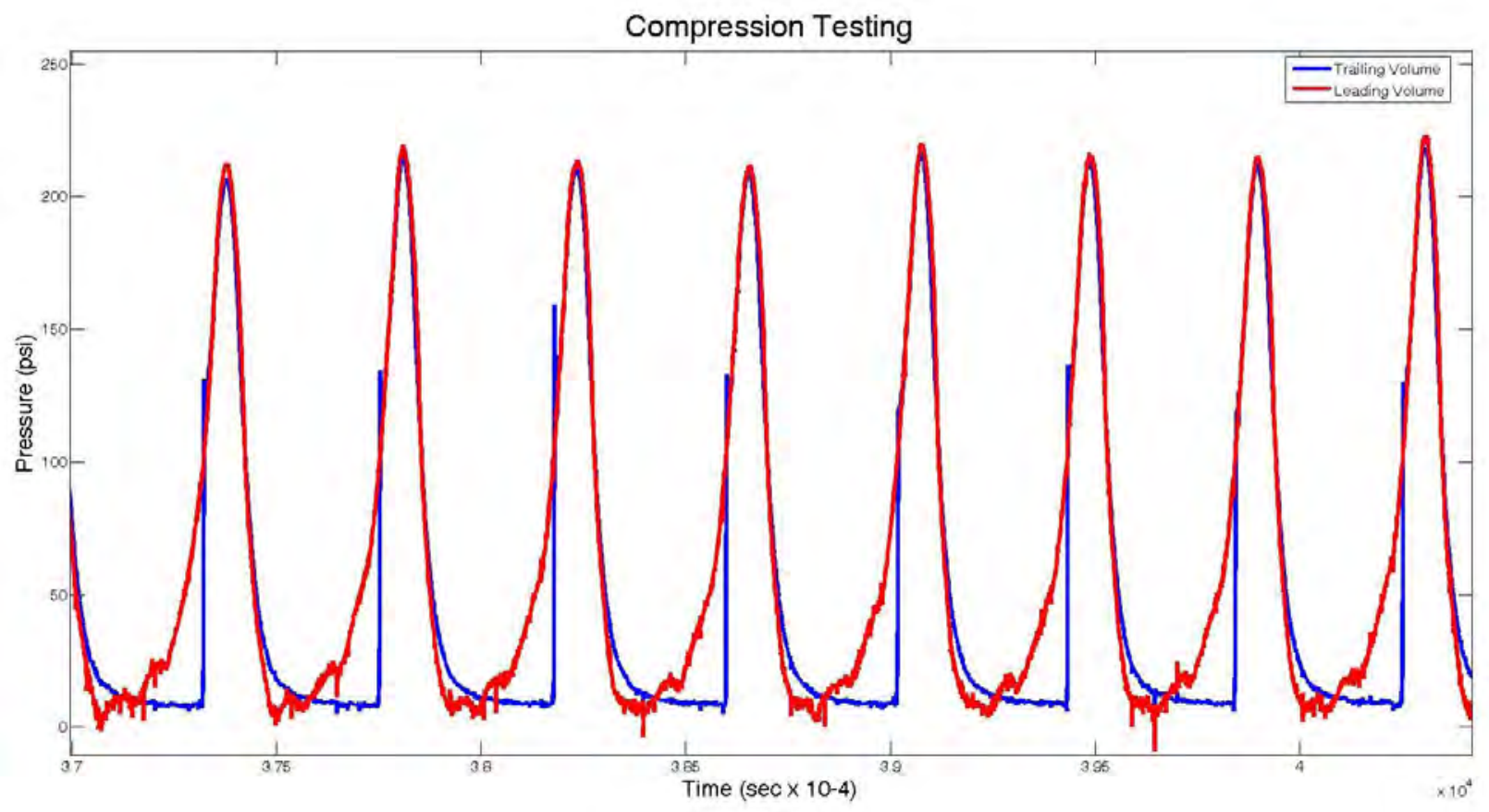

Figure 53. Typical compression testing results

The maximum achieved compression pressure was approximately $225 \mathrm{psi}$, which is not adequate for continuing forward to combustion testing. Observations during the testing indicated leakage past the roton side seals near top dead center.

Unlike the roton tip seals, the side seals and button seals in both the housing and the rotons achieve their sealing pressure from spring force. To increase the sealing pressure of these seals, the following modifications were made to the design:

- Modifications to the button seals in the housing as well as the button seals in the rotons were designed to reduce the contact area, and thus increase the sealing pressure

- Two wave springs were used under the roton side seals, as well as the housing side seals.

\subsubsection{Second Round of Testing}

The GEN2.5B was re-assembled after the modification to the button seals in the housing as well as the roton button seals. Two wave springs were used under the roton side seals; two wave springs were also used under the housing side seals as in previous testing. Compression testing was performed to evaluate the effect of the modified button seals, and the two wave springs, on the maximum compression pressure. The results are shown in Figure 54. 


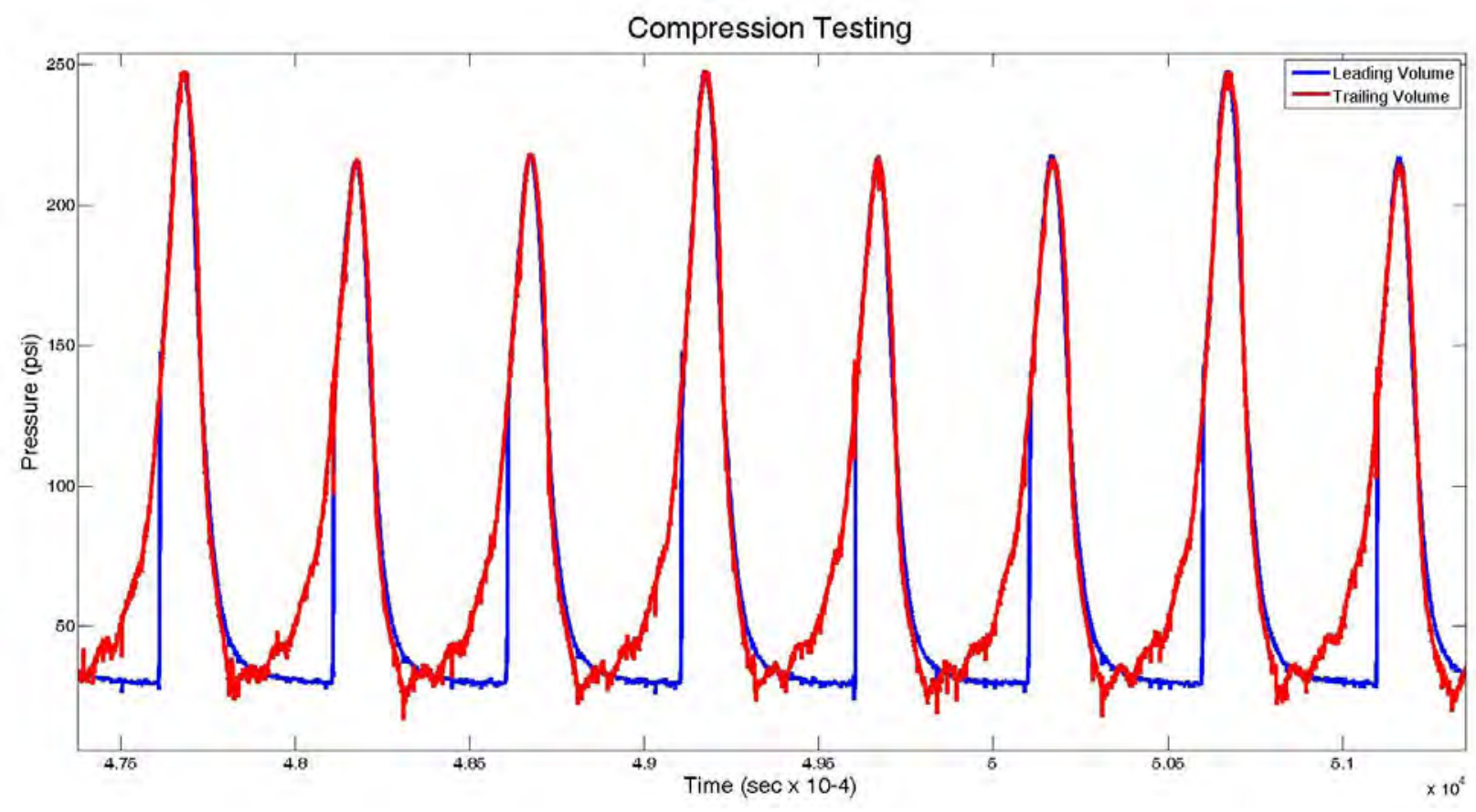

Figure 54. Typical compression testing results

The maximum achieved compression pressure was approximately $250 \mathrm{psi}$, which is an increase of 25 psi over previous tests but still not adequate for continuing forward to combustion testing. 
During stationary periods in the compression testing, a small quantity of lubricating oil makes its way into the combustion chambers. This oil ignites and partially burns, leaving a visible residue in the engine. This presence of this residue allows for visual inspection of the engine sealing system for leakage. Visible residue beyond the sealing boundary indicates leakage past that particular feature of the sealing system. Inspection of the engine during disassembly revealed minimum leakage past the housing button seals and housing side seals in the area of the leading volume. This result demonstrates that the previous modification was successful.

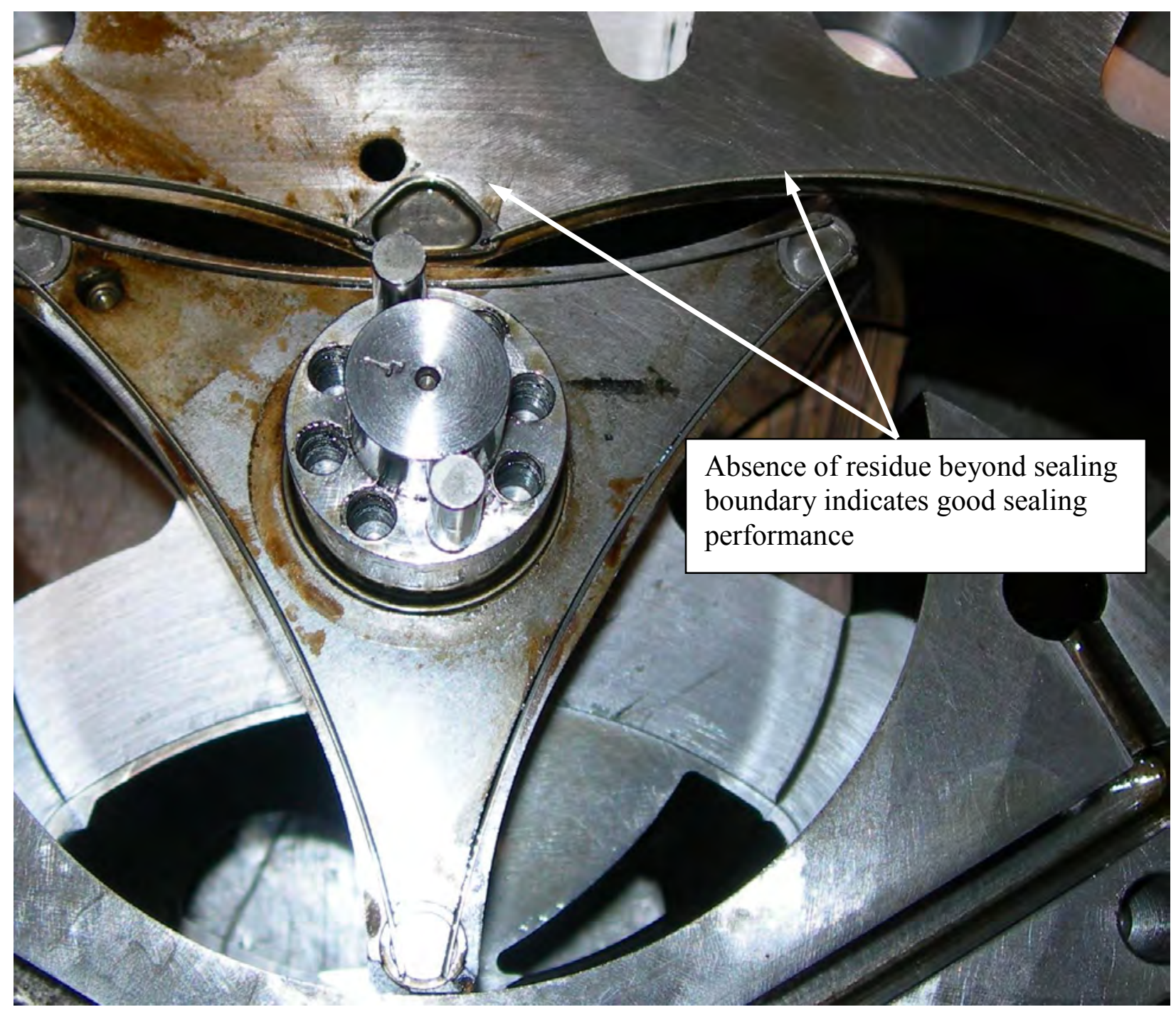

Figure 55. Evaluation of disassembled engine 
Other issues were observed that must be addressed:

1. Leakage past the housing side seals in the area of the trailing volume-

The cause of this is believed to be too little clearance between the roton face and the housing near top dead center. The combustion pockets on all three faces of one roton will be modified to provide more clearance.

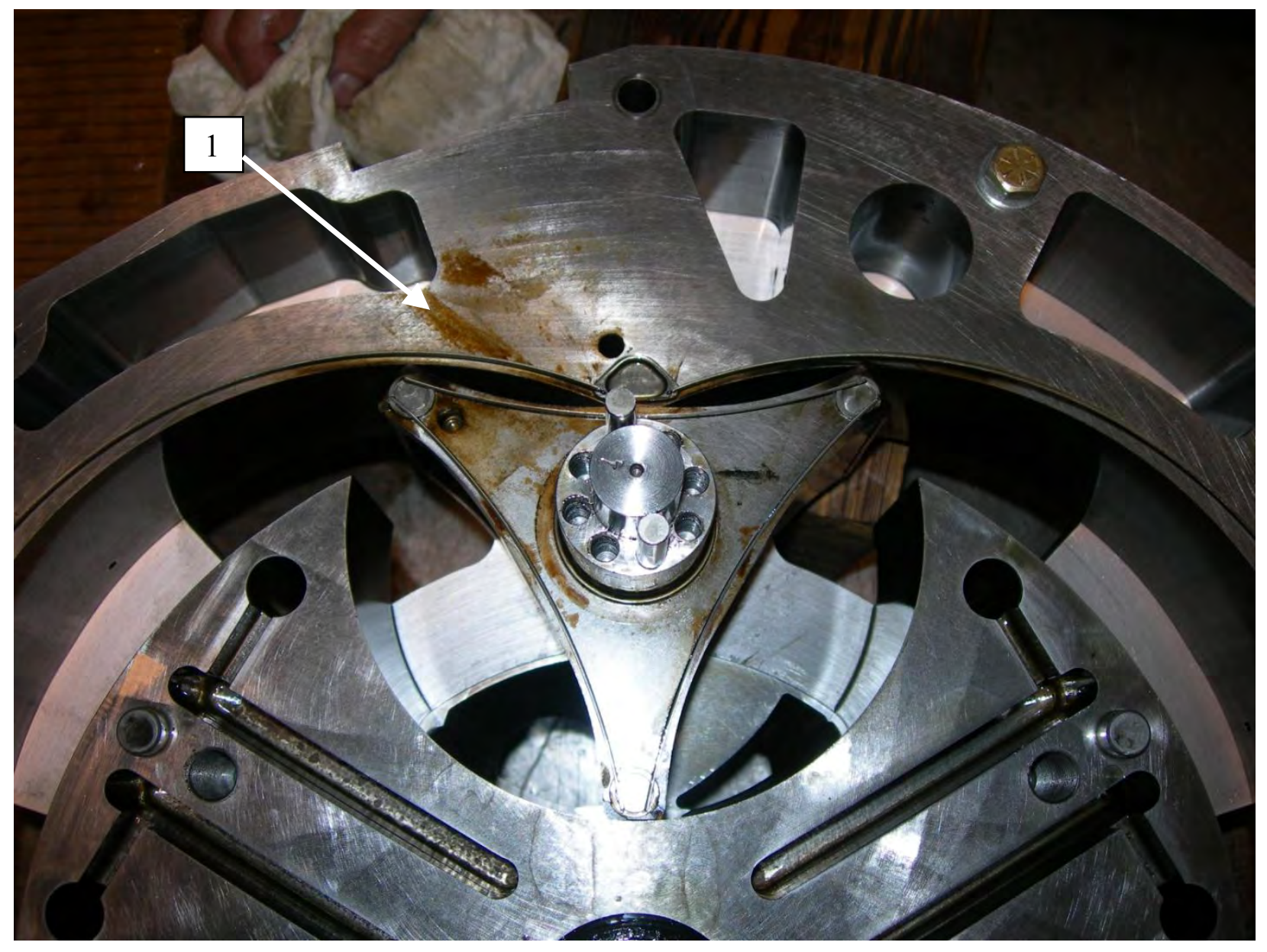

Figure 56. Leakage past the housing side seals in the area of the trailing volume 
2. Leakage past the ends of the roton tip seals along the face of the rotons-

The cause of this was determined to be too much clearance between the ends of the roton tip seals and the bearing plates. New longer tip seals will be produced to reduce this clearance to .001 inch total from the existing .004 inch per side.

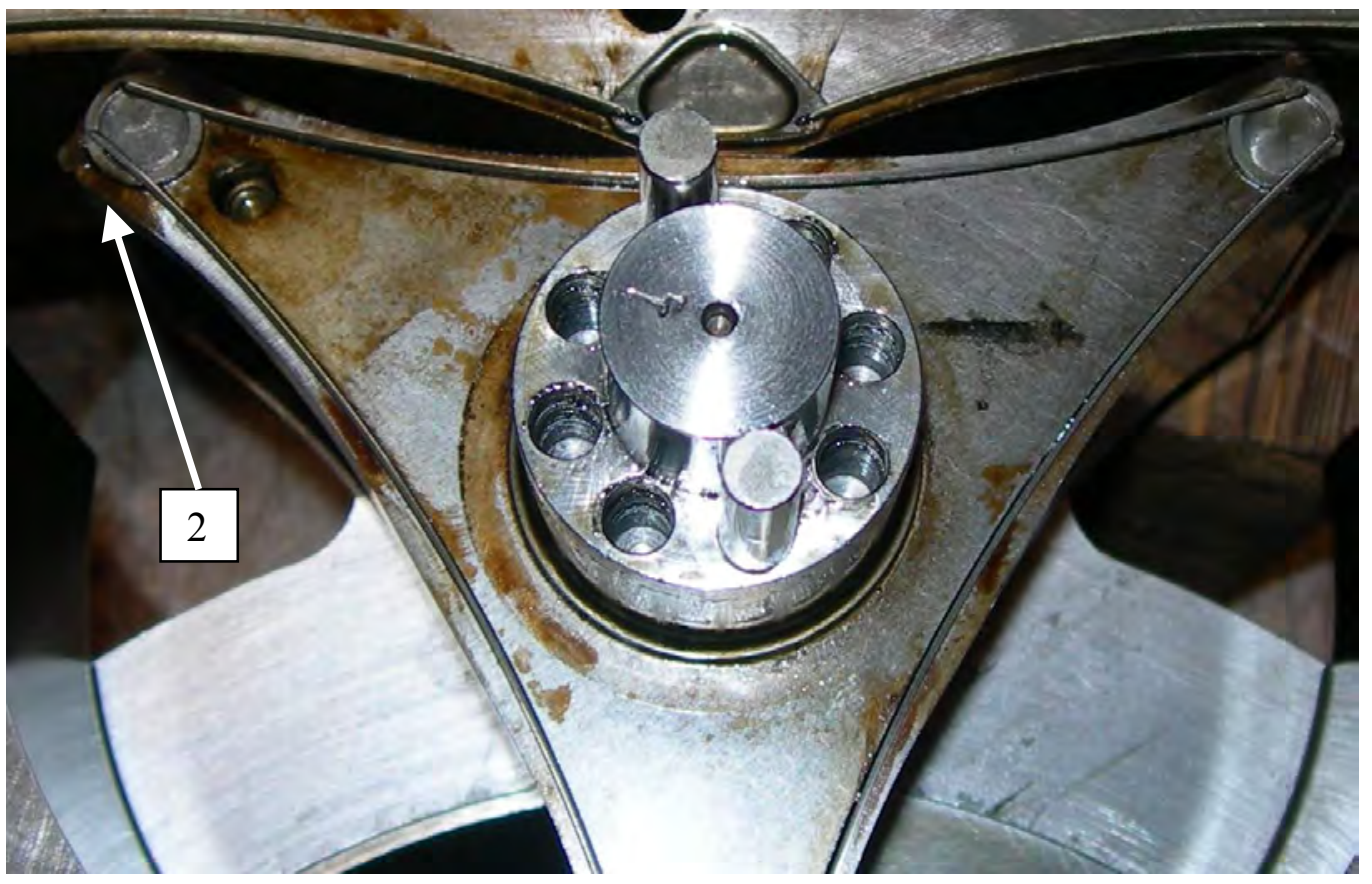

Figure 57. Leakage past the ends of the roton tip seals along the face of the rotons

3. Deposits on the roton tip seal leaf springs indicating that the pressure ports under the tip seals were at least partially blocked by the leaf springs-

The rotons will be modified to accept the second set of Mazda tip seal leaf springs. This will provide clearance around the pressure ports. In addition, the ports will be enlarged on two faces of each of the rotons, with one face retaining the original port size. One drill size larger will be used on one face, and two drill sizes larger will be used on the other face.

4. The slots for the side seals in the roton button seals and the housing mid-span button seals are not deep enough, the side seals protrude above the button seals. This effectively prevents the button seals from sealing against the bearing plates. The slots in the modified top dead center housing button seals are adequately deep-

Rather than modifying or re-making the button seals, the side seals will be ground to remove material such that the side seals will no longer protrude above the button seals. This modification will not affect the top dead center housing button seals' performance.

5. The roton side seals on the aspiration plate side of the rotons exhibited damage from impacting the exhaust port opening. This was due to inadequate support caused by the previous modification to the roton button seal.- 
New roton button seals will be will be produced for the aspiration plate side with a smaller spotface in their centers

\subsubsection{Third Round of Testing}

After reassembly with the modified rotons and new tip seals documented in the GEN2.5B Design section, the engine was instrumented with two magnetic position sensors that indicate rotor position via teeth machined into the rear bearing plate. One tooth is wider than the other two, which allows identification of each individual roton face with respect to the recorded pressure data. Figure 58 shows the engine positioned with roton \#1 at top dead center (TDC) at position \#1 of the housing. The roton faces are labeled A through I; the pertinent features of each face are identified in Table 2.

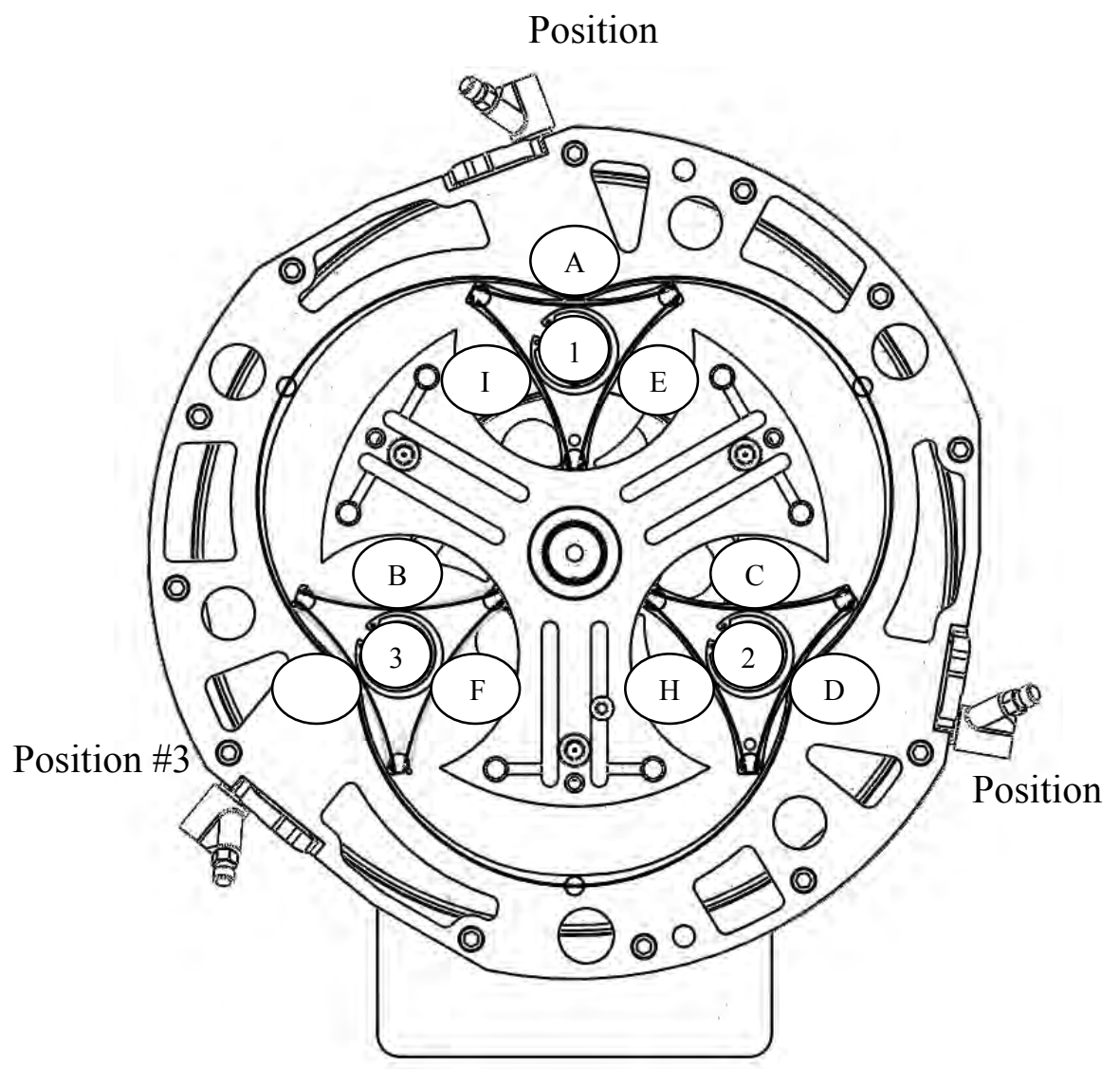

Figure 58. Roton face identification 
Table 2. Roton features by face

\begin{tabular}{|c|c|c|c|c|c|}
\hline \multicolumn{2}{|l|}{ Position 1} & \multicolumn{2}{|l|}{ Position 2} & \multicolumn{2}{|l|}{ Position 3} \\
\hline Roton Face & Modification & Roton Face & Modification & Roton Face & Modification \\
\hline $\mathrm{A}$ & ø.043 ports & $\mathrm{D}$ & $\begin{array}{l}\text { ø.026 ports, } 2 \text { tip } \\
\text { seal springs }\end{array}$ & $\mathrm{G}$ & $1 / 2 "$ slot \\
\hline B & $1 \frac{1}{2}$ " slot & $\mathrm{E}$ & ø.026 ports & $\mathrm{H}$ & $\begin{array}{l}\text { ø.060 ports, } 2 \\
\text { tip seal } \\
\text { springs }\end{array}$ \\
\hline $\mathrm{C}$ & $\begin{array}{l}\text { ø.043 ports, } 2 \text { tip } \\
\text { seal springs }\end{array}$ & $F$ & 1" slot & $\mathrm{I}$ & ø.060 ports \\
\hline
\end{tabular}

Table 3 shows the sequencing of the roton faces at each housing position corresponding to the signal from the magnetic position sensor. Note that the wide tooth corresponds to roton \#1 at TDC at position \#1 of the housing.

Table 3. Roton face sequencing

\begin{tabular}{|c|c|c|c|c|c|c|}
\hline $\begin{array}{l}\text { Position } \\
\text { Sensor }\end{array}$ & & & & & & \\
\hline \multicolumn{7}{|c|}{ Roton Face } \\
\hline Position 1 & $\mathrm{~A}$ & $\mathrm{~B}$ & $\mathrm{C}$ & A & B & $\mathrm{C}$ \\
\hline Position 2 & D & $\mathrm{E}$ & $\mathrm{F}$ & D & $\mathrm{E}$ & $\mathrm{F}$ \\
\hline Position 3 & $\bar{G}$ & $\mathrm{H}$ & I & $G$ & $\mathrm{H}$ & I \\
\hline
\end{tabular}

The modified GEN2.5B was compression tested in the test cell at UT to evaluate the effect of the modifications. Test results showed the maximum compression pressure ranged from approximately 240 psi to approximately 300 psi. Typical results are shown in Figure 59, Figure 60 and Figure 61. 


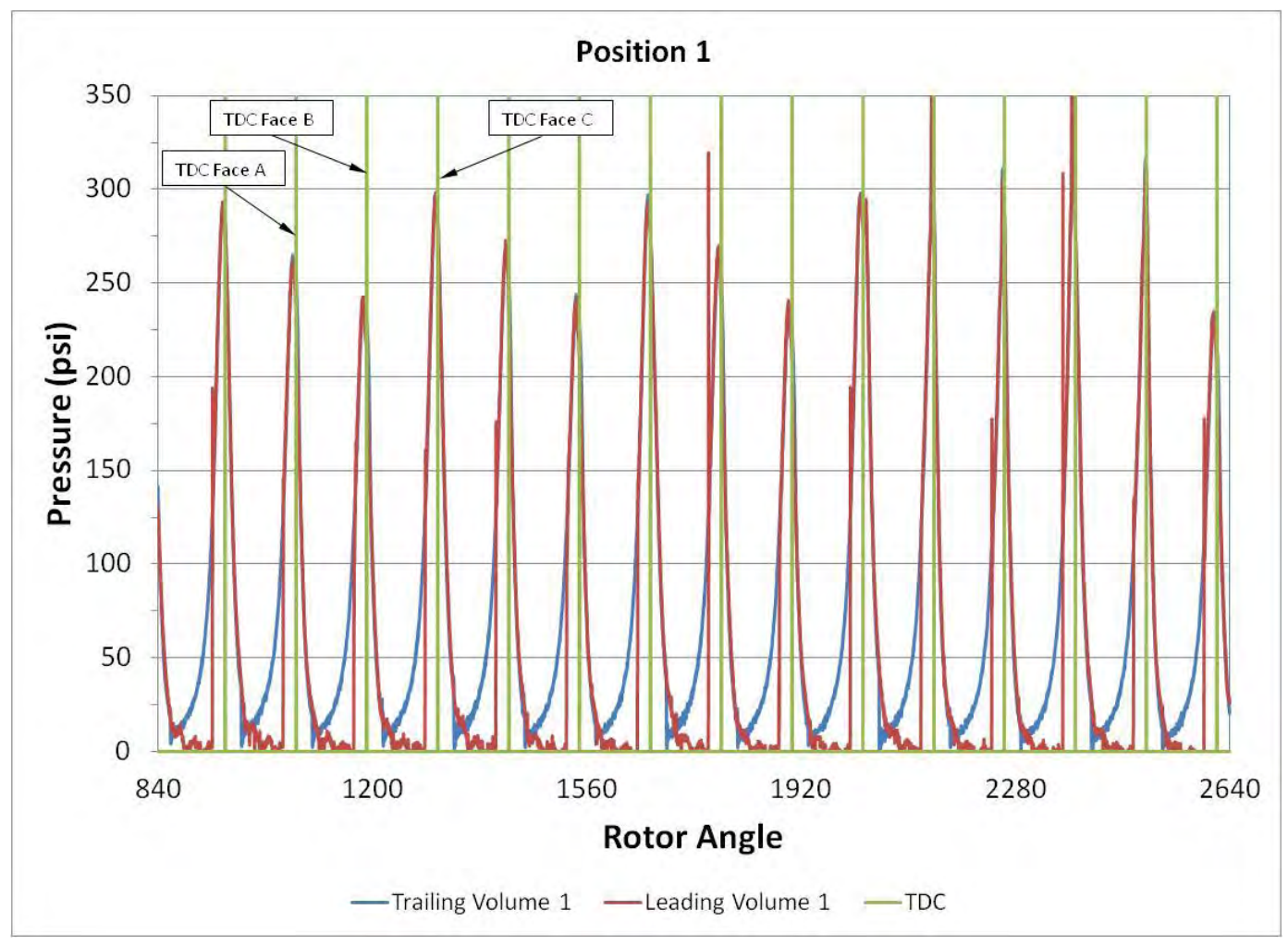

Figure 59. Position \#1 pressure data

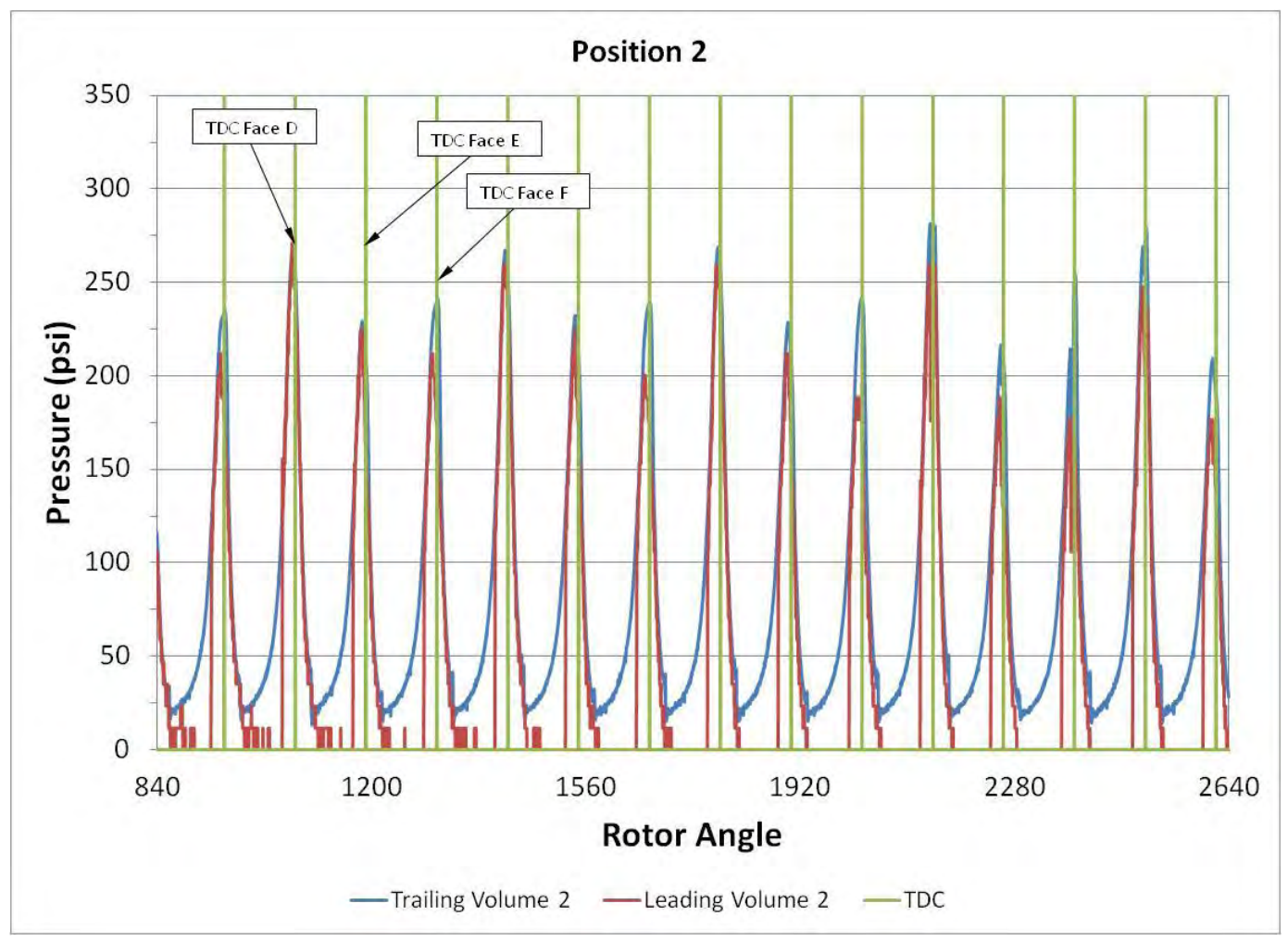

Figure 60. Position \#2 pressure data 


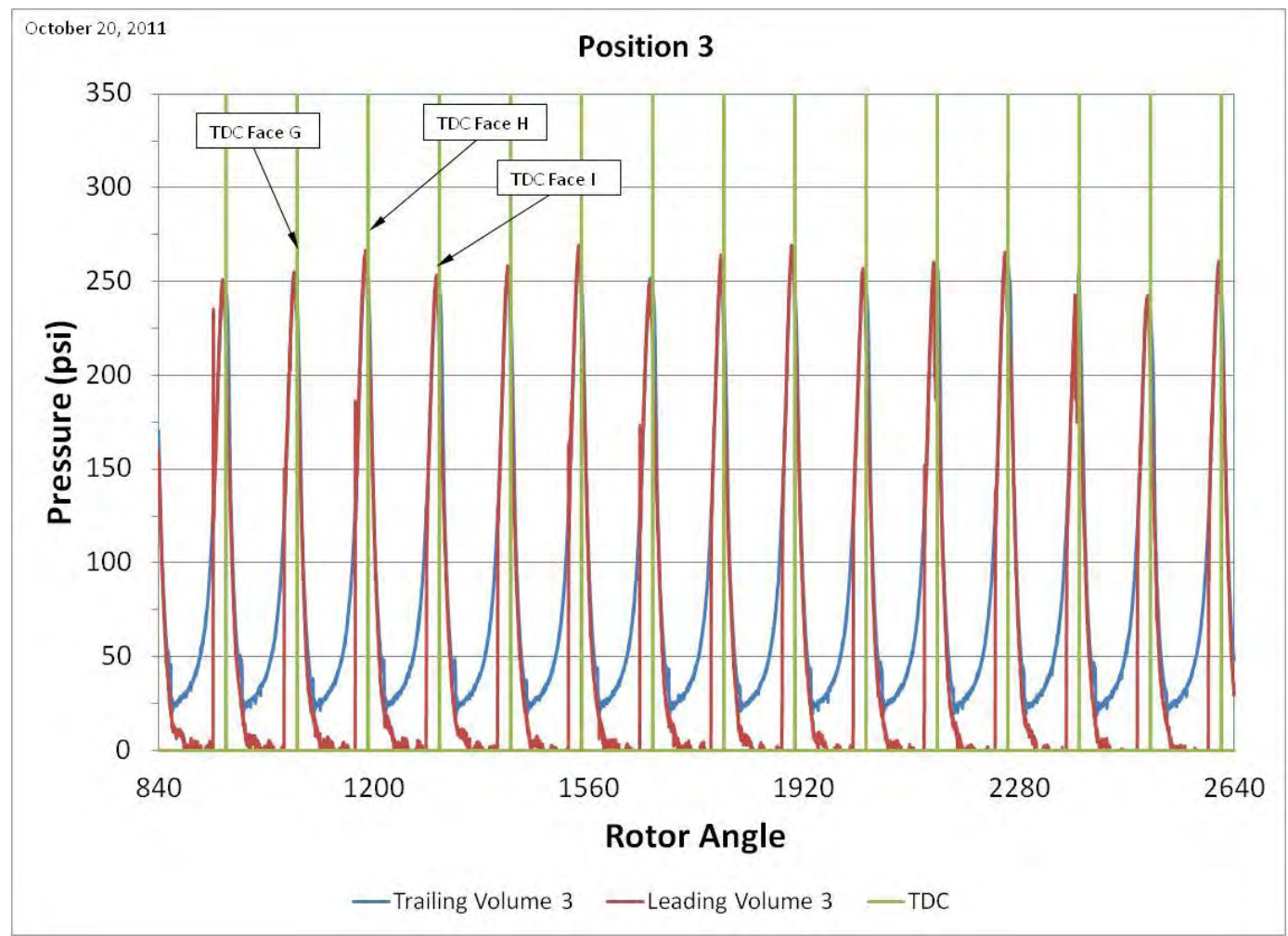

Figure 61. Position \#3 pressure data

The results were not significantly different than previous results prior to the roton modifications. The variation in compression pressures with respect to individual roton faces (sequence of pressure peak variations) was consistent with previous results. Although the position sensors were not used in previous testing, the same pattern of pressure variation was observed in this round of testing as had previously been observed.

Evaluation and analysis of the latest results with respect to previous results, including the housing side seal evaluation on the test fixture, point to leakage past the housing side seals as being the limiting factor on the maximum compression pressure. The previous modification to include double springs under the roton side seals resulted in the greatest increase in compression pressure over previous testing. However, the latest modifications to the rotons resulted in no further increase in compression pressure. Testing of the housing side seal system in the test fixture showed leakage past the seals at approximately 250 psi. Greater pressures were anticipated in the engine due to the dynamic sealing effect of the rotating bearing plates, and that has been demonstrated by the latest results with six of the nine roton faces' compression pressure exceeding 250 psi. Pressures exceeding 500 psi have been recorded when the lubricating oil ignites; however, these are near-instantaneous pressure spikes with very little time for leakage to occur.

These results led to the decision to further modify the housing side seal system to include a second pressure boundary to increase the achievable compression pressure as described in the GEN2.5B Design section. Figure 49, on page 39, shows the additional side seal which provides the second pressure boundary in the housing. 
The original development plan for this modification was:

- The design was to be first implemented and evaluated in the test fixture.

- As the modifications to the test fixture are being made, the new design will be incorporated into the GEN2.5B design, such that modifications to the engine can begin immediately if the results of the test fixture evaluation are positive.

As described below, the original plan was revised due to problems with the engine controller.

Data from testing the GEN2.0 was reviewed for comparison. The maximum pressure achieved prior to fueling that prototype was approximately 250 psi. Successful combustion was demonstrated at that compression pressure with a very lean air/fuel ratio. While greater compressions pressure is desired, and anticipated, with the modification to the housing sides seal system, the decision was made to fuel the GEN2.5B in its current configuration.

The fuel system was assembled in the test cell at UT and connected to the engine. During prefueling testing, the engine controller was discovered to be malfunctioning. The controller operated correctly, firing the injectors, with a simulated engine speed signal; however, there was no injection signal while using the real engine speed input signal. Trouble-shooting efforts were unsuccessful in diagnosing the problem, and the input module was returned to the manufacturer for diagnosis.

Due to the malfunctioning engine controller, we were not able to fuel the engine for combustion testing as planned. After reviewing the schedule, it was decided to proceed with the modifications to the engine to incorporate the side seal system modifications, rather than wait on results from the test fixture. It was felt that the side seal modifications would increase the compression pressures, with very low risk of negative impact.

The modifications to the test fixture and the engine are being completed as this report is written. Evaluation of the addition of the second pressure boundary will be conducted during continuing research beyond the conclusion of this project. 
This page intentionally left blank. 


\section{Chapter 4 - Conclusion}

The PST concept for the roton tip seal has been developed into a manufacturable design. The design was evaluated using a custom designed and fabricated seal test fixture and further refined. This design was incorporated into the GEN2.5A prototype and tested for achievable compression pressure.

Enhancements to the tip seal design were incorporated into the GEN2.5B prototype and tested and evaluated. Compression pressures adequate for compression ignition of diesel fuel were achieved, although not consistently in all combustion volumes. The variation in compression pressures was characterized versus design features.

While greater compressions pressure is desired, and anticipated, with the modification to the housing sides seal system, the demonstrated pressure was adequate for proceeding with combustion testing had the controller issues not occurred. Combustion in the Legacy engine has been previously demonstrated; however, at only one very lean operating point. Therefore, merely demonstrating combustion was not a primary focus of the project. The overarching goal of this project was to develop a viable roton tip seal, and that has been accomplished.

Along the course of executing the project, additional challenges have been identified and addressed:

- As the roton tip seal performance was improved, results pointed toward inadequate performance of the housing side seals. Enhancement of the housing side seal system was accomplished using a custom designed side seal test fixture. The design enhancements developed with the test fixture were also incorporated into the GEN2.5B prototype and tested and evaluated using the iterative research strategy described below.

- Finally, to simplify the requirements for the roton tip seals and to enhance the introduction and combustion of fuel, a flush-mount fuel injector was designed, manufactured and demonstrated in the GEN2.5B prototype.

The key technical challenge to the Legacy engine's commercialization, and the focus of this project, was the development of a viable roton tip seal. Continued development of the Legacy engine would not be possible without a solution to this challenge. Validation of the asymmetric tip seal system represents a major milestone in the development of the Legacy engine. Based on the results described in this report, the project has been successful. The asymmetric tip seal system has functioned as intended and achieved compression pressures adequate for compression ignition. The importance of this achievement cannot be overstated in terms of the continuing development of the Legacy engine. 
This page intentionally left blank. 


\section{Chapter 5 - Further Research}

\subsection{Chapter Overview}

The development of a functioning tip seal, completed during this project, allows for the further research required for the continuing development of the Legacy engine. These identified technical challenges represent only the most difficult issues that must be addressed. Numerous other challenges exist but are typical of challenges that must be addressed in any internal combustion engine development program.

\subsection{Supplemental Ideas}

Key areas of required research and development include:

- Induction and exhaust optimization

- The Legacy engine relies on scavenging of the exhaust to introduce the fresh charge, similar to a two-stroke conventional engine. Aspiration of the Legacy Engine is accomplished with ports rather than valves. This eliminates a complex subsystem, which lowers cost and improves reliability. To realize these benefits of port induction and exhaust, optimal intake and exhaust port design are absolutely critical to the performance of the engine.

- Combustion Optimization

- Combustion optimization is the key to the increased efficiency predicted by our modeling and simulation. The unique geometry of the Legacy engine provides the opportunity to optimize the combustion processes and gain additional efficiencies beyond what is possible in a conventional engine. Additionally, the combustion chamber is divided into two separate volumes as illustrated in Figure 36 on page 27. Fuel is injected into the leading volume and as the engine rotates air is forced from the trailing volume into the leading volume creating high turbulence and improved mixing. Improved mixing will result in improved combustion and lower emissions.

- Thermal management

- Increased cooling demands are integral with unparalleled power density and high power to volume ratios. Providing the required cooling for such a compact engine design is an extreme challenge that requires an innovative approach to both the cooling system and the various materials in the engine.

- Subsystem Development

○ Controls

- The prototype engine control system used thus far is fairly simple. It is capable of controlling the fuel injection parameters at single operating points. The injection timing and duration are real-time user inputs to the control software. For continued development of the Legacy engine, a more 
production-like control system must be developed that calculates and changes the control parameters based on sensor inputs.

○ Fuel injection

- While the flush-mount fuel injector nozzle was successfully developed and demonstrated on this project, further development in combustion optimization requires research and development of the fuel injection system. Particularly, emissions compliance for compression ignition engines depends heavily on optimizing the injection parameters (timing, duration, pressure, orifice size, etc.).

\subsection{Conclusions}

Successful completion of research and development in the listed areas will lead to validation of the predicted improvements in efficiency and will provide the foundation necessary for continued development and eventual commercialization the Legacy engine. 